UNIVERSIDADE DE SÃO PAULO

FACULDADE DE MEDICINA DE RIBEIRÃO PRETO

DEPARTAMENTO DE PATOLOGIA E MEDICINA LEGAL

PÓS-GRADUAÇÃO EM PATOLOGIA EXPERIMENTAL

LARISSA DUTRA BITTENCOURT DE OLIVEIRA

Análise proteômica do esmalte de dentes decíduos para a estimativa do sexo em crianças

Ribeirão Preto 
LARISSA DUTRA BITTENCOURT DE OLIVEIRA

\section{Análise proteômica do esmalte de dentes decíduos para a estimativa do sexo em crianças}

\section{Versão Original}

Tese apresentada ao Departamento de Patologia e Medicina Legal da Faculdade de Medicina de Ribeirão Preto da Universidade de São Paulo para a obtenção do título de Doutor em Ciências Médicas.

Área de Concentração: Patologia

Orientador: Prof. Dr. Ricardo Henrique Alves da Silva

Coorientadora: Prof ${ }^{a}$. Dra . Raquel Fernanda Gerlach

Ribeirão Preto 
Autorizo a reprodução e divulgação total ou parcial deste trabalho, por qualquer meio convencional ou eletrônico, para fins de estudo e pesquisa, desde que citada a fonte.

Assinatura:

Data:

\section{Ficha catalográfica}

Elaborada pela Biblioteca Central do Campus USP - Ribeirão Preto

Oliveira, Larissa Dutra Bittencourt de

Análise proteômica do esmalte de dentes decíduos para a estimativa do sexo em crianças. Ribeirão Preto, 2019.

146 f. : il. ; $30 \mathrm{~cm}$

Tese (Doutorado em Ciências Médicas), Programa de Pósgraduação em Patologia da Faculdade de Medicina de Ribeirão Preto, Universidade de São Paulo, USP. Área de concentração: Patologia.

Orientador: Silva, Ricardo Henrique Alves da.

Versão original

1. Identificação Humana. 2. Antropologia Forense. 3. Aminoácidos, peptídeos e proteínas. 4. Proteômica. 5. Espectrometria de Massas. 
OLIVEIRA, L. D. B. Análise proteômica do esmalte de dentes decíduos para a estimativa do sexo em crianças. 2019. 146 f. Tese (Doutorado em Ciências Médicas) - Departamento de Patologia e Medicina Legal da Faculdade de Medicina de Ribeirão Preto, Universidade de São Paulo, São Paulo, 2019.

Aprovado em:

Banca Examinadora

Orientador: Prof. Dr.

Instituição:

Assinatura:

Prof. Dr.

Instituição:

Julgamento: Assinatura:

Prof. Dr.

Instituição:

Julgamento:

Assinatura:

Prof. Dr.

Instituição:

Julgamento:

Assinatura: 
Dedícatóría 
Dedico este trabalho à minha avó Vilma, minha guerreira, triunfadora na vida, meu exemplo de força e determinação, que pelo seu amor incondicional à família, em especial à minha mãe Laize, me proporcionou segurança e tranquilidade para realizar este sonho distante delas. Muito obrigada, minha avó, por dedicar a sua vida a nós! 
Agradecimentos 


\section{AGRADECIMENTOS}

Agradeço ao meu pai Fernando, meu irmão Vinicius, à minha mãe Laize e à minha avó Vilma, meus maiores incentivadores, sempre ao meu lado me apoiando e conquistando os meus sonhos junto comigo.

Às cuidadoras da minha avó e mãe, em especial à Cleuza e à Tânia, que com tanta dedicação e carinho nos ajudam estar distantes para conquistarmos os nossos sonhos sabendo que elas estão bem cuidadas e seguras.

À minha família Andrade Dutra e Bittencourt, e aos amigos pela compreensão da minha ausência, pela torcida e apoio na conquista dessa etapa.

À Paula pelo apoio e cuidados dispensados à minha avó e mãe.

Agradeço ao Antonio, meu sobrinho lindo por trazer tanto amor e alegria à nossa casa, e peço desculpas por não poder estar sempre presente ao seu lado brincando de dinossauro.

À Márcia que com tanto carinho cuidou do meu apartamento e de mim também.

Ao grande mestre, amigo e incentivador dessa fase, Carlos Eduardo Palhares Machado.

Ao professor Ricardo Henrique Alves da Silva, por me aceitar e confiar em mim grandes responsabilidades. Obrigada por compartilhar tanto conhecimento, pelas oportunidades e por me proporcionar a participação no Curso de Especialização de Odontologia Legal.

À professora Raquel Fernanda Gerlach, por aceitar a coorientação deste trabalho e se dedicar tanto a mim.

Ao professor Marco Aurelio Guimarães, por me aceitar no estágio na disciplina de Medicina Forense, compartilhar comigo tanto conhecimento e me fazer apaixonar mais ainda pela área. Obrigada pela força, atenção e carinho com a minha avó, além do apoio nos momentos difíceis. 
À todos os professores das disciplinas cursadas durante o doutorado dentro e fora do Programa de Patologia.

Às secretárias do Departamento de Patologia e Medicina Legal.

À turma do Departamento de Estomatologia, Saúde Coletiva e Odontologia Legal - USP - Faculdade de Odontologia de Ribeirão Preto, em especial ao senhor Dorival Gaspar.

Ao CNPq pelo apoio financeiro que permitiu minha dedicação exclusiva e a realização deste trabalho.

Ao Laboratório de Proteínas e Histologia do Departamento de Biologia Básica e Oral da Faculdade de Odontologia de Ribeirão Preto, USP. Em especial à Júnia Ramos, Patrícia Adriana Basile, e Renê Seabra Oliezer.

À Faculdade de Medicina de Ribeirão Preto, Faculdade de Odontologia de Ribeirão Preto, Faculdade de Ciências Farmacêuticas de Ribeirão Preto, Faculdade de Filosofia, Ciências e Letras de Ribeirão Preto por oferecerem e me aceitarem nas disciplinas fundamentais para a evolução desta pesquisa.

Ao CEMEL - Centro de Medicina Legal por me receber como estagiária do Programa de Aperfeiçoamento de Ensino PAE na Disciplina de Medicina Forense com os professores Marco Aurelio Guimarães, Hermes de Freitas Barbosa e Sérgio Britto Garcia, à secretária Celia Regina Lattaro Marino e ao técnico José Marcelo Schieri por me receber no Laboratório de Antropologia Forense e compartilhar comigo todo o seu conhecimento e experiência, e aos demais funcionários.

Agradeço também às Instituições externas à USP/RP:

Ao Programa de Pós-graduação em Agronomia (Genética e Melhoramento de Plantas) da Faculdade de Ciências Agrárias e Veterinárias da UNESP/Jaboticabal em especial ao professor Tiago Santana Balbuena, por me receber na espetacular disciplina de "Introdução à Proteômica". 
Ao Laboratório de Química de Proteínas/Unidade Proteômica, do Departamento de Bioquímica, Instituto de Química da Universidade Federal do Rio de Janeiro UFRJ, em especial aos professores Gilberto Barbosa Domont e Fábio César Sousa Nogueira e seus alunos de pós-graduação, pelo acolhimento, receptividade e dedicação dispensadas.

Ao apoio financeiro concedido pela CAPES - Coordenação de Aperfeiçoamento de Pessoal de Nível Superior - Brasil, do CNPq - Conselho Nacional e Tecnológico de Desenvolvimento Científico e Tecnológico - Brasil, e pela FAPESP - Fundação de Amparo à Pesquisa do Estado de São Paulo. 
Epígrafe 
"Pior que a morte de alguém querido é o seu desaparecimento.

$\mathcal{A}$ morte causa dor na alma. Mas permite que o futo ocorra e transforme a dor em saudade.

O desaparecimento de alguém querído é pior do que a morte. Causa um luto que não se resolve, não termina até que se encontre quem desapareceu, vivo ou morto.

Identificar os remanescentes de alguém desaparecido, mais do que resgatar sua memóría e dignidade, é dar o direito a quem amava esta pessoa de terminar uma busca que parecia interminável.

$\hat{\mathcal{E}}$ dar o direito de concluir o luto, de transformar angústia em saudade." 
Resumo 
OLIVEIRA, Larissa Dutra Bittencourt de. Análise proteômica do esmalte de dentes decíduos para a estimativa do sexo em crianças. 2019. $146 \mathrm{f}$. Tese (Doutorado em Ciências Médicas) - Faculdade de Medicina de Ribeirão Preto, Universidade de São Paulo, Ribeirão Preto, 2019.

\section{RESUMO}

Os métodos de estimativa de sexo em contextos forenses são realizados em esqueletos adultos por meio de análises métricas, morfológicas ou por DNA especificamente pelo gene da amelogenina relacionado ao cromossomo sexual. Porém, a aplicação de metodologias semelhantes em amostras forenses de esqueletos subadultos enfrentam limitações que levam ao insucesso da estimativa correta do sexo. A proteína amelogenina é expressa no elemento dental, que devido à sua dureza, durabilidade e resistência a insultos post mortem, sobrevive a uma variedade de efeitos destrutivos causados por alterações mecânicas, químicas, físicas e térmicas, se tornando um repositório de informações. As amelogeninas, por splicing alternativo, derivam isoformas que diferenciam suas origens dos cromossomos $\mathrm{X}$ ou Y. Por atuação de enzimas MMP-20 e KLK4 durante a amelogênese, peptídeos são gerados permanecendo no interior dos prismas do esmalte. Sendo assim, o presente trabalho objetivou extrair, identificar e analisar qualitativamente e quantitativamente, por cromatografia líquida e espectrometria de massas, esses peptídeos derivados das isoformas $Y$ e $X$ do gene da amelogenina, AMELY e AMELX respectivamente, presentes no esmalte de dentes decíduos de crianças entre 6 e 8 anos de idade para estimar o sexo no processo de identificação humana em esqueletos subadultos. Foram extraídos peptídeos da AMELY e AMELX do esmalte dental de 40 dentes decíduos pela técnica de ataque ácido com $\mathrm{HCl}$ a $10 \%$ na coroa dental utilizando uma ponteira Zip Tip ${ }^{\circledR}$ C18 e posterior injeção para análise no sistema EASY-nLC IIM acoplado a um espectrômetro de massas LTQ Orbitrap Velos para sequenciar e diferenciar os peptídeos AMELY e AMELX para a estimativa do sexo biológico das crianças. Os raw data gerados pelo espectrômetro de massas foram confrontados no software Proteome Discoverer 2.3 juntamente com o SEQUEST contra o banco de dados UniProt. Foram selecionados para estudos os 4 peptídeos da AMELY e 9 peptídeos da AMELX mais prevalentes identificados nas amostras. Os resultados mostraram que foi possível diferenciar e identificar peptídeos AMELY e AMELX utilizando o software Tracefinder ${ }^{\mathrm{TM}}$, e analisar qualitativamente as amostras. Os resultados mostraram que 15 amostras do grupo feminino e 19 amostras do grupo masculino tiveram concordância entre os sexos real e estimado das crianças. Quantitativamente foi demonstrado a prevalência de expressão e equilíbrio de distribuição da AMELX nas amostras do grupo masculino em relação ao grupo feminino. E pode-se concluir que a análise por nLC-MS/MS dos peptídeos dimórficos da amelogenina presentes em dentes decíduos pode ser utilizada de forma segura para a estimativa do sexo biológico em esqueletos de crianças entre 6 e 8 anos de idade na prática forense, sobressaindo de forma confiável e vantajosa às metodologias aplicadas nos dias atuais por análises métricas e morfológicas.

Palavras-chave: Identificação Humana. Antropologia Forense. Aminoácidos, peptídeos e proteínas. Proteômica. Espectrometria de Massas. 
Abstract 
OLIVEIRA, Larissa Dutra Bittencourt de. Proteomic analysis of primary tooth enamel for sex estimation in children. 2019. 146 f. Tese (Doutorado em Ciências Médicas) - Faculdade de Medicina de Ribeirão Preto, Universidade de São Paulo, Ribeirão Preto, 2019.

\begin{abstract}
Sex estimation methods in forensic contexts are performed on adult skeletons by metric, morphological or DNA analysis specifically by the sex chromosome-related amelogenin gene. However, the application of similar methodologies to forensic samples of subadult skeletons face limitations that lead to the failure to correctly estimate sex. Amelogenin protein is expressed in the dental element, which due to its hardness, durability and resistance to post mortem insults, survives a variety of destructive effects caused by mechanical, chemical, physical and thermal changes, becoming a repository of information. Amelogenins, by alternative splicing, derive isoforms that differentiate their origins from $X$ or $Y$ chromosomes. By acting MMP-20 and KLK4 enzymes during amelogenesis, peptides are generated remaining within the enamel prisms. Thus, the present work aimed to extract, identify and analyze qualitatively and quantitatively, by liquid chromatography and mass spectrometry, these peptides derived from the amelogenin gene $Y$ and $X, A M E L Y$ and AMELX respectively, present in the primary teeth enamel of children between 6 and 8 years old to estimate sex in the human identification process in subadult skeletons. AMELY and AMELX peptides were extracted from 40 primary teeth enamel by $10 \% \mathrm{HCl}$ acid etching technique using a Zip Tip $\mathrm{C} 18^{\circledR}$ tip and subsequent injection for analysis on the EASY-nLC IITM system coupled to a mass spectrometer LTQ Orbitrap Velos to sequence and differentiate the AMELY and AMELX peptides to estimate the biological sex of children. The raw data generated by the mass spectrometer were compared in Proteome Discoverer 2.3 software together with SEQUEST against the UniProt database. The 4 AMELY peptides and 9 most prevalent AMELX peptides identified in the samples were selected for studies. The results showed that it was possible to differentiate and identify AMELY and AMELX peptides using Tracefinder ${ }^{\mathrm{TM}}$ software, and to qualitatively analyze the samples. The results showed that 15 samples from the female group and 19 samples from the male group had agreement between the real and estimated sexes of the children. Quantitatively, the prevalence of AMELX expression and distribution equilibrium in the samples of the male group in relation to the female group was demonstrated. It can be concluded that nLC-MS / MS analysis of amelogenin dimorphic peptides present in primary teeth can be safely used to estimate biological sex in skeletons of children aged 6 to 8 years in forensic practice, reliably and advantageously stand out to the methodologies applied today by metric and morphological analysis
\end{abstract}

Keywords: Human Identification. Forensic Anthropology. Amino Acids, Peptides, and Proteins. Proteomics. Mass Spectrometry. 
Listas 


\section{LISTA DE FIGURAS}

Figura 01 - Capela de fluxo laminar.................................................... 51

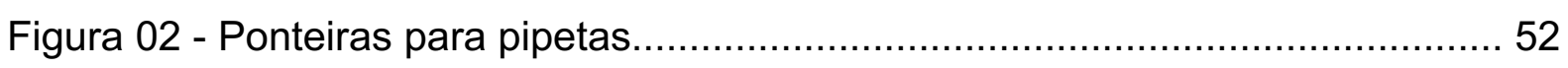

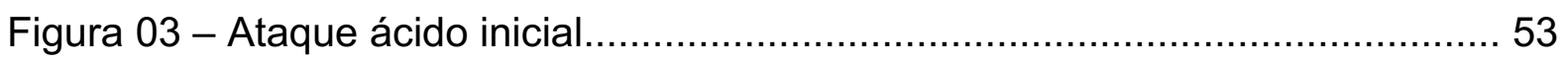

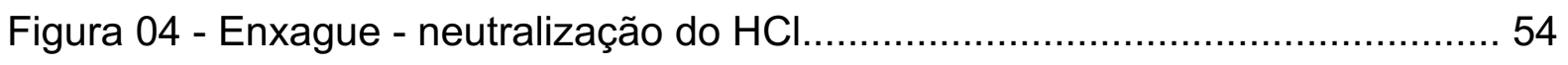

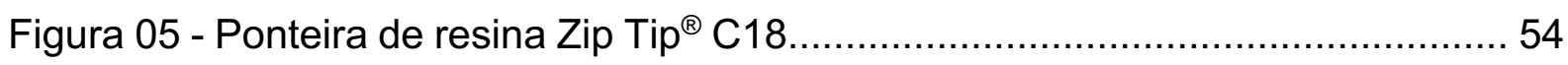

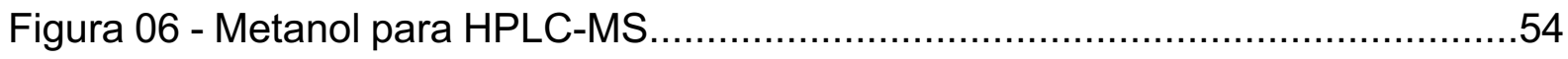

Figura 07 - Procedimento “Zip Tip on Target'................................................ 54

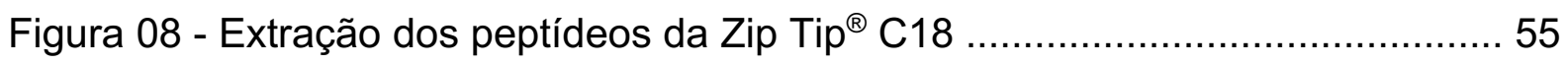

Figura 09 - Tubos HPLC Vials................................................................... 56

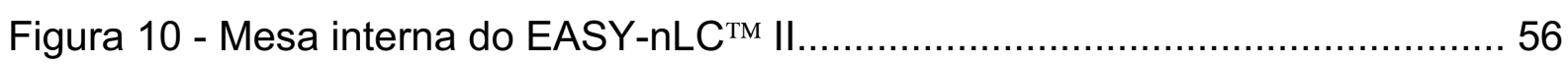

Figura 11 - EASY-nLC $\|^{\mathrm{TM}}$ acoplado ao LTQ Orbitrap Velos ${ }^{\mathrm{TM}} \ldots \ldots \ldots \ldots \ldots \ldots \ldots \ldots \ldots . \ldots . \ldots \ldots$

Figura 12 - Espectro do peptídeo PEP1Y................................................ 66

Figura 13 - Espectro do peptídeo PEP2Y.................................................. 70

Figura 14 - Espectro do peptídeo PEP3Y .................................................. 74

Figura 15 - Espectro do peptídeo PEP4Y................................................. 78

Figura 16 - Espectro do peptídeo PEP1X................................................... 82

Figura 17 - Espectro do peptídeo PEP2X................................................ 86

Figura 18 - Espectro do peptídeo PEP3X................................................ 90

Figura 19 - Espectro do peptídeo PEP4X................................................... 94

Figura 20 - Espectro do peptídeo PEP5X.................................................. 98

Figura 21 - Espectro do peptídeo PEP6X.......................................................102

Figura 22 - Espectro do peptídeo PEP7X ..................................................106

Figura 23 - Espectro do peptídeo PEP8X................................................110

Figura 24 - Espectro do peptídeo PEP9X...............................................114

Figura 25 - Quantificação dos peptídeos AMELY nas amostras masculinas...........120

Figura 26 - Quantificação dos peptídeos AMELX nas amostras femininas.............121

Figura 27 - Quantificação dos peptídeos AMELX nas amostras masculinas...........122 


\section{LISTA DE QUADROS}

Quadro 1 - Sequência de aminoácidos da amelogenina.................................. 40

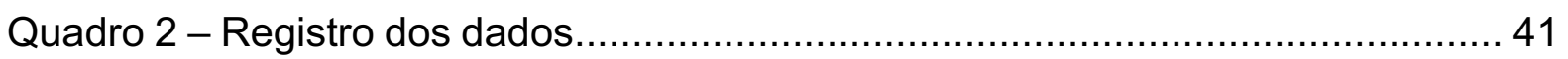

Quadro 3 - Fragmentos peptídicos totais AMELY e AMELX .............................. 63

Quadro 4 - Fragmentos peptídicos AMELY................................................ 64

Quadro 5 - Fragmentos peptídicos AMELX.................................................. 65 


\section{LISTA DE TABELAS}

Tabela 1 - Frequências absoluta e relativa de cada peptídeo na amostra total..... 117

Tabela 2 - Frequências absoluta e relativa de cada peptídeo por sexo....................118

Tabela 3 - Quantificação dos peptídeos na amostra total $(n=40)$ e por sexo $(n=20)$ 119

Tabela 4 - Concordância entre o sexo real e o sexo estimado por LC-MS/MS 122 


\section{LISTA DE ABREVIATURAS}

min - minutos

$\mathrm{s}$ - segundos

LC/CL - Liquid Chromatography / Cromatografia Líquida

MS/EM - Mass Spectrometry / Espectrometria de Massas

$\mathrm{m} / \mathrm{z}$ - massa/carga

RT/TR - Retention Time / Tempo de Retenção 


\section{LISTA DE SIGLAS}

ACN

$\mathrm{HCl}$

TFA

CAAE

CEP

FMRP

FORP

USP
Acetonitrila

Ácido clorídrico

Ácido trifluoroacético

Certificado de Apresentação para Apreciação Ética

Comitê de Ética em Pesquisa

Faculdade de Medicina de Ribeirão Preto

Faculdade de Odontologia de Ribeirão Preto

Universidade de São Paulo 


\section{LISTA DE SÍMBOLOS}

A Aminoácido alanina

$\mathrm{Da}$ - daltons, unidade de medida de massa atômica

D Aminoácido aspartato

E Aminoácido glutamato

F Aminoácido fenilalanina

G Aminoácido glicina

H Aminoácido histidina

I Aminoácido isoleucina

$K$ Aminoácido lisina

L Aminoácido leucina

M Aminoácido metionina

( ) Marca Registrada

$\mu \mathrm{L}$ Microlitro

N Aminoácido asparagina

P Aminoácido prolina

$\%$ Porcentagem

Q Aminoácido glutamina

R Aminoácido arginina

S Aminoácido serina

T Aminoácido treonina

$\checkmark$ Aminoácido valina

v/v Concentração do volume

W Aminoácido triptofano

Y Aminoácido tirosina 
Sumárío 


\section{SUMÁRIO}

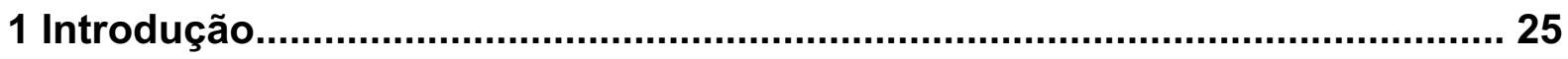

1.1 A estimativa de sexo na Antropologia Forense..................................... 26

1.2 A estimativa de sexo na Antropologia Forense em esqueleto subadultos....... 28

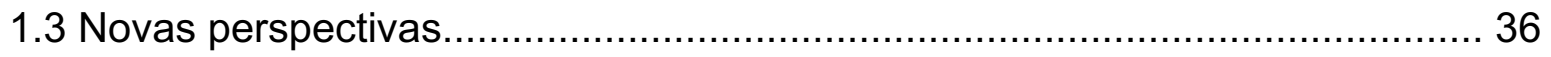

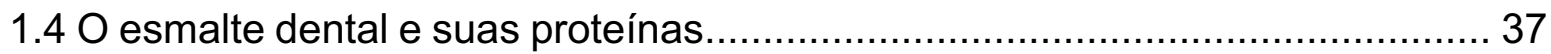

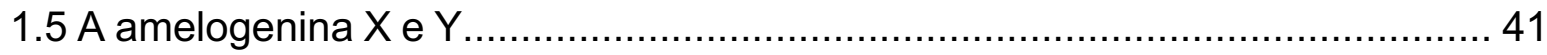

1.6 Cromatografia líquida e espectrometria de massas............................... 43

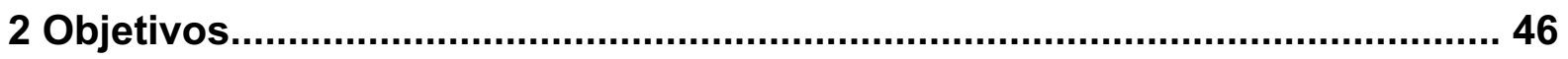

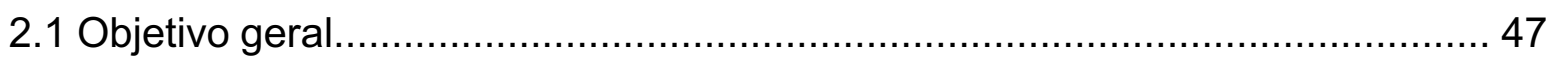

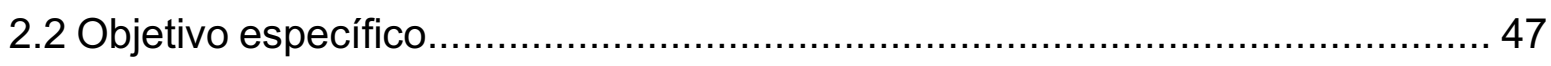

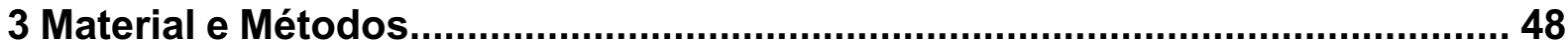

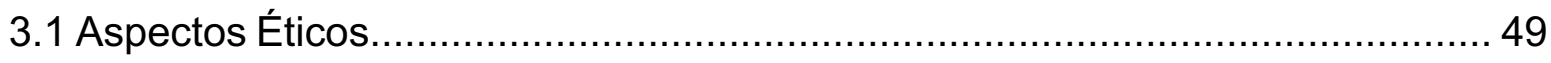

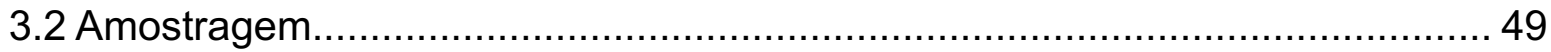

3.2.1 Critérios de seleção das amostras................................................ 49

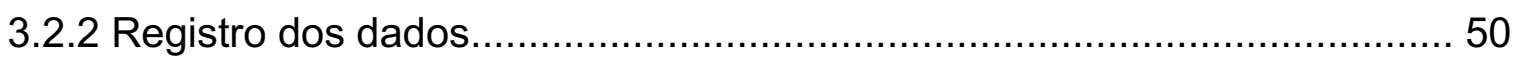

3.3 Preparo das amostras e extração dos peptídeos.................................... 51

3.3.1 Limpeza das amostras................................................................ 51

3.3.2 Preparação inicial e extração dos peptídeos........................................ 51

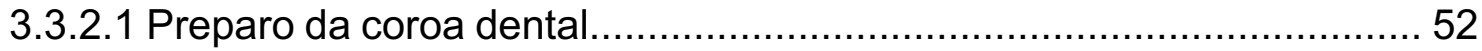

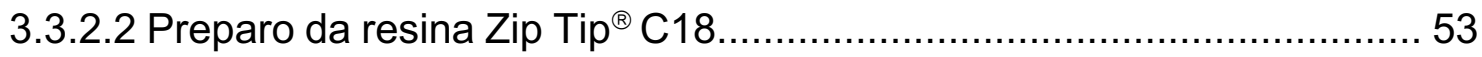

3.3.2.3 Procedimento propriamente dito - "ZipTip on Target"........................ 54

3.4 Cromatografia líquida e espectrometria de massas................................ 55

3.4.1 Suspensão das amostras........................................................ 56

3.4.2 Análise por espectrometria de massas nLC-MS/MS ............................ 56

3.5 Metodologia de análise dos dados.................................................... 58

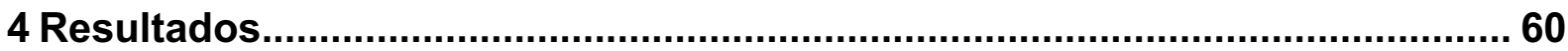

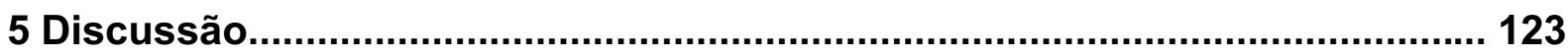

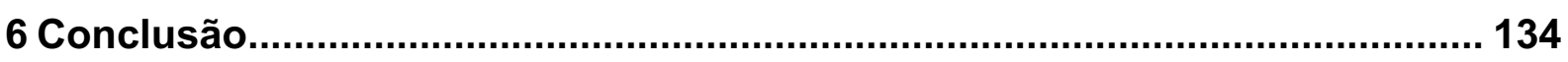

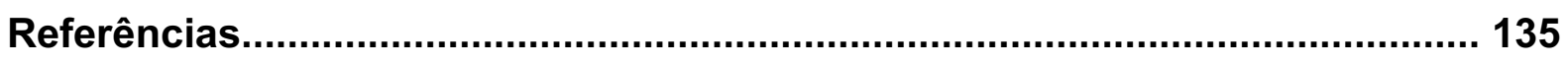

Anexo

ANEXO A - Aprovação da emenda do Comitê de Ética em Pesquisa..................143 

Introdução 


\section{INTRODUÇÃO}

\subsection{A estimativa de sexo na Antropologia Forense}

A estimativa de sexo a partir de restos esqueléticos se baseia na identificação e avaliação de características que mostram diferenças de tamanho e forma entre os esqueletos feminino e masculino expressas de maneira variável em todo o esqueleto. Essas diferenças estão relacionadas principalmente ao tamanho e à arquitetura que resultam de diferentes funções biomecânicas das articulações para a eficiência na locomoção e no parto (CHRISTENSEN; PASSALACQUA, 2018).

O perfil biológico de um indivíduo, especialmente nas etapas preliminares de uma investigação, é crucial no processo de identificação humana (CHRISTENSEN; PASSALACQUA, 2018; STEWART et al., 2016). A correta estimativa do sexo elimina efetivamente aproximadamente $50 \%$ de uma amostra, auxiliando e agilizando substancialmente na busca por registros e bases de dados em casos de pessoas desaparecidas (CHRISTENSEN; PASSALACQUA, 2018; WILLIAMS et al., 2004), além de que as técnicas utilizadas para traçar o perfil biológico de um indivíduo no processo de identificação humana como a ancestralidade, a idade, a estatura, também são dependentes do sexo (CATTANEO, 2007; STEWART et al., 2017).

Desde os primeiros estudos realizados sobre a estimativa de sexo através de ossos e dentes (HUNT; GLEISER, 1955), pesquisas vem sendo desenvolvidas para encontrar um método confiável a ser aplicado na identificação humana. Confiável pode ser definido como estudos com uma precisão acima de $80 \%$. Como $80 \%$ não fornece discriminação absoluta na prática forense, os resultados abaixo dessa porcentagem devem ser seguidos por uma segunda análise para a confirmação (CAPITANEANU; WILLEMS; THEVISSEN, 2017). Métodos antropológicos e odontológicos são utilizados para estimar o sexo por meio de diferentes variáveis métricas, não métricas e análises bioquímicas (CAPITANEANU; WILLEMS; THEVISSEN, 2017).

Os métodos antropológicos para a estimativa de sexo geralmente são por análise morfológica e métrica de diversos ossos do corpo como a pelve, o crânio, o sacro, a escápula, a clavícula, o esterno, o úmero e o fêmur. A análise morfológica avalia visualmente as características esqueléticas, e a análise métrica envolve medições nas dimensões máximas ou mínimas com base em detalhes osteológicos para avaliar quantitativamente as diferenças de tamanho e forma entre os sexos. As 
diferenças são avaliadas usando certos ossos ou padrões gerais, dependendo do grau e da qualidade do dimorfismo sexual naquele osso ou região anatômica (CHRISTENSEN; PASSALACQUA, 2018).

A pelve é a região mais sexualmente dimórfica do esqueleto humano portanto, sua avaliação é o método mais preciso para estimar o sexo a partir de material esquelético (CHRISTENSEN; PASSALACQUA, 2018; KLALES, 2016; PHENICE, 1969). O método de Phenice é predominantemente o método preferido de estimativa morfológica do sexo na antropologia forense e biológica (KLALES, 2016). Apesar de ter sido criado usando uma amostra histórica, é utilizado até os dias atuais mesmo em esqueletos recentes e adultos, com uma precisão máxima de $95 \%$ se a pelve estiver presente e preservada, mas isso nem sempre é possível para todos os casos (KLALES, 2016; STEWART et al., 2017).

Os métodos odontológicos baseiam-se nas características morfológicas e métricas dos elementos dentais e estruturas adjacentes como análises cefalométricas, da mandíbula, dos lábios, das rugas palatinas, dos seios maxilares e frontais, e análise bioquímica das estruturas dentais como esmalte, dentina e cemento, bem como dos ossos (CAPITANEANU; WILLEMS; THEVISSEN, 2017).

A análise de DNA de restos humanos tornou-se uma prática comum para identificar restos humanos. Ossos, dentes e cabelos são os materiais biológicos mais duráveis e, portanto, em muitos casos forenses e estudos antropológicos, representam a fonte potencial única de material genético (PILLI et al., 2018). Ao trabalhar com amostras ósseas forenses, em determinados casos, depara-se com baixas quantidades de moléculas, com degradação do DNA e presença de inibidores da reação em cadeia da polimerase (PCR) (ANDERUNG et al., 2008; PILLI et al., 2018; WADSWORTH et al., 2017), o que pode dificultar ou impedir a sua amplificação para análise da amelogenina e consequentemente, a estimativa do sexo.

A análise bioquímica dos dentes foi o método odontológico mais preciso para estimar o sexo, com acurácia variando entre 82,5 e 100\%, mas apresenta limitações na prática forense. As restrições estão relacionadas à necessidade de contar com marcadores bioquímicos de alta qualidade e quantidade nas evidências odontológicas disponíveis, nos custos e tempo necessários para a realização das análises (CAPITANEANU; WILLEMS; THEVISSEN, 2017; PILLI et al., 2018).

Certamente a genética desempenha um papel fundamental, no entanto, fatores ambientais gerais, morbidade, nutrição, evolução e outras influências também 
contribuem para a estimativa de sexo (MANIFOLD, 2014; UBELAKER; DEGAGLIA, 2017). Além disso, a avaliação da variação populacional da expressão do dimorfismo sexual no esqueleto também pode refletir questões de amostragem e viés. Estudos de amostras em regiões específicas documentam aspectos de variação que fornecem dados úteis e críticos para a interpretação forense. Dados locais e a metodologia utilizada devem ser consultados. Caso não estejam disponíveis, uma análise minuciosa da ancestralidade deve ser seguida para selecionar abordagens metodológicas que se relacionem o mais próximo possível com a amostra a ser estudada (CATTANEO, 2007; IŞCAN, 2005; RAMSTHALER et al., 2010; RISSECH; MALGOSA, 2007; UBELAKER; DEGAGLIA, 2017).

\subsection{A estimativa de sexo na Antropologia Forense em esqueletos subadultos}

A Antropologia Forense encontra grandes dificuldades em estimar o sexo em subadultos por meio de seus restos esqueléticos devido a incompleta formação dos ossos do corpo humano, o que torna uma tarefa de diagnóstico muito complexa quando da utilização das características morfológicas (CHRISTENSEN; PASSALACQUA, 2018; DARMAWAN et al., 2015; OLIVARES; AGUILERA, 2016; STEWART et al., 2017; VICIANO; LÕPEZ-LÁZARO; ALEMÁN, 2013). A incompleta formação de ossos do corpo não evidencia as características morfológicas dos sexos, não havendo relatos de diferenças sexuais na massa óssea do esqueleto antes da puberdade (BONJOUR et al., 2012; CHRISTENSEN; PASSALACQUA, 2018; STEWART et al., 2017), também não há diferenças entre os sexos na massa e na densidade óssea ao nascer, aparentando-se semelhantes os esqueletos recémnascidos do sexo feminino e masculino (BONJOUR et al., 2012; MANIFOLD, 2014; OLIVARES; AGUILERA, 2016).

Em subadultos, a estimativa do sexo por análises morfológicas e métricas do esqueleto é geralmente considerada inadequada (CHRISTENSEN; PASSALACQUA, 2018; LEWIS, 2009; PILLI et al., 2018; STEWART et al., 2017), ou muito mais imprecisa do que em indivíduos adultos (OLIVARES; AGUILERA, 2016), pois o dimorfismo sexual no esqueleto não aparece até a puberdade por não haver ainda influências hormonais e metabólicas que tem seu início por volta dos 14 anos de idade (BIANCHI, 2007; BONJOUR et al., 2012; CHRISTENSEN; PASSALACQUA, 2018; OLIVARES; AGUILERA, 2016; PILLI et al., 2018; STEWART et al., 2017). O aparecimento de características do dimorfismo sexual é produzido devido a alteração 
dos níveis hormonais e a ação muscular na puberdade, o que afeta o tamanho dos ossos e não a sua densidade mineral volumétrica (BONJOUR et al., 2012), fatores estes que interferem em uma estimativa sexual mais precisa.

Em indivíduos que ainda não atingiram a puberdade, as características ósseas discriminatórias são mínimas, sendo a metodologia utilizada para estimar o sexo dos adultos (principalmente por meio de características do crânio e da pelve) não aplicável a crianças. Além disso, outros indicadores, como diferenças químicas nos ossos, com base nos níveis de citrato, cálcio, fósforo e estrôncio, também são vistos apenas em indivíduos que atingiram a idade reprodutiva (LEWIS, 2009).

A idade inicial do surto puberal e do processo de crescimento é mais precoce nas meninas, mas a duração do surto de crescimento e o pico máximo de crescimento são maiores nos meninos (BIANCHI, 2007). Diferentes variáveis antropométricas parecem ter efeitos diferenciais no desenvolvimento esquelético das crianças (MILLER et al., 1991). Cerca de $85 \%$ do esqueleto é constituído por osso cortical e $15 \%$ por osso trabecular. A densidade óssea trabecular é influenciada por fatores hormonais e metabólicos associados ao desenvolvimento sexual (BIANCHI, 2007).

Além disso, a expressão do dimorfismo sexual no esqueleto humano reflete fatores genéticos e ambientais que influenciam o crescimento e o desenvolvimento, e a variação global desses fatores produz diferenças consideráveis nas manifestações do dimorfismo sexual esquelético humano que impactam a metodologia e o trabalho a ser realizado (LOTH; HENNEBERG, 2001; LUNA; ARANDA; SANTOS, 2017; MANIFOLD, 2014; UBELAKER; DEGAGLIA, 2017).

Apesar dessas limitações, numerosos estudos demonstraram a existência de diferenças morfométricas entre os sexos de esqueletos subadultos apresentando resultados diversos, o que permitiu projetar métodos que forneçam uma estimativa do sexo para essa faixa etária, embora, sejam mais imprecisos em comparação aos adultos.

Schutkowski (1993) analisou traços morfológicos sexualmente dimórficos na mandíbula e no ílio de uma amostra histórica de 61 crianças de sexo e idade conhecidos entre nascimento e 5 anos, 37 meninos e 24 meninas de Spitalfields, Londres, no Reino Unido. As características apresentadas neste estudo permitiram identificar o sexo com taxas entre 70 e $90 \%$ dos casos (SCHUTKOWSKI, 1993).

Foi aplicado o mesmo método antropológico para a estimativa de sexo em duas coleções osteológicas históricas diferentes analisando os ossos faciais, 
especificamente a morfologia da órbita e dois aspectos da mandíbula, o ângulo mandibular e o mento, em esqueletos infantis com idades entre 1 e 14 anos. Concluíram que características da face e da mandíbula foram encontradas nas duas coleções e são úteis na estimativa do sexo de crânios juvenis com taxa de sucesso de 78\% (MOLLESON; CRUSE; MAYS, 1998).

Estudos analisaram a expressão sexualmente dimórfica em mandíbulas de sete amostras masculinas e 12 amostras femininas entre idades do nascimento aos 19 anos, e discutiram fatores que afetaram o seu desenvolvimento, bem como introduziram critérios para a análise, os quais não foram recomendados para uso em indivíduos acima de 6 anos, devido a transição do esqueleto para a idade adulta. Concluíram que a estimativa do sexo das amostras obteve taxas de sucesso entre 74 a $89 \%$ pela análise visual de três avaliadores, e pela análise por tomografia computadorizada de amostras selecionadas obteve sucesso de $82 \%$ (LOTH; HENNEBERG, 2001).

Grande parte das análises do sexo em esqueletos subadultos foi desenvolvida em restos fetais e jovens como nos trabalhos iniciais de Weaver em 1980; Schutkowski em 1993; Molleson et al., em 1998; e Loth e Henneberg, em 2001, descritos previamente. Posteriormente, trabalhos foram replicados por outros autores e obtiveram resultados menos precisos do que os obtidos pelos autores originais Scheuer (2002) e Sutter (2003). Testes das mesmas técnicas usando esqueletos jovens e adolescentes mais velhos também tiveram o sucesso limitado.

Variáveis morfológicas de 36 mandíbulas também foram observadas em amostras com sexo conhecido e idades entre 5 meses a 4 anos e 7 meses, da coleção histórica de Spitalfields no Museu de História Natural de Londres, no Reino Unido. O autor atribuiu corretamente o sexo das amostras em $75 \%$ dos casos (SCHEUER, 2002).

Um estudo testou oito características não-métricas usando 85 esqueletos subadultos pré-históricos mumificados com sexo conhecido, do norte do Chile, com idades entre recém-nascidos e 15 anos. Os resultados mostraram que todos os oito traços relacionados ao sexo subadulto propostos foram relacionados ao sexo conhecido, mas há uma grande variação por sexo e idade. No entanto, apenas quatro características demonstraram níveis aceitáveis de precisão para aplicações forenses. Essas características incluíram os critérios do arco $(82,3 \%)$, ângulo $(80,7 \%)$, profundidade $(79 \%)$ e formato mandibular $(77,6 \%)$. Para subadultos com idade de 
recém-nascidos a cinco anos, apenas a profundidade $(81,5 \%)$ e os critérios do arco $(81,5 \%)$ se aproximaram de níveis aceitáveis para uso em casos forenses (SUTTER, 2003) .

Em um estudo foi avaliada a precisão do método morfológico de estimativa de sexo de Rogers proposto em 1999 utilizando o úmero distal em esqueletos jovens. Foram avaliados 7 esqueletos subadultos documentados da coleção Christ Church Spitalfields no Museu Britânico de História Natural e 35 esqueletos subadultos da coleção esquelética Luis Lopes, alojada no Museu Nacional de História (Museu Bocage) da Universidade de Lisboa, Portugal, com idades entre 11 a 20 anos. A técnica alcançou uma precisão de $81 \%$ e concluiu que o método pode ser aplicado a esqueletos subadultos quando a tróclea começa a se fundir à diáfise do úmero, que ocorreu aos 11 anos de idade nas amostras do teste (ROGERS, 2009).

Pesquisadores investigaram o dimorfismo sexual dos ossos longos, no úmero e no fêmur, em indivíduos com idade desde o nascimento até 1 ano. Foram analisadas 85 radiografias, e destas 85 imagens do fêmur e 45 do úmero. A análise discriminante mostrou-se um método mais bem-sucedido, com taxas de erro de $3 \%$ ao utilizar a largura máxima no eixo médio do fêmur e 11\% com a largura distal máxima do úmero. Concluiu-se que é possível estimar o sexo restos esqueléticos subadultos menores de 1 ano de idade pela análise métrica do úmero e do fêmur (STULL; GODDE, 2013).

Foram avaliados padrões de crescimento para as dimensões craniofaciais de meninos e meninas europeus de 3 a 6 anos de idade através de análises craniofaciais antropométricas, levando em consideração o peso e a altura corporais, e 23 medidas craniofaciais de 681 crianças (362 meninos e 319 meninas) da Alemanha, Itália e Lituânia. Os resultados mostraram que as medidas craniofaciais exibem padrões relacionados à idade e ao sexo, independentemente do peso e da altura corporal das crianças europeias estudadas e podem ser aplicados em contextos forenses (TUTKUVIENE et al., 2016).

Foram testadas características do ílio e da mandíbula propostas por Schutkowski em 1993 para validar a estimativa de sexo em esqueletos subadultos em 109 meninos e 76 meninas, com idades entre 5 meses de gestação e 6 anos, na coleção osteológica identificada de Granada, Espanha. Concluiu-se que foi insuficiente provar a eficácia dos métodos, pois não permitiu conhecer a influência de outros fatores, como a população ou a idade, como variáveis independentes. Embora as condições não sejam adequadas, o estudo de validação permitiu chegar a um 
consenso mais próximo, identificar problemas e aperfeiçoar gradualmente os métodos de análise. Alerta o autor que o método de Schutkowski não é aceitável para fins forenses pois as taxas de atribuição correta do sexo foram menores (54 a 80\%) que os estudos apresentados em 1993 (65 a 94\%) (OLIVARES; AGUILERA, 2016).

Uma pesquisa avaliou a superfície auricular do osso ilíaco subadulto em 34 indivíduos, 21 do sexo feminino e 13 do sexo masculino, com idades entre 7 e 18 anos, da Coleção de Esqueletos Identificados de Coimbra, Universidade de Coimbra, Portugal. Conclui-se que duas razões relacionadas à forma da área anterior da superfície auricular ofereceram os dados mais dimórficos, classificando corretamente $82,35 \%$ das amostras femininas e $88,23 \%$ das amostras masculinas, porém há a necessidade de avaliar outros indicadores para melhorar a precisão dos resultados obtidos (LUNA; ARANDA; SANTOS, 2017).

Apesar de trabalhos apresentarem resultados com taxas de sucesso relativamente satisfatórias, por outro lado, estudos revelaram insucessos e limitações no uso de metodologias para aplicações forenses.

Weaver (1980) analisou o ílio de uma amostra conhecida de 153 recémnascidos e bebês por métodos métricos e não métricos para a estimativa de sexo da coleção do Instituto Smithsonian. Os três índices usados falharam em mostrar diferenças sexuais significativas (WEAVER, 1980).

Foi aplicado o método de Schutkowski para a estimativas de sexo em 56 esqueletos subadultos pela análise da morfologia do ílio de uma coleção esquelética do Museu Bocage em Lisboa, Portugal. Concluíram que a aplicação deste método em amostras arqueológicas e forenses pode ser problemática e sugeriram que o método não estima o sexo com precisão em todas as populações (VLAK; ROKSANDIC; SCHILLACI, 2008).

Em contrapartida, os estudos de Rissech e Malgosa (2007) analisaram também o crescimento de cinco variáveis da área isquiopúbica de 327 esqueletos de idades entre o nascimento até 97 anos, de quatro diferentes coleções osteológicas da Europa. As variáveis clássicas da área isquiopúbica (comprimento do púbis e índice isquiopúbico) e três novas variáveis da área acetabular pubiana (diâmetro horizontal e vertical da área acetabular pubiana e do índice acetabular pubiano). Concluíram que todas as variáveis são úteis para a estimativa do sexo em adultos, exceto o índice acetabular pubiano. O comprimento do púbis em adultos mostrou diferença entre os sexos apenas nas amostras inglesas, e não nas lbéricas, o que sugere ser uma 
consequência do tamanho corporal da população. O índice isquiopúbico, o diâmetro vertical da área acetabular pubiana e o índice acetabular pubiano parecem ser boas variáveis para a estimativa do sexo do esqueleto subadulto (RISSECH; MALGOSA, 2007).

Dentre os métodos odontológicos, estudos demonstram a aplicação de metodologias de análises métricas e morfológicas dos arcos e das coroas dentais.

Foram analisadas 20 medidas mesiodistais e bucolinguais de 133 coroas de dentes decíduos de crianças para obter informações sobre o dimorfismo sexual e realizar a discriminação sexual. Embora diferenças consistentes tenham sido encontradas para apenas 15 das 20 medições, a análise discriminante mostrou a possibilidade estimar o sexo com sucesso em 63.9 a $67.7 \%$ das amostras subadultas (BLACK, 1978).

Medidas do diâmetro mesiodistal e vestíbulo lingual da coroa de todos os dentes decíduos, bem como os dos primeiros molares permanentes, foram realizadas de 162 crianças do Burlington Orthodontic Growth Study, realizado em Burlington, Ontário, Canadá. Todos os 40 diâmetros dos dentes decíduos (20 mesiolinguais e 20 vestíbulos linguais) foram significativamente diferentes entre os sexos, assim como os diâmetros dos dentes permanentes. Valores entre 76 a 90\% foram corretamente classificados por sexo e concluíram que as diferenças no tamanho das coroas desses dentes entre os sexos não foram discriminadores sexuais confiáveis, em contraste com essas diferenças nos dentes permanentes (DE VITO; SAUNDERS, 1990).

Cardoso (2008) pesquisou métodos de estimativa de sexo específicos para amostras de restos esqueléticos adultos $(n=107)$ e subadultos $(n=49)$ identificados com base nas dimensões dos diâmetros dos dentes, da coleção esquelética do Museu Nacional de História Natural de Lisboa, Portugal. Os diâmetros mesiodistal e vestíbulo lingual das coroas foram medidos e concluíram que as taxas de sucesso na estimativa de sexo nos esqueletos subadultos foram de 64 a 88\% (CARDOSO, 2008).

Em um estudo foram avaliados 269 indivíduos da coleção osteológica de Granada, Espanha, composta por esqueletos identificados de crianças, jovens e adultos. Foram realizadas mensurações em 118 indivíduos entre fetos com 9 meses de gestação e crianças com 8 anos de idade, baseadas nos diâmetros mesio distal, buco lingual e diagonal da coroa e do colo cervical da dentição decídua e permanente e concluíram que o primeiro e o segundo molares decíduos e os caninos permanentes são os dentes com maior dimorfismo sexual, atribuindo corretamente o sexo entre 
78,1 e $93,1 \%$ na dentição decídua e entre 79,4 e $92,6 \%$ nos dentes permanentes, utilizando diferentes dimensões. Os resultados indicaram que esse método pode ser aplicável como um complemento de outros métodos para a estimativa de sexo em amostras arqueológicas ou forenses (VICIANO; LÕPEZ-LÁZARO; ALEMÁN, 2013).

Foi avaliado o grau de dimorfismo sexual nas dimensões marginais do esmalte, dentina e polpa de dentes segundos molares decíduos em 124 crianças (64 masculinos e 60 femininos) de 4 a 6 anos de idade. As análises métricas foram realizadas em radiografias bitewings da maior largura de esmalte, dentina e polpa nos dentes superiores e inferiores. A precisão da identificação sexual foi de aproximadamente $68 \%$ e esses dados odontométricos, em conjunto com outras características esqueléticas, podem ser usados como uma ferramenta adicional na estimativa de sexo na antropologia forense (PAKNAHAD; VOSSOUGHI; AHMADI ZEYDABADI, 2016).

Foram pesquisadas 146 meninas e 218 meninos do sul da Índia, com idades entre 3 e 5 anos através de análises métricas dos arcos dentais. Após a moldagem com alginato da arcada dental superior e vazamento em gesso, foram feitas mensurações com um compasso digital. Os resultados mostraram dimorfismo sexual apresentados no canino inferior, nos incisivos central e lateral superior e no segundo molar superior variando de $83.5 \%$ a $85 \%$ (SHANKAR et al., 2018).

López-Lazaro et al. (2018) estudaram o dimorfismo sexual da superfície oclusal dos primeiros molares decíduos superiores usando técnicas morfométricas geométricas em 195 esqueletos de indivíduos subadultos identificados do Cemitério Municipal de Granada, em San José, Espanha. Concluiu-se que tanto os primeiros molares decíduos superiores quanto os inferiores apresentaram dimorfismo sexual evidente, embora estatisticamente significativo apenas no molar superior (LÓPEZLÁZARO et al., 2018).

Um estudo testou metodologias propostas por Black (1978), De Vito e Saunders (1990) e Zadzinska et al. (2008) para a estimativa do sexo a partir das dimensões da coroa dental de dentes decíduos, em 46 esqueletos subadultos (20 masculinos e 26 femininos), com idades do nascimento até 10 anos, nascidos entre 1911 e 1971, da coleção esquelética identificada do Museu Nacional de História Natural de Lisboa, Portugal. As coroas dos dentes decíduos foram medidas com um paquímetro digital em suas dimensões mésio distal e vestíbulo lingual. Os resultados mostraram baixa precisão geral $(33,3-75 \%)$ e baixa validação cruzada dos dados $(46,2-60,0 \%)$ com os 
estudos anteriores, ressaltando que as dimensões das coroas dos dentes decíduos são pouco discriminantes do sexo para uso confiável. Confirmaram também os obstáculos enfrentados na estimativa do sexo no contexto forense utilizando análises métricas na dentição decídua pois as dimensões dos dentes decíduos são menos dimórficas sexualmente do que os dentes permanentes além do grau de dimorfismo variar dentro e entre populações (CARDOSO, 2010).

Métodos bioquímicos para a análise do DNA de elementos dentais por PCR estão sendo estudados e aplicados na prática forense. Todavia, diversos resultados demonstraram limitações na Antropologia Forense. Na ausência de DNA, os métodos de avaliação do sexo esquelético subadulto produziram resultados diversos e opostos, demonstrando frequentemente um sucesso significativamente maior nos homens do que nas mulheres (SUTTER, 2003).

Um estudo analisou a técnica de DNA baseado por PCR em dentes para a estimativa de sexo usando o marcador do gene da amelogenina AMEL, de amostras indianas. Concluiu que o gene serviu como um bom marcador para a estimativa sexual em amostras indianas (SIVAGAMI; RAO; VARSHNEY, 2000).

Um estudo analisou 84 dentes molares decíduos de amostras de sexo conhecido, as quais foram expostas a uma faixa de temperaturas de incineração de 100 a $500^{\circ} \mathrm{C}$ por 15 minutos. A amplificação por PCR foi usada para identificar regiões específicas da amelogenina humana. Concluíram que foi possível identificar o sexo biológico a partir de dentes decíduos expostos a temperaturas de incineração de até $200^{\circ} \mathrm{C}$ (WILLIAMS et al., 2004), o que limita o seu uso em casos de corpos carbonizados dependendo da temperatura de exposição da vítima.

Diante da literatura revisada, o desenvolvimento e os testes de métodos de estimativa de sexo em subadultos mostram-se problemáticos, motivos atribuídos à falta de amostras esqueléticas adequadamente identificadas com o sexo conhecido para estudos, idades desigualmente distribuídas entre fetos, bebês, crianças e adolescentes, e as limitações em se definir os indicadores sexuais específicos para aplicação de forma padronizada em diferentes populações, além de o desenvolvimento de métodos utilizando amostras históricas para o uso em populações atuais (KLALES, 2016; ROGERS, 2009).

Em um contexto forense, características morfológicas específicas do esqueleto geralmente são os únicos dados que podem ser analisados antropologicamente e, consequentemente, o método utilizado para a análise deve expressar a probabilidade 
de ser do sexo feminino ou masculino quando o indicador está presente. E para obter uma probabilidade representativa de uma população real, uma distribuição sexual semelhante deve ser usada, ou seja, se o número de indivíduos do sexo masculino for maior que o do sexo feminino, obviamente a probabilidade de observar uma característica no sexo masculino será maior (OLIVARES; AGUILERA, 2016).

Diante do contexto apresentado, um método confiável e conveniente que atribua corretamente o sexo biológico de restos humanos de qualquer idade é altamente desejável, fornecendo evidências mais confiáveis e informativas para a utilização na prática forense (PORTO et al., 2011a, 2011b; STEWART et al., 2016a, 2017).

\subsection{Novas perspectivas}

Pesquisas têm demonstrado que a proteína mais abundante envolvida no desenvolvimento dental, a amelogenina, é dimórfica e codificada tanto no cromossomo $X$ (homens e mulheres), como no cromossomo $Y$ (apenas nos homens) e que o seu sequenciamento diferencia os sexos masculino e feminino, o que possibilita sua utilização na Antropologia Forense de esqueletos subadultos, especialmente quando nenhum outro biomaterial estiver disponível (STEWART et al., 2017).

Considerando que o genoma é quase idêntico em cada célula do corpo humano e, também, relativamente constante ao longo da vida de um organismo, existem expressões proteicas em cada célula nas diferentes partes do corpo, e que mudam dramaticamente ao longo do tempo em diferentes estágios do ciclo de vida e em diferentes condições ambientais (MUÑOZ; HECK, 2014).

As proteínas são macrocélulas que constroem e controlam os organismos, e devido aos seus diferentes níveis de expressão, interações alternativas e muitas possíveis modificações pós-translacionais, não estão diretamente relacionadas à informação veiculada no DNA. Portanto, a busca por informações sobre proteínas em amostras degradadas é extremamente importante (PORTO et al., 2011b).

Todas as células vivas são constituídas por proteínas, responsáveis por uma multiplicidade de funções essenciais necessárias para a manutenção da vida (LINDSKOG, 2015), representando os principais componentes das vias fisiológicas e metabólicas das células (ABHILASH, 2009). Elas apresentam diferentes funções 
celulares capazes de expressar genes, catalisar reações metabólicas e compor a parte estrutural de uma célula. As proteínas são feitas de cadeias de moléculas menores chamadas aminoácidos, que são geralmente mais resistentes que o DNA (DEMARCHI et al., 2016) e demonstram importante vantagem na sua estabilidade e longevidade (CAPPELLINI; COLLINS; GILBERT, 2014).

A rápida degradação do DNA em diferentes ambientes (PARKER et al., 2016; WADSWORTH et al., 2017; WELKER, 2018) pode chegar a níveis abaixo do amplificado por PCR (MASON et al., 2018; PILLI et al., 2018) levando amostras antigas ao fracasso (WELKER et al., 2015). No contexto forense onde, geralmente, as amostras são escassas em quantidade e degradadas pelo tempo, há a necessidade de uma análise sensível que seja capaz de detectar com confiabilidade essas proteínas informativas. As moléculas antigas são altamente modificadas por micróbios, agentes endógenos ou exógenos (SCHWEITZER, 2004). Contudo, reconhece-se que as condições ambientais, particularmente água/umidade, história térmica e a idade são de grande importância na sobrevivência das amostras (WELKER et al., 2015).

O estudo das proteínas, além de detectar o nível de expressão do gene, o estado do desenvolvimento celular, as interações gênicas e as diversas respostas celulares, em relação às diferentes condições em que a célula está submetida, torna possível uma análise mais detalhada e dinâmica (LINDSKOG, 2015).

\subsection{0 esmalte dental e suas proteínas}

O desenvolvimento do esmalte, chamado de amelogênese, pode ser dividido em quatro estágios definidos: pré-secretório, secretório, transição e maturação. As diferenças entre os estágios se baseiam na morfologia e função dos ameloblastos, que são células únicas que cobrem o esmalte em desenvolvimento e são responsáveis pela composição do esmalte. $O$ esmalte secretório é rico em proteínas e tem uma consistência amolecida. O estágio pré-secretório, imediatamente antes da formação mineral, é a deposição de pré-dentina pelos odontoblastos. A fase secretória é caracterizada pela transformação dos pré-ameloblastos em ameloblastos, alongando-se em células colunares altas e formando os processos de Tomes em suas extremidades apicais mais próximas do esmalte em formação. O processo de Tomes é uma estrutura cônica voltada para a matriz de esmalte em formação. As proteínas 
da matriz de esmalte são secretadas principalmente pela face secretora do processo de Tomes, e todos os ameloblastos dentro de uma linha secretam proteínas do mesmo lado dos processos de Tomes (BARTLETT, 2013). Os ameloblastos começam a secretar grandes quantidades de proteínas da matriz do esmalte à medida que se afastam da superfície da dentina, para que a camada inicial do esmalte possa engrossar. Quando isso ocorre, os ameloblastos secretam quatro proteínas diferentes na matriz de esmalte, três são proteínas estruturais e uma é uma proteinase. As proteínas estruturais são amelogenina (AMELX), ameloblastina (AMBN) e enamelina (ENAM), e a proteinase é a metaloproteinase-20 da matriz (MMP20) (BARTLETT, 2013). O primeiro grupo é a amelogenina, que é uma proteína hidrófoba de 25 kDa; a segunda é a enamelina, uma proteína ácida de $143 \mathrm{kDa}$, e o terceiro grupo representado pela ameloblastina de $62 \mathrm{kDa}$. As proteínas da matriz do esmalte interagem umas com as outras, assim como com os cristais de hidroxiapatita (BANSAL et al., 2012; DUTTA et al., 2017). Essas interações bioquímicas são importantes para guiar o crescimento dos cristais de hidroxiapatita e influenciar sua estrutura e orientação (BANSAL et al., 2012).

A amelogenina compreende aproximadamente $80-90 \%$ da matéria orgânica dentro da matriz de esmalte do estágio secretório, e a ameloblastina e a enamelina compreendem aproximadamente $5 \%$ e 3-5\%, respectivamente. A MMP20 está presente em pequenas quantidades (BARTLETT, 2013).

O esmalte dental maduro é o tecido mais resistente e mineralizado dos mamíferos, contendo $95 \%$ de minerais, menos de $1 \%$ de matéria orgânica e uma quantidade ainda menor de proteínas, a maioria das quais são específicas do esmalte (SMITH, 1998). Possui conteúdo inorgânico representado por 96 a 97\% do peso. Como o componente mineral pesa três vezes mais do que o componente orgânico, é mais adequado expressar as relações entre seus componentes em volume. Cerca de $86 \%$ do volume do esmalte maduro é constituído por material inorgânico, $12 \%$ é água e cerca de $2 \%$ do volume total é formado pela matriz orgânica. O osso por sua vez, também um tecido mineralizado, tem sua composição mineral representada por 55 a $60 \%$ do seu peso, e seu conteúdo orgânico constitui cerca de $25 \%$, e os 15 a $20 \%$ restantes de água, o que torna o grau de mineralização do tecido ósseo variado devido a processos fisiológicos de remodelação que ocorrem durante a vida (MJÖR; FEJERSKOV, 1990). 
Devido à sua dureza, durabilidade e resistência a insultos post mortem, o esmalte dental sobrevive a uma variedade de efeitos destrutivos causados por alterações mecânicas, químicas, físicas e térmicas (PARKER et al., 2019). Como resultado dessas características, o esmalte é uma das categorias mais duradouras de evidência física do corpo humano após a morte, é altamente inerte às mudanças provocadas pelo tempo e pelo ambiente, e, portanto, é uma fonte muito importante de informações para paleólogos, paleontólogos e antropólogos (PARKER et al., 2019; PORTO et al., 2011b; WANG et al., 2018; XIA; REN; PUGACH, 2016). Sendo assim, a natureza única do esmalte dental como o tecido mais denso e mais duro do corpo humano o torna um repositório perfeito para proteínas e peptídeos que sobrevivem excepcionalmente bem, mesmo diante da degradação do esqueleto ou do DNA (DEMARCHI et al., 2016; PORTO et al., 2011b; XIA; REN; PUGACH, 2016).

A formação do esmalte dental inicia-se por volta da décima semana de vida intrauterina (BARTLETT et al., 2006), momento em que a matriz do esmalte é secretada pelos ameloblastos. Como a maior parte do volume da matéria orgânica são várias formas de amelogenina (90\%), é fácil compreender a grande importância destas proteínas para a formação do esmalte dentário. $O$ alinhamento das sequências dos aminoácidos que compõem as isoformas da amelogenina é demonstrada no Quadro 1, em formato FASTA, do banco de dados UniProt (https://www.uniprot.org/). 
Quadro 1. Sequência de aminoácidos da amelogenina.

\begin{tabular}{|c|c|c|}
\hline SP & |Q99217|AMELX_HUMAN & MGTWILFACLLGAAFAMPLPPHPGHPGYINFSYE--------------VLTPLKWYQS-I 45 \\
\hline SP & |Q99217-2 |AMELX_HUMAN & 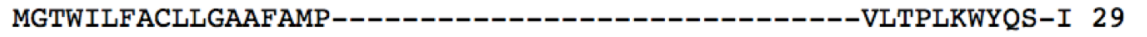 \\
\hline SP & | Q99217-3 |AMELX_HUMAN & MGTWILFACLLGAAFAMPLPPHPGHPGYINFSYENSHSQAINVDRTALVLTPLKWYQS-I 59 \\
\hline SP & |Q99218|AMELY_HUMAN & MGTWILFACLVGAAFAMPLPPHPGHPGYINFSYENSHSQAINVDRIALVLTPLKWYQSMI 60 \\
\hline \multirow[t]{2}{*}{ SP } & | Q99218-1|AMELY_HUMAN & MGTWILFACLVGAAFAMPLPPHPGHPGYINFSYE----------------VLTPLKWYQSMI 46 \\
\hline & & 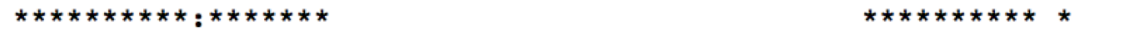 \\
\hline SP & |Q99217|AMELX_HUMAN & RPPYPSYGYEPMGGWLHHQIIPVLSQQHPPTHTLQPHHHIPVVPAQQPVIPQQPMMPVPG 105 \\
\hline SP & | Q99217-2 |AMELX_HUMAN & RPPYPSYGYEPMGGWLHHQIIPVLSQQHPPTHTLQPHHHIPVVPAQQPVIPQQPMMPVPG 89 \\
\hline SP & | Q99217-3 |AMELX_HUMAN & RPPYPSYGYEPMGGWLHHQIIPVLSQQHPPTHTLQPHHHIPVVPAQQPVIPQQPMMPVPG 119 \\
\hline SP & |Q99218|AMELY_HUMAN & RPPYSSYGYEPMGGWLHHQIIPVVSQQHPLTHTLQSHHHIPVVPAQQPRVRQQALMPVPG 120 \\
\hline SP & | Q99218-1|AMELY_HUMAN & 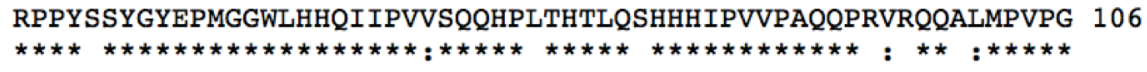 \\
\hline SP & | Q99217|AMELX_HUMAN & QHSMTPIQHHQPNLPPPAQQPYQPQPVQPQPHQPMQPQPPVHPMQPLPPQPPLPPMFPMQ 165 \\
\hline SP & | Q99217-2 |AMEIX_H_HUMAN & QHSMTPIQHHQPNLPPPAQQPYQPQPVQPQPHQPMQPQPPVHPMQPLPPQPPLPPMFPMQ 149 \\
\hline SP & | Q99217-3 |AMELX_HUMAN & QHSMTPIQHHQPNLPPPAQQPYQPQPVQPQPHQPMQPQPPVHPMQPLPPQPPLPPMFPMQ 179 \\
\hline SP & | Q99218|AMELY_HUMAN & QQSMTPTQHHQPNLPLPAQQPFQPQPVQPQPHQPMQPQPPVQPMQPLLPQPPLPPMFPLR 180 \\
\hline SP & | Q99218-1|AMELYY_HUMAN & 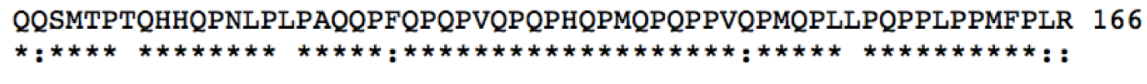 \\
\hline SP & | Q99217|AMELX_HUMAN & PLPPMLPDLTLEAWPSTDKTKREEVD 191 \\
\hline $\mathrm{SP}$ & Q99217-2 |AMEL̄X_HUMAN & PLPPMLPDLTLEAWPSTDKTKREEVD 175 \\
\hline SP & | Q99217-3 |AMELX_HUMAN & PLPPMLPDLTLEAWPSTDKTKREEVD 205 \\
\hline SP & | Q99218|AMELY_HUMAN & PLPPILPDLHLEAWPATDKTKQEEVD 206 \\
\hline \multirow[t]{2}{*}{ SP } & | Q99218-1|AMELY_HUMAN & PLPPILPDLHLEAWPATDKTKQEEVD 192 \\
\hline & & 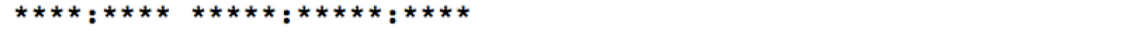 \\
\hline
\end{tabular}

Fonte: UniProt (2019).

As amelogeninas apresentam grande diversidade. Primeiramente porque seus diferentes mRNAs são formados por splicing alternativo, a seguir, porque há dimorfismo sexual e, finalmente, pelo processamento proteolítico, que gera fragmentos das diferentes formas da amelogenina. Assim, desde o início da formação do esmalte toda esta gama de diversas proteínas "amelogeninas" está presente (SALIDO et al., 1992), semelhanças entre as isoformas estão em destaque na cor cinza e as diferenças destacadas em vermelho são demonstradas pelo alinhamento das suas isoformas utilizando o banco de dados UniProt (Quadro 2). 
Quadro 2. Semelhanças e diferenças as isoformas da amelogenina.

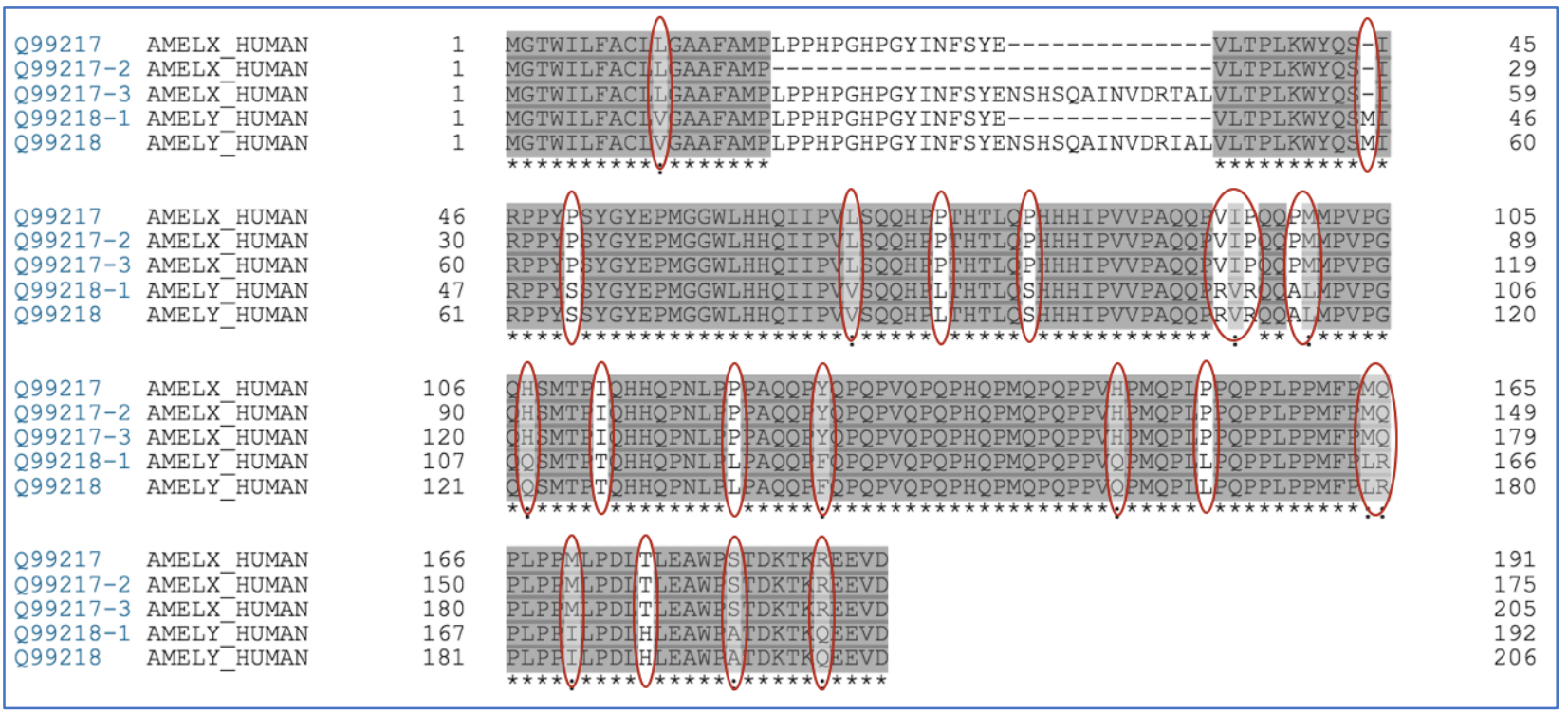

Fonte: Oliveira, L. D. B. (2019).

\subsection{A amelogenina $X$ e $Y$}

A amelogenina constitui cerca de $90 \%$ das proteínas totais da matriz do esmalte e desempenha um papel importante na mineralização e nas alterações morfológicas deste (BANSAL et al., 2012). Essa proteína, a mais abundante envolvida no desenvolvimento dental, é dimórfica e codificada tanto no cromossomo X, presente em homens e mulheres, como no cromossomo $\mathrm{Y}$ presente apenas em homens. $\mathrm{O}$ sequenciamento de regiões peptídicas do dimorfismo sexual pode ser útil para a estimativa do sexo, especialmente quando nenhum outro biomaterial estiver disponível (PARKER et al., 2019; STEWART et al., 2017).

O gene da amelogenina humana foi localizado no cromossomo X em Xp22.1 p22.3 e no locus AMELY no braço curto do cromossomo $Y$ na região p11.2, com 90\% dos transcritos expressos no cromossomo $X$ e o restante no cromossomo $Y$. As cópias $\mathrm{X}$ e $\mathrm{Y}$ do gene da amelogenina não são submetidas à recombinação homóloga, o que o torna o marcador genético de preferência para a estimativa do sexo na ciência forense (BANSAL et al. 2012). O gene da amelogenina do cromossomo $X$ (AMELX) e o gene da amelogenina do cromossomo $Y$ (AMELY) diferem em tamanho e sequência e, portanto, podem ser explorados para a sexagem (OU et al., 2012; PARKER et al., 2019; SALIDO et al., 1992; STEWART et al., 2017).

Segundo Stewart et al. (2016), há uma sequência de 8 a 15 peptídeos das principais proteínas estruturais do esmalte incluindo amelogenina, ameloblastina e 
enamelina. Porto et al. (2011) encontraram 23 diferenças entre a AMELY e a AMELX, sendo possível identificar vários peptídeos da sequência de amelogenina codificados apenas no cromossomo $\mathrm{Y}$, diferenciando assim homens e mulheres. A potencial recuperação de fragmentos proteicos bem preservados do esmalte dental pode abrir novas perspectivas na análise proteica de remanescentes esqueléticos. Portanto, este procedimento é muito eficaz na geração de amostras para análises por cromatografia líquida e espectrometria de massas e representa um forte potencial no estudo em áreas forenses e / ou arqueológicas.

Em 2017, foi apresentado por Stewart et al. um método para estimar o sexo de restos humanos usando peptídeos recuperados do esmalte dental por meio de ataque ácido na superfície e subsequente identificação de isoformas da amelogenina ligadas ao cromossomo sexual. Peptídeos com essas diferenças foram identificados por cromatografia líquida e espectrometria de massas (nanoLC-MS) para atribuir corretamente o sexo a restos humanos arqueológicos de várias idades cronológicas, de centenas a milhares de anos. Os dois peptídeos dimórficos escolhidos, AMELX e AMELY, diferenciaram claramente o sexo masculino do sexo feminino, com os peptídeos AMELX encontrados nas amostras masculinas e femininas, e o peptídeo AMELY encontrado apenas nas amostras masculinas.

Um trabalho mais recente pesquisou as proteínas da amelogenina, AMELX e AMELY expressas no órgão dental através da análise por cromatografia líquida e espectrometria de massas de 40 amostras de esmalte dental de 25 indivíduos, incluindo dentes decíduos, permanentes e terceiros molares de amostras recentes e arqueológicas. Os resultados identificaram peptídeos específicos da isoforma do cromossomo $X$ da amelogenina, AMELX, que foram detectados em todas as amostras, e os peptídeos específicos da isoforma do cromossomo $Y, A M E L Y$, foram detectados em 26 amostras de 13 indivíduos, em todos os períodos de tempo, incluindo dentes decíduos de contextos arqueológicos. Foi demonstrada uma concordância entre a estimativa de sexo baseada na osteologia e na amelogenina, confirmando que a estimativa sexual baseada em proteínas do esmalte dental pode ser obtida de forma confiável (PARKER et al., 2019).

\subsection{Cromatografia líquida e espectrometria de massas}

A cromatografia líquida (LC) é uma técnica de separação de misturas que contêm um grande número de compostos similares. Também chamada de alta 
velocidade, alta pressão, alto desempenho, alta resolução e alta eficiência. É uma técnica que utiliza colunas recheadas com materiais específicos e uma fase móvel, no caso uma amostra a ser analisada, que flui por essas colunas sob altas pressões (JARDIM; COLLINS; GUIMARÃES, 2017).

A LC possui a capacidade de realizar separações e análises quantitativas de diversos compostos em variados tipos de amostras, de forma rápida, com alta resolução, eficiência e detectabilidade. Nas últimas décadas, o desenvolvimento de detectores espectrofotométricos e o acoplamento da LC ao espectrômetro de massas, possibilitou a detecção de uma faixa mais ampla de compostos, inclusive a detecção e análise de compostos em baixas concentrações presentes em misturas e amostras complexas, como sangue, urina, solo, alimentos, entre outros (JARDIM; COLLINS; GUIMARÃES, 2017).

A espectrometria de massas (MS) é uma técnica microanalítica extremamente sensível e específica, capaz de fornecer dados analíticos qualitativos e quantitativos de um determinado analito, de uma amostra. A MS também é usada para determinar a composição elementar e alguns aspectos da estrutura molecular de uma substância. Isso é possível através da medição experimental da massa de íons da fase gasosa produzidos a partir de moléculas de um analito. As características únicas da MS incluem sua capacidade de determinar diretamente a massa nominal (e, em alguns casos, a massa molar) de um analito, produzir e detectar fragmentos da molécula que correspondem a grupos discretos de átomos de diferentes elementos que revelam características estruturais. Ela tem também a capacidade de gerar mais informações estruturais por quantidade unitária de um analito do que qualquer outra técnica analítica. Grande parte da MS diz respeito à massa dos isótopos dos elementos, não à massa atômica dos elementos. Ela não determina diretamente a massa; determina a relação massa / carga (m / z) dos íons (WATSON; SPARKMAN, 2008).

Em um fluxo de trabalho padrão para qualquer tipo de experimento, as proteínas são extraídas de uma amostra usando métodos bioquímicos e uma protease é usada para recortar a proteína em peptídeos em resíduos de aminoácidos definidos. Os peptídeos são separados por cromatografia líquida e as frações são analisadas por ionização por eletropulverização acoplada à espectrometria de massas. O espectrômetro de massas mede e relata a razão massa / carga ( $\mathrm{m} / \mathrm{z}$ ) dos íons peptídicos (DOERR, 2013). 
Para uma identificação e caracterização de proteínas usando dados de MS / MS, é seguido basicamente algumas etapas durante o processo. Inicialmente uma amostra de proteína, única ou uma mistura complexa de proteínas, é quebrada, muitas vezes por tripsina, enzima mais utilizada ou por ionização, que fraciona as proteínas em peptídeos. Peptídeos são selecionados um de cada vez usando o primeiro estágio da análise de massa. Cada peptídeo isolado é então induzido a fragmentar-se, possivelmente por colisão, e o segundo passo de análise de massa é utilizado para capturar um espectro de MS / MS. Para cada espectro de MS / MS, um software é utilizado para determinar qual sequência de peptídeo em um banco de dados de sequências de proteína ou ácido nucleico já conhecidos e registrados dá a melhor correspondência (COTTRELL, 2011; DOERR, 2013).

O bancos de dados são repositórios que hospedam sequências de proteínas distintas e suas variantes, que incluem vários programas computacionais desenvolvidos para a identificação de peptídeos MS / MS. Dado um espectro de MS / MS, a busca de banco de dados encontra o melhor peptídeo correspondente de um banco de dados de sequências de proteínas (XU; MA, 2006).

Como os dados em cada espectro de MS / MS correspondem a um peptídeo isolado, não faz diferença se a amostra original era uma única proteína ou uma mistura. São identificadas sequências peptídicas individuais, depois o conjunto de sequências peptídicas é utilizado para inferir quais as proteínas que podem estar presentes (COTTRELL, 2011). A correspondência de banco de dados MS / MS é possível porque os íons moleculares peptídicos se fragmentam preferencialmente em certos pontos ao longo da cadeia (CANCER et al., 2005; PAPAYANNOPOULOS, 1995), o que possibilita separá-los e identificá-los.

Uma vez identificados, a MS baseada em ensaio-alvo facilita a detecção e quantificação inequívoca de proteínas de baixa abundância, em um contexto de outras moléculas não alvo. Esta abordagem resultou numa riqueza de novas oportunidades para aplicações forenses. A elevada sensibilidade da MS e sua capacidade de identificar quantidades mínimas de proteínas de misturas complexas, combinada com sistemas de expressão proteica, a torna adequada em amostras pequenas, antigas e degradadas (PATEL et al., 2016; WELKER et al., 2015).

Perfis precisos de sexo são cruciais para reconstruir sociedades do passado em termos de demografia, identidade e epidemiologia, e também são essenciais em contextos médico-legais. As técnicas para estimar outras características-chave de 
identificação humana, como a idade à morte e a estatura, também são dependentes do sexo. A capacidade de atribuir característica como o sexo biológico a esqueletos humanos em ciências arqueológicas, paleoantropológicas e médico-legais é um requisito fundamental para a reconstrução do passado humano (STEWART et al., 2017). 
Objetivos 


\section{OBJETIVOS}

\subsection{Objetivo geral}

Analisar os peptídeos de proteínas presentes no esmalte dental derivados das isoformas AMELY e AMELX do gene da amelogenina para a estimativa do sexo no processo de identificação humana no contexto forense.

\subsection{Objetivo específico}

Identificar e analisar qualitativamente e quantitativamente por cromatografia líquida e espectrometria de massas os peptídeos derivados das isoformas $\mathrm{Y}$ e $\mathrm{X}$ do gene da amelogenina, AMELY e AMELX respectivamente, presentes no esmalte de dentes decíduos de crianças entre 6 e 8 anos de idade visando auxiliar os métodos de estimativa de sexo no processo de identificação humana na Antropologia Forense em esqueletos subadultos aumentando a sua confiabilidade. 
Material e Métodos 


\section{MATERIAL E MÉTODOS}

\subsection{Aspectos éticos}

Inicialmente, o projeto de pesquisa foi submetido ao Comitê de Ética em Pesquisa da Faculdade de Odontologia de Ribeirão Preto da Universidade de São Paulo - FORP/USP, sendo aprovado sob o registro CAAE n 82840018.8.0000.5419 (Anexo B), sendo o presente projeto uma emenda ao projeto "Análise da presença de metais no esmalte em dentes decíduos de crianças residentes em regiões distintas da cidade de Ribeirão Preto - SP: relações neurotóxicas e abertura de dados junto às comunidades escolares" realizada pelo Departamento de Psicobiologia da Faculdade de Filosofia, Ciências e Letras de Ribeirão Preto (FFCLRP/USP) em parceria com a Faculdade de Odontologia de Ribeirão Preto (FORP/USP). Emenda esta, aprovada sob o mesmo número (Anexo $A$ ).

\subsection{Amostragem}

A amostra deste estudo foi composta por 40 (quarenta) dentes decíduos de crianças com idades entre 6 e 8 anos, que foram doados e armazenados no Biobanco de dentes humanos da FORP/USP para a realização da pesquisa "Análise da presença de metais no esmalte em dentes decíduos de crianças residentes em regiões distintas da cidade de Ribeirão Preto - SP: relações neurotóxicas e abertura de dados junto às comunidades escolares" realizada pelo Departamento de Psicobiologia da Faculdade de Filosofia, Ciências e Letras de Ribeirão Preto (FFCLRP/USP) em parceria com a Faculdade de Odontologia de Ribeirão Preto (FORP/USP).

\subsubsection{Critérios de seleção das amostras}

Como critérios de inclusão, foram incluídas amostras de dentes decíduos devidamente identificadas pelos pais ou responsáveis, que continham dados completos da criança como sexo e data de nascimento; e como critérios de exclusão das amostras, foram excluídas amostras de dentes permanentes e/ou que estavam com dados cadastrados incompletos como o sexo e a data de nascimento da criança. 


\subsubsection{Registro dos dados}

Foi realizado o registro dos dados das 40 (quarenta) crianças contendo o sexo real conhecido e a data de nascimento fornecidos pelos pais ou responsáveis constantes no termo de doação dos dentes para posteriormente à análise dos peptídeos do esmalte dental por cromatografia líquida e espectrometria de massas, realizar a concordância entre o sexo real conhecido e o estimado (Quadro 2).

Quadro 2. Registro dos dados

\begin{tabular}{|c|c|c|}
\hline Amostra & Nascimento & Sexo \\
\hline 1 & $02 / 07 / 10$ & $\mathrm{~F}$ \\
\hline 2 & $21 / 05 / 10$ & $\mathrm{~F}$ \\
\hline 3 & $09 / 11 / 10$ & $\mathrm{~F}$ \\
\hline 4 & $28 / 01 / 11$ & $\mathrm{~F}$ \\
\hline 5 & $18 / 01 / 11$ & $\mathrm{~F}$ \\
\hline 6 & $18 / 10 / 10$ & $\mathrm{~F}$ \\
\hline 7 & $05 / 05 / 11$ & $\mathrm{~F}$ \\
\hline 8 & $23 / 09 / 10$ & $\mathrm{~F}$ \\
\hline 9 & $27 / 08 / 10$ & $\mathrm{~F}$ \\
\hline 10 & $30 / 11 / 10$ & $\mathrm{~F}$ \\
\hline 11 & $07 / 05 / 10$ & $\mathrm{~F}$ \\
\hline 12 & $02 / 03 / 10$ & $\mathrm{~F}$ \\
\hline 13 & $17 / 05 / 11$ & $\mathrm{~F}$ \\
\hline 14 & $25 / 11 / 10$ & $\mathrm{~F}$ \\
\hline 15 & $14 / 01 / 11$ & $\mathrm{~F}$ \\
\hline 16 & $16 / 02 / 11$ & $\mathrm{~F}$ \\
\hline 17 & $08 / 11 / 10$ & $\mathrm{~F}$ \\
\hline 18 & $09 / 12 / 10$ & $\mathrm{~F}$ \\
\hline 19 & $28 / 02 / 11$ & $\mathrm{~F}$ \\
\hline 20 & $19 / 01 / 10$ & $\mathrm{~F}$ \\
\hline 21 & $23 / 12 / 10$ & $M$ \\
\hline 22 & $17 / 02 / 11$ & $M$ \\
\hline 23 & $10 / 06 / 10$ & $M$ \\
\hline 24 & $03 / 03 / 11$ & $M$ \\
\hline 25 & $05 / 02 / 10$ & $M$ \\
\hline 26 & 28/03/11 & $M$ \\
\hline 27 & $28 / 11 / 10$ & $M$ \\
\hline 28 & $02 / 03 / 10$ & $\mathrm{M}$ \\
\hline 29 & $10 / 03 / 11$ & $\mathrm{M}$ \\
\hline 30 & $11 / 02 / 11$ & $\mathrm{M}$ \\
\hline 31 & $26 / 03 / 10$ & $M$ \\
\hline 32 & $28 / 09 / 10$ & $M$ \\
\hline 33 & $03 / 03 / 11$ & $M$ \\
\hline 34 & $25 / 02 / 11$ & $M$ \\
\hline 35 & $16 / 05 / 11$ & $M$ \\
\hline 36 & $26 / 07 / 10$ & $M$ \\
\hline 37 & $05 / 08 / 10$ & $M$ \\
\hline 38 & $20 / 10 / 10$ & $M$ \\
\hline 39 & $21 / 05 / 11$ & $M$ \\
\hline 40 & $07 / 02 / 11$ & $M$ \\
\hline
\end{tabular}

Fonte: Oliveira, L. D. B. (2019).

Os dados como o sexo e a data de nascimento da criança constantes no cadastro de cada amostra foram registrados em planilha Microsoft Excel ${ }^{\circledR}$ para posterior 
comparação com os resultados obtidos na pesquisa. Os dados do cadastro de cada amostra foram considerados o padrão ouro para a concordância posterior com os dados encontrados através da metodologia utilizada.

\subsection{Preparo das amostras e extração dos peptídeos}

\subsubsection{Limpeza das amostras}

A coroa dental foi primeiramente enxaguada com água ultrapura Milli- ${ }^{\circledR}$ (Merck KGaA, Darmstadt, Alemanha) apenas para a limpeza da superfície. Posteriormente as amostras foram identificadas, separadas uma a uma e armazenadas em tubos Eppendorf ${ }^{\circledR}$ (Eppendorf International, Hamburg, Alemanha) até o procedimento.

Todo o procedimento de preparo das amostras foi realizado no interior da capela de fluxo laminar (Pachane, Pa 400 ECO, Piracicaba, SP, Brasil) (Figura 01).

Figura 01. Capela de fluxo laminar.

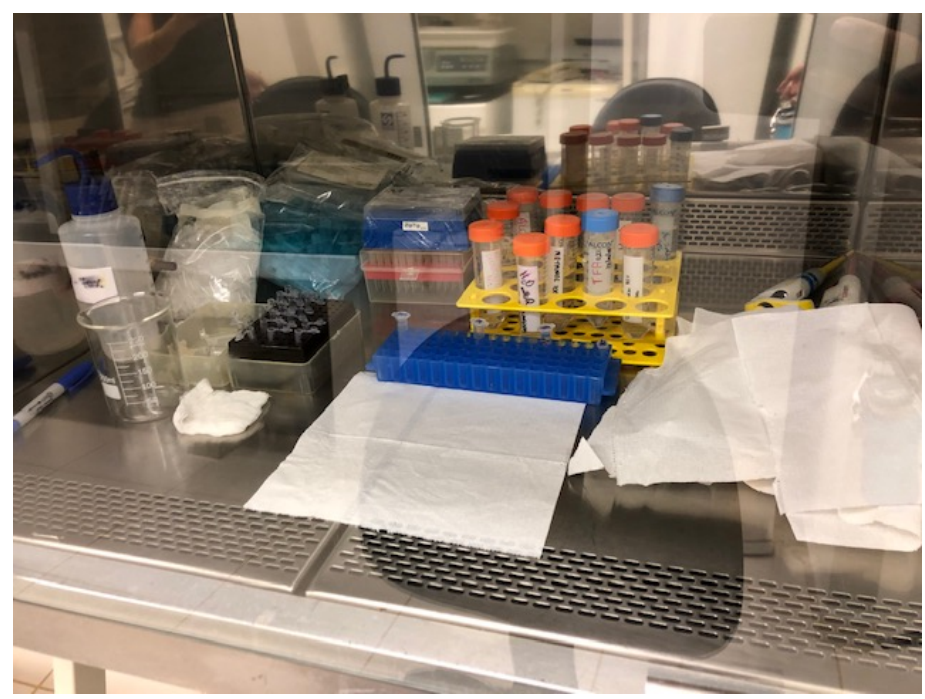

Fonte: Oliveira, L. D. B. (2019).

\subsubsection{Preparação inicial e extração dos peptídeos}

Esta etapa visou a preparação inicial para a extração dos peptídeos do esmalte dos dentes decíduos. A técnica escolhida e realizada foi chamada de "Zip Tip on Target", ou seja, o ataque ácido foi feito com a ponteira posicionada diretamente no local de interesse no esmalte dental. Esse ataque ácido foi realizado na coroa dental 
utilizando apenas uma pequena área do esmalte, conservando e preservando o elemento dental. A etapa de extração de peptídeos da superfície do esmalte dos dentes decíduos foi realizada baseada na técnica descrita por Stewart et al. (2016 e 2017), com algumas adaptações que serão descritas posteriormente e foi dividida em cinco fases dentre elas: o preparo da coroa, o preparo da resina Zip Tip C18, o procedimento propriamente dito - "Zip Tip on Target", a eluição dos peptídeos e a secagem da amostra.

\subsubsection{Preparo da coroa}

Após a seleção e limpeza das amostras, iniciou-se o procedimento de extração dos peptídeos utilizando ponteiras para pipetas de 10, 100 e 1000 microlitros $(\mu \mathrm{L})$ (Figura 02). Foi realizado um ataque ácido inicial com o objetivo de lavar e remover sujidades superficiais do esmalte dental utilizando $100 \mu \mathrm{L}$ de ácido clorídrico $(\mathrm{HCl}) \mathrm{a}$ $10 \%$ (v/v) em uma ponteira com a pipeta ajustada para $100 \mu \mathrm{L}$ (Figura 03); a coroa foi então enxaguada 2 (duas) vezes com $1000 \mu \mathrm{L}$ de água Milli-Q ${ }^{\circledR}$ (Merck KGaA, Darmstadt, Alemanha) em uma ponteira com a pipeta ajustada para $1000 \mu \mathrm{L}$ para a neutralização do $\mathrm{HCl}$ (Figura 04). Após essa primeira lavagem, removeu-se levemente o excesso de água da superfície dental com uma gaze.

Figura 02. Ponteiras para pipetas.

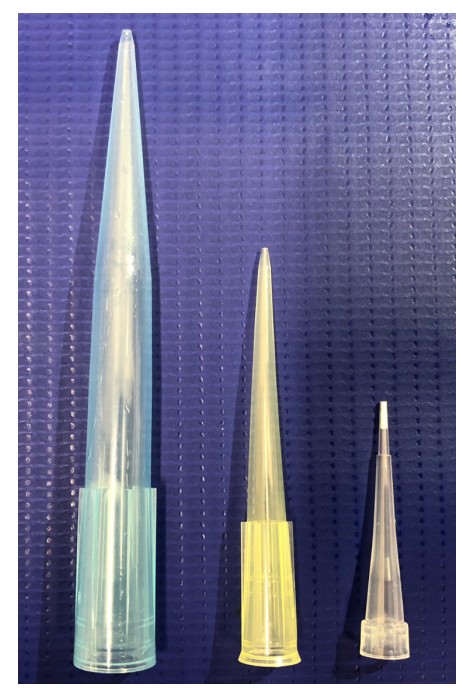

Fonte: Oliveira, L. D. B. (2019). 
Figura 03. Ataque ácido inicial.

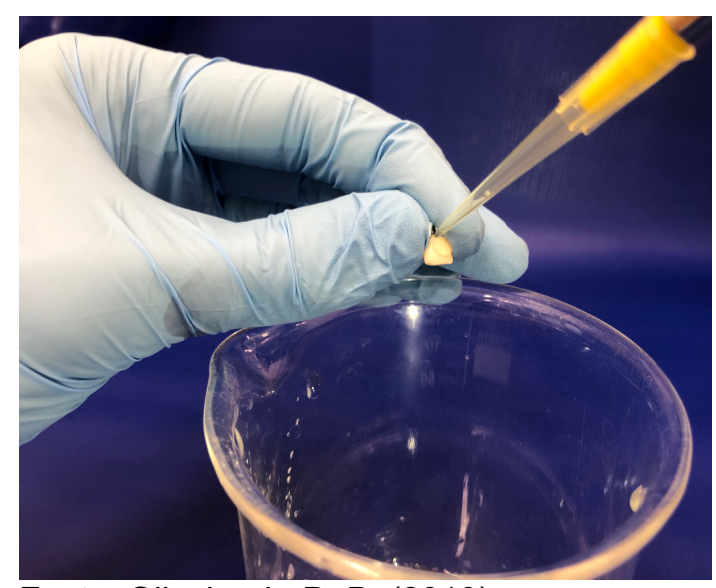

Fonte: Oliveira, L. D. B. (2019).
Figura 04. Enxague - neutralização do $\mathrm{HCl}$.

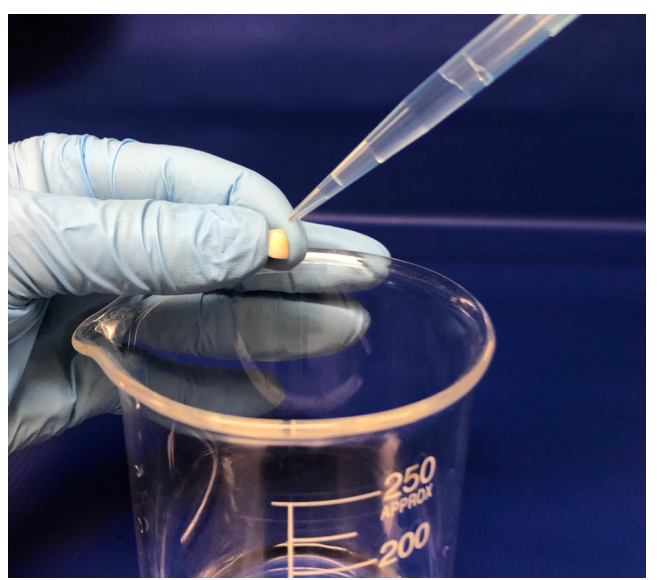

Fonte: Oliveira, L. D. B. (2019).

\subsubsection{Preparo da resina Zip Tip $\mathrm{C} 18^{\circledR}$}

Após o preparo inicial do dente, foi necessário preparar equilibrando a ponteira de resina Zip Tip ${ }^{\circledR}$ C18 (ZTC18S096; EMD Millipore, Merck KGaA, Darmstadt, Germany) (Figura 05), apropriada para reter peptídeos de baixo peso molecular, visando melhorar a coleta e a retenção desses peptídeos do esmalte dental na resina. A Zip Tip ${ }^{\circledR} \mathrm{C} 18$ foi acoplada a uma pipeta ajustável para $10 \mu \mathrm{L}$.

Para o equilíbrio da resina, esta foi condicionada com $10 \mu \mathrm{L}$ de metanol a $100 \%$ (FLUKA Methanol, LC-MS CHROMASOLV ${ }^{\circledR}$, Honeywell, Charlotte, North Carolina) próprio para análises em cromatografia líquida e espectrometria de massas HPLC-MS (Figura 06) por 02 (duas) vezes e descartado. Em seguida, a resina foi lavada com 10 $\mu \mathrm{L}$ de ácido trifluoroacético (TFA) a $0,2 \%$ por 10 (dez) vezes e descartado para alcançar a ligação iônica máxima à ZipTip ${ }^{\circledR} \mathrm{C} 18$. O pH final da solução $\mathrm{pH}<4$ é importante para o equilíbrio iônico da solução da amostra. 
Figura 05. Ponteira de resina Zip Tip ${ }^{\circledR}$ C18.

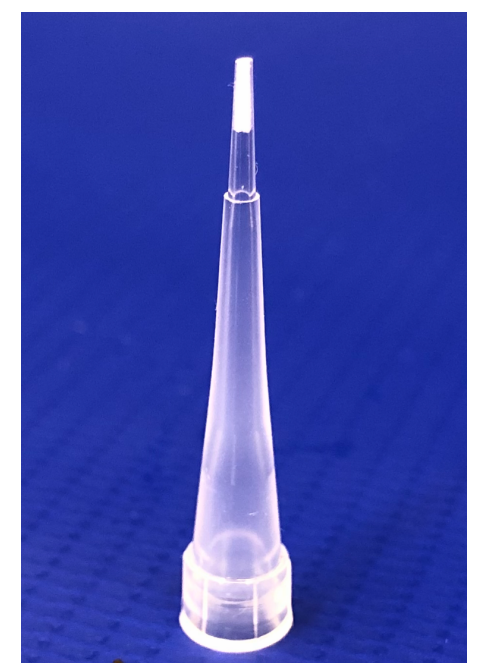

Fonte: Oliveira, L. D. B. (2019).
Figura 06. Metanol para HPLC-MS.

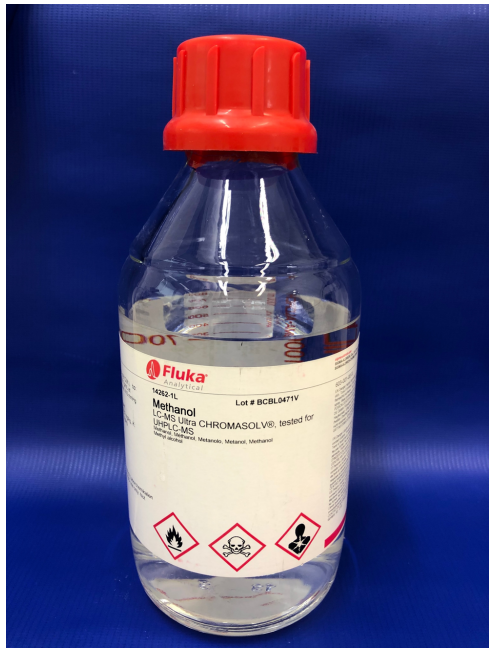

Fonte: Oliveira, L. D. B. (2019).

\subsubsection{Procedimento propriamente dito - "ZipTip on Target"}

O procedimento propriamente dito de ataque ácido para a extração dos peptídeos dos dentes decíduos foi realizado com aspiração de $10 \mu \mathrm{L}$ de $\mathrm{HCl}$ a $10 \%$ (v/v) na ponteira de resina Zip Tip ${ }^{\circledR} \mathrm{C} 18$ levando a uma proximidade do esmalte dental que permitia visualizar o $\mathrm{HCl}$ sendo injetado e aspirado sobre a superfície alvo por 05 (cinco) vezes, descartando-o em seguida (Figura 07). Em seguida, a resina Zip Tip ${ }^{\circledR}$ C18 foi lavada em $10 \mu \mathrm{L}$ de TFA a 0,2\% por 10 (dez) vezes e descartado, e o dente foi lavado com água MilliQ ${ }^{\circledR}$.

Figura 07. Procedimento "Zip Tip on Target".

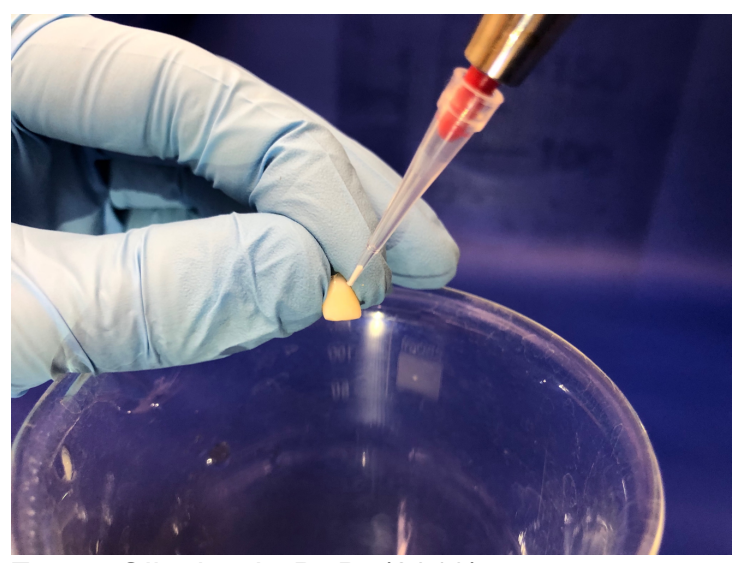

Fonte: Oliveira, L. D. B. (2019). 
Para a eluição dos peptídeos da resina Zip Tip ${ }^{\circledR}$ C18, esta foi lavada com $10 \mu \mathrm{L}$ de acetonitrila (ACN) a 80\% por 03 (três) vezes dentro do tubo Eppendorf ${ }^{\circledR}$ definitivo com o objetivo de desprender os peptídeos da resina Zip Tip ${ }^{\circledR}$ C18 (Figura 08). Estes $10 \mu \mathrm{L}$ da amostra em ACN é o conteúdo final que foi seco para posterior suspensão e análise por LC-MS/MS.

Figura 08. Extração dos peptídeos da Zip Tip ${ }^{\circledR}$.

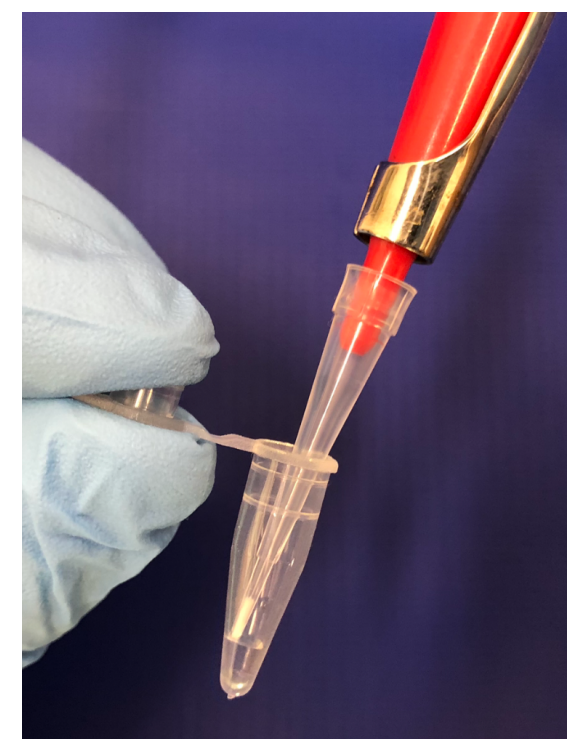

Fonte: Oliveira, L. D. B. (2019).

As amostras foram deixadas apoiadas no suporte com as tampas dos tubos Eppendorf ${ }^{\circledR}$ abertas para a secagem no interior da capela de fluxo laminar. Após a secagem, as tampas foram fechadas e lacradas uma a uma com filmes de laboratório Parafilm ${ }^{\circledR} \mathrm{M}$ Bemis (AMCOR, Zürich, Switzerland), até o processamento por LCMS/MS.

\subsection{Cromatografia líquida e espectrometria de massas}

Após todo o preparo e extração dos peptídeos das amostras, iniciou-se a etapa de análise por cromatografia líquida e espectrometria de massas. As amostras enviadas para processamento no cromatógrafo líquido e espectrômetro de massas foram devidamente identificadas por números de 1 a 40 , com o objetivo de realizar uma análise cega. 


\subsubsection{Suspensão das amostras}

Como as amostras encontravam-se secas, foi necessário realizar a suspensão para a injeção no equipamento. As amostras dos tubos Eppendorf ${ }^{\circledR}$ foram suspensas adicionadas $10 \mu \mathrm{L}$ de solução contendo $95 \%$ água destilada $+5 \%$ de $\mathrm{ACN}+0,1 \%$ de ácido fórmico. Os tubos Eppendorf ${ }^{\circledR}$ foram posteriormente colocados num agitador Vortex por 1 minuto para a mistura e dissolução rápida dos componentes da amostra, levadas em uma cuba de ultrassom por 10 minutos e em seguida no Spin por aproximadamente 10 segundos.

\subsubsection{Análise por espectrometria de massas nLC-MS/MS}

Para as amostras de peptídeos do esmalte de dentes decíduos, os $10 \mu \mathrm{L}$ dos tubos Eppendorf ${ }^{\circledR}$ foram transferidos para tubos HPLC Vials (Figura 09) e posteriormente colocados na mesa do cromatógrafo líquido, sendo identificada a localização de cada amostra (Figura 10). Foram injetados $04 \mu \mathrm{L}$ para cada amostra a ser analisada pelo sistema EASY-nLC II ${ }^{\mathrm{TM}}$ (Proxeon Biosystems, Thermo Fisher Scientific, Waltham, Massachusetts, United States) acoplado a um espectrômetro de massas LTQ Orbitrap Velos (Thermo Fisher Scientific, Waltham, Massachusetts, United States) (Figura 11).

Figura 09. Tubos HPLC Vials

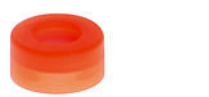

Fonte: Thermo Scientific ${ }^{\mathrm{TM}}$.
Figura 10. Mesa interna do EASY-nLC ${ }^{\mathrm{TM}}$ II.

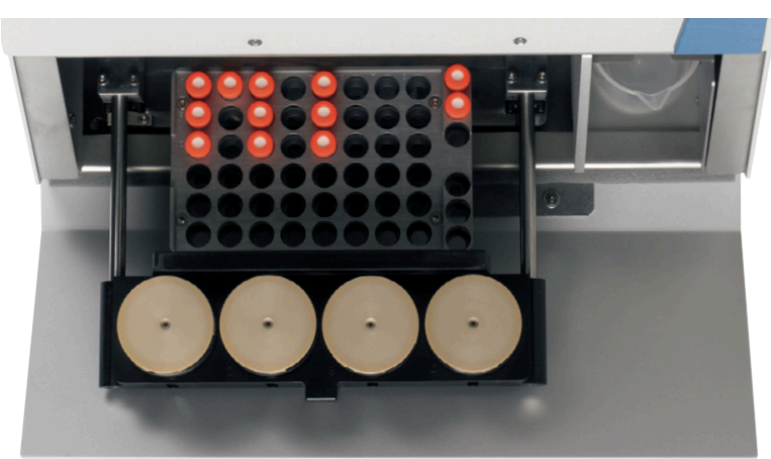

Fonte: Thermo Scientific ${ }^{\mathrm{TM}}$. 
Figura 11. EASY-nLC II ${ }^{\mathrm{TM}}$ acoplado ao LTQ Orbitrap Velos ${ }^{\mathrm{TM}}$.

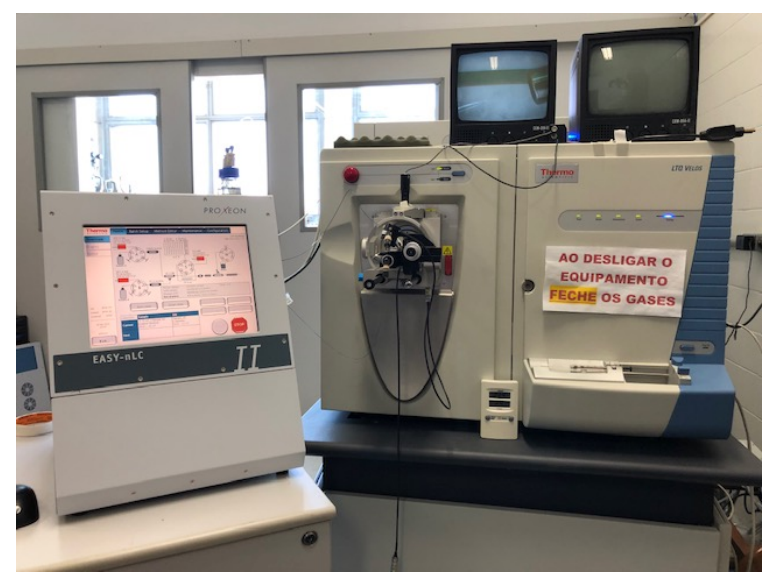

Fonte: Oliveira, L. D. B. (2019).

Inicialmente os peptídeos foram carregados em pré-coluna FS-110 Fused Silica Tubing (3 cm x $100 \mu \mathrm{m}$ de diâmetro interno, IDEX Health \& Science, Middleboro, MA, USA), empacotada com resina, partículas de sílica esférica porosa ReproSil, Gold 200 C18 - AQ, $5 \mu \mathrm{m}$, Dr. Maisch GmbH; Ammerbuch, Germany) e para a separação dos peptídeos, foi usada uma coluna analítica PicoFrit Self-Pack ${ }^{\mathrm{TM}}(20 \mathrm{~cm}$ x $75 \mu \mathrm{m}$ de diâmetro interno, PicoFrit ${ }^{\circledR}$, Thermo Fisher Scientific, Waltham, Massachusetts, United States), empacotada com resina, partículas de sílica esférica porosa ReproSil Gold 300 C18, 3 um Dr. Maisch GmbH; Ammerbuch, Germany). O gradiente aplicado foi de 120 minutos, partindo de $98 \%$ de fase $\mathrm{A}(0,1 \%$ ácido fórmico, $5 \% \mathrm{ACN})$ até $20 \%$ da fase $B(0,1 \%$ de ácido fórmico, $95 \% A C N)$ até os $77 \mathrm{~min}$, chegando a $40 \%$ de fase $B$ aos $107 \mathrm{~min}$, passando de $40 \%$ a $95 \%$ até os 112 min e mantido em $95 \%$ de fase B até o fim da corrida, durante $8 \mathrm{~min}$. Ao final, as colunas foram reequilibradas com fase A para uma nova corrida.

A ionização e transferência dos íons foi feita utilizando uma fonte de ionização de nano-eletrospray (Thermo Fisher Scientific, Waltham, Massachusetts, United States), em polaridade positiva, com potencial de $2.3 \mathrm{kV}$ e aquecimento de $200{ }^{\circ} \mathrm{C}$. Ao eluírem da coluna, os peptídeos foram ionizados por eletronebulização (Electrospray Ionization, ESI) e tinham então suas massas/carga $(\mathrm{m} / \mathrm{z})$ analisadas pelo LTQ Orbitrap Velos (Thermo Fisher Scientific, Waltham, Massachusetts, United States). Os espectros MS1 foram adquiridos em modo positivo e os espectros MS/MS em modo de aquisição análise dependente de dados (Data Dependent Acquisition DDA). Cada evento de full scan compreendeu um intervalo de 350-1800 m/z, resolução de 60.000 FWHM (para m/z 400) e AGC (Automatic Gain Control) 
intensidade mínima de $1 \times 10^{6}$. Para a obtenção do MS/MS, os 10 íons mais abundantes das amostras foram selecionados e fragmentados usando dissociação induzida por colisão (Colision Induced Dissociation - CID) com energia de colisão normalizada de 30 , janela de isolamento do íon de $\mathrm{m} / \mathrm{z} 2$ e exclusão dinâmica de $45 \mathrm{~s}$.

Os cromatogramas foram visualizados pelos softwares Proteome Discoverer ${ }^{\mathrm{TM}}$ 2.3 (Thermo Fisher Scientific, Waltham, Massachusetts, United States), Xcalibur ${ }^{\mathrm{TM}}$ (Thermo Fisher Scientific, Waltham, Massachusetts, United States), e Tracefinder ${ }^{\text {тм }}$ (Thermo Fisher Scientific, Waltham, Massachusetts, United States), nos quais foi realizado o processamento automático dos dados, análises qualitativas e quantitativas, verificado o padrão cromatográfico quanto à complexidade de cada fragmento, a presença ou ausência, e a quantificação dos peptídeos em cada amostra.

\subsection{Metodologia de análise dos dados}

Os arquivos com os dados (raw data) de cada amostra gerados da espectrometria de massas foram submetidos a análise no software Proteome Discoverer 2.3, Xcalibur ${ }^{\mathrm{TM}}$ e Tracefinder ${ }^{\mathrm{TM}}$ (Thermo Fisher Scientific, Waltham, Massachusetts, United States). A identificação dos peptídeos por Peptide Spectrum Match - PSM foi realizada utilizando o Sequest HT, programa usado para a identificação de proteínas, contra um banco de dados UniProt (Proteome ID UP000005640, Taxonomia 9606 - Homo Sapiens) disponível em http://www.uniprot.org/. O parâmetro de busca está sujeito ao equipamento utilizado e modo de aquisição de cada uma das amostras. Para peptídeos do esmalte de dentes decíduos foram utilizadas configurações de pesquisa como: oxidação (M e P) e fosforilação (ST e STY) como modificação variável e carbamidometilação de cisteína como modificação fixa, modo de digestão inespecífica, tolerância de massa do íon precursor de 10 ppm e íons fragmento de 0,5 Da, e um comprimento mínimo de peptídeo de 6 aminoácidos. Além da inspeção nos dados brutos, foram analisados a identificação e a quantificação dos peptídeos.

Dos resultados obtidos do report do Tracefinder ${ }^{\mathrm{TM}}$ (Thermo Fisher Scientific, Waltham, Massachusetts, United States) foi realizada uma análise descritiva com a variável qualitativa nominal - sexo biológico (feminino e masculino) através da identificação dos peptídeos AMELX nas amostras femininas e masculinas, e AMELY 
apenas nas amostras masculinas, gerado assim uma tabela de frequência do sexo, e posterior concordância entre o sexo real e o estimado pela análise por nLC-MS/MS através do software estatístico R Core (TEAM, 2016). 
Resultados 


\section{RESULTADOS}

Após a análise por LC - MS/MS, os raw data gerados pelo espectrômetro de massas foram confrontados no software Proteome Discoverer 2.3 juntamente com o SEQUEST (Thermo Fisher Scientific, Waltham, Massachusetts, United States) contra o banco de dados UniProt (Proteome ID UP000005640, Taxonomia 9606 - Homo Sapiens) disponível em http://www.uniprot.org/, para interpretar o espectro obtido do conjunto de sequências de peptídeos candidatos a uma determinada proteína que poderiam ser comparados com o espectro gerado, inclusive as sequencias de $\mathrm{m} / \mathrm{z}$ próximas à massa dos íons peptídicos detectados. Para cada íon peptídico gerado, o programa gera um espectro teórico e compara através de uma correlação cruzada entre os dados. A sequência peptídica candidata que apresenta o melhor espectro de massa teórica correspondente é considerada como a melhor identidade para determinado espectro.

A análise de pontuações fornece valores da certeza da identificação correta, além de fornecer informações sobre a qualidade da correspondência de uma determinada sequência peptídica e os picos de fragmentação observados. Nos espectros de uma mesma amostra, vários peptídeos podem corresponder a uma única proteína ou estar presente em outras também. Quando um peptídeo pertence a uma única proteína, tem-se uma maior certeza de sua presença (TABB; ENG; YATES, 2001).

O resultado do escaneamento completo das amostras, também chamado de Full Scan ou MS1 encontrou as principais proteínas do esmalte dental que foram localizadas e identificadas no banco de dados UniProt dentre elas a amelogenina (AMELX - Q99217 e AMELY - Q99218), a ameloblastina (Q9NP70), e enamelina (Q9NRM1). Outras proteínas também foram observadas porém não são de interesse para a presente pesquisa pois o foco desta pesquisa é a identificação e a quantificação da amelogenina e suas isoformas AMELY e AMELX buscando a diferenciação e consequentemente a estimativa dos sexos feminino e masculino das amostras. As análises dos peptídeos AMELY e AMELX geraram resultados qualitativos e resultados quantitativos. Os primeiros indicaram a presença ou ausência de cada peptídeo e o segundo, a quantificação desses peptídeos sendo calculada pela área do pico detectado em cada amostra. 
As identificações obtidas pelo Proteome Discoverer 2.3 não foram muito sensíveis, identificando uma quantidade de peptídeos menor do que o esperado, fato que gerou a necessidade de realizar a busca pelo Tracefinder ${ }^{\mathrm{TM}}$ (Thermo Fisher Scientific, Waltham, Massachusetts, United States), contra o mesmo banco de dados UniProt (Proteome ID UP000005640, Taxonomia 9606 - Homo Sapiens) disponível em http://www.uniprot.org/.

Encontram-se listados no Quadro 3 os fragmentos peptídicos totais identificados nas amostras das isoformas da amelogenina, AMELY e AMELX. Foram identificados um total de 31 peptídeos da AMELY e 35 da AMELX. 
Quadro 3. Fragmentos peptídicos totais AMELY e AMELX.

\begin{tabular}{|c|}
\hline AMELY \\
\hline MPLPPHPGHPGYINFSYEVLTPLK \\
\hline YINFSYEVLTPLK \\
\hline GHPGYINFSYEVLTPLK \\
\hline PGHPGYINFSYEVLTPLK \\
\hline INFSYEVLTPLK \\
\hline PGYINFSYEVLTPLK \\
\hline SYEVLTPLKWYQ \\
\hline GYINFSYEVLTPLK \\
\hline SYEVLTPLKWYQS \\
\hline MPLPPHPGHPGYINF \\
\hline LPPHPGHPGYINFS \\
\hline INFSYEVLTPLKW \\
\hline TDKTKQEEVD \\
\hline SYEVLTPLKW \\
\hline MPLPPHPGHPGYINFS \\
\hline SMIRPPYSSYGYEPMG \\
\hline FSYEVLTPLKWYQ \\
\hline YEVLTPLKWYQSM \\
\hline SMIRPPYSS \\
\hline PHPGHPGYINFSYEVLTPLK \\
\hline LPPHPGHPGYINFSYEVLTPLK \\
\hline PPHPGHPGYINFSYEVLTPLK \\
\hline LPPHPGHPGYINFSYEVLTPLK \\
\hline HPGYINFSYEVLTPLK \\
\hline MPLPPHPGHPGYINFS \\
\hline NFSYEVLTPLK \\
\hline YEVLTPLKWYQS \\
\hline MPLPPHPGHPG \\
\hline MPLPPHPGHPGYINF \\
\hline SMIRPPYSSYGYEPMGGW \\
\hline SYEVLTPLKWYQS \\
\hline
\end{tabular}

\begin{tabular}{|c|}
\hline AMELX \\
\hline MPLPPHPGHPGYINFSYEVLTPLK \\
\hline YINFSYEVLTPLK \\
\hline GHPGYINFSYEVLTPLK \\
\hline PGHPGYINFSYEVLTPLK \\
\hline INFSYEVLTPLK \\
\hline PGYINFSYEVLTPLK \\
\hline SIRPPYPSYGYEPMGGW \\
\hline SYEVLTPLKWYQ \\
\hline GYINFSYEVLTPLK \\
\hline SIRPPYPSYGYEPM \\
\hline SYEVLTPLKWYQS \\
\hline SIRPPYPSYGYEPMG \\
\hline MPLPPHPGHPGYINF \\
\hline LPPHPGHPGYINFS \\
\hline INFSYEVLTPLKW \\
\hline SYENSHSQAINVDR \\
\hline SYEVLTPLKW \\
\hline DLTLEAWPSTDKTKREEVD \\
\hline MPLPPHPGHPGYINFS \\
\hline FSYEVLTPLKWYQ \\
\hline PHPGHPGYINFSYEVLTPLK \\
\hline LPPHPGHPGYINFSYEVLTPLK \\
\hline PPHPGHPGYINFSYEVLTPLK \\
\hline LPPHPGHPGYINFSYEVLTPLK \\
\hline HPGYINFSYEVLTPLK \\
\hline MPLPPHPGHPGYINFS \\
\hline SIRPPYPSYGYEPMGG \\
\hline NFSYEVLTPLK \\
\hline YEVLTPLKWYQS \\
\hline MPLPPHPGHPG \\
\hline SIRPPYPSYGYEPMG \\
\hline MPLPPHPGHPGYINF \\
\hline SYEVLTPLKWYQS \\
\hline YEVLTPLKWYQSIRPPYP \\
\hline SIRPPYPSYGYEPMGGW \\
\hline
\end{tabular}

Fonte: Oliveira, L. D. B. (2019).

Após uma triagem dos fragmentos quanto a presença no maior número de amostras, foram considerados os peptídeos mais prevalentes, ou seja, aqueles peptídeos mais observados nos espectros para realizar a análise estatística. Da listagem da AMELY foram selecionados 04 (quatro) peptídeos com as seguintes 
denominações e respectivas sequências de aminoácidos indicados pelas setas: PEP1Y - SMIRPPYSSYGYEPMG; PEP2Y - SMIRPPYSSYGYEPMGGW; PEP3Y SMIRPPYSS; e PEP4Y - YEVLTPLKWYQSM (Quadro 4); e da listagem da AMELX foram selecionados 09 (nove) peptídeos denominados PEP1X - INFSYEVLTPLK; PEP2X - LPPHPGHPGYINFS; PEP3X - SIRPPYPSYGYEPMG; PEP4X SIRPPYPSYGYEPM; PEP5X - SYENSHSQAINVDR; PEP6X - SIRPPYPSYGYEPMGG; PEP7X - TDKTKQEEVD; PEP8X - SIRPPYPSYGYEPMGGW e PEP9X GHPGYINFSYEVLTPLK (Quadro 5). Os quadros a seguir mostram os peptídeos selecionados e identificados em cores diferentes e sua localização dentro da estrutura da amelogenina.

Quadro 4. Fragmentos peptídicos AMELY.

\begin{tabular}{|c|c|c|c|c|}
\hline \multicolumn{5}{|c|}{ PEP1Y PEP2Y PEP3Y PEP4Y } \\
\hline $\begin{array}{l}\text { Q99217 } \\
\text { Q99217-2 } \\
\text { Q99217-3 } \\
\text { Q99218-1 } \\
\text { Q99218 }\end{array}$ & $\begin{array}{l}\text { AMELX_HUMAN } \\
\text { AMELX_HUMAN } \\
\text { AMELX_HUMAN } \\
\text { AMELY_HUMAN } \\
\text { AMELY_HUMAN }\end{array}$ & $\begin{array}{l}1 \\
1 \\
1 \\
1 \\
1\end{array}$ & 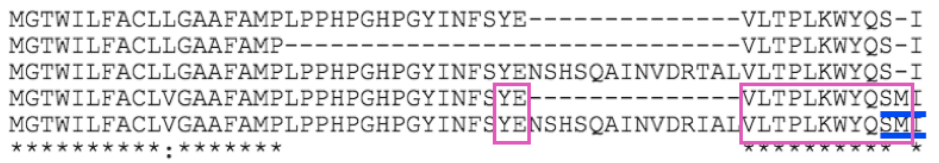 & $\begin{array}{l}45 \\
29 \\
59 \\
46 \\
60\end{array}$ \\
\hline $\begin{array}{l}\text { Q99217 } \\
\text { Q99217-2 } \\
\text { Q99217-3 } \\
\text { Q99218-1 } \\
\text { Q99218 }\end{array}$ & $\begin{array}{l}\text { AMELX_HUMAN } \\
\text { AMELX_HUMAN } \\
\text { AMELX_HUMAN } \\
\text { AMELY_HUMAN } \\
\text { AMELY_HUMAN }\end{array}$ & $\begin{array}{l}46 \\
30 \\
60 \\
47 \\
61\end{array}$ & 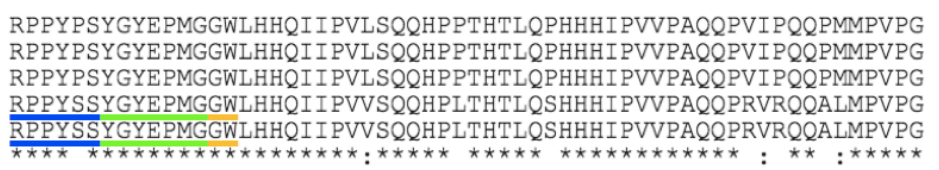 & $\begin{array}{r}105 \\
89 \\
119 \\
106 \\
120\end{array}$ \\
\hline $\begin{array}{l}\text { Q99217 } \\
\text { Q99217-2 } \\
\text { Q99217-3 } \\
\text { Q99218-1 } \\
\text { Q99218 }\end{array}$ & $\begin{array}{l}\text { AMELX_HUMAN } \\
\text { AMELX_HUMAN } \\
\text { AMELX_HUMAN } \\
\text { AMELY_HUMAN } \\
\text { AMELY_HUMAN }\end{array}$ & $\begin{array}{r}106 \\
90 \\
120 \\
107 \\
121\end{array}$ & 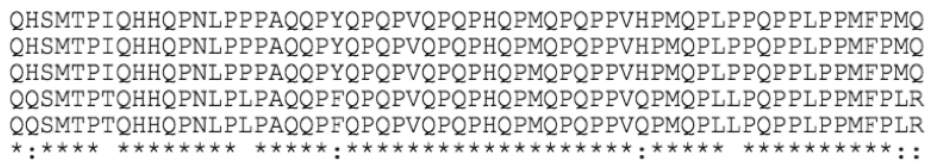 & $\begin{array}{l}165 \\
149 \\
179 \\
166 \\
180\end{array}$ \\
\hline $\begin{array}{l}\text { Q99217 } \\
\text { Q99217-2 } \\
\text { Q99217-3 } \\
\text { Q99218-1 } \\
\text { Q99218 }\end{array}$ & $\begin{array}{l}\text { AMELX_HUMAN } \\
\text { AMELX_HUMAN } \\
\text { AMELX_HUMAN } \\
\text { AMELY_HUMAN } \\
\text { AMELY_HUMAN }\end{array}$ & $\begin{array}{l}166 \\
150 \\
180 \\
167 \\
181\end{array}$ & 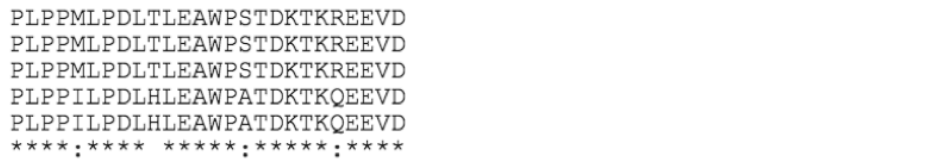 & $\begin{array}{l}191 \\
175 \\
205 \\
192 \\
206\end{array}$ \\
\hline
\end{tabular}

Fonte: Oliveira, L. D. B. (2019). 
Quadro 5. Fragmentos peptídicos AMELX.

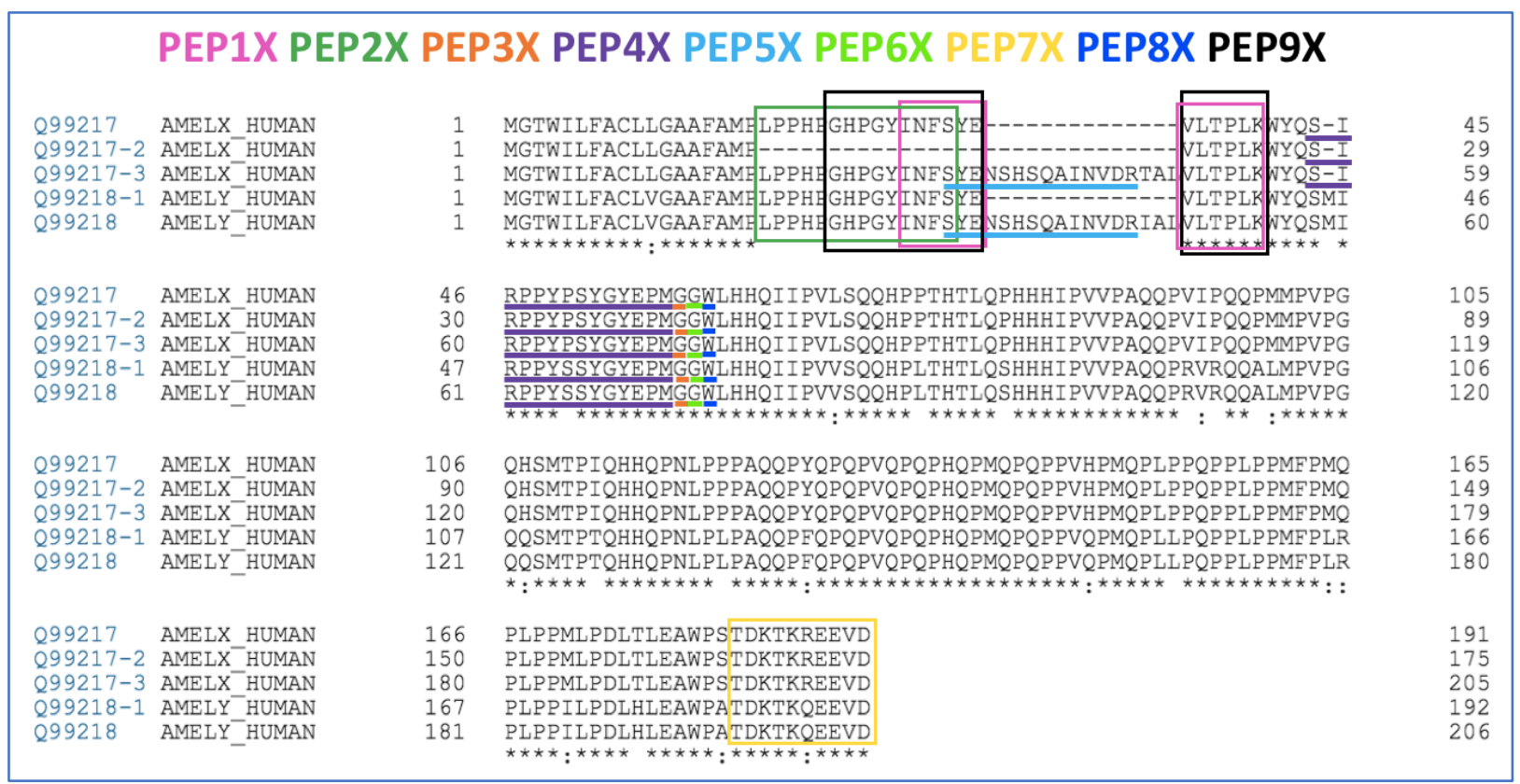

Fonte: Oliveira, L. D. B. (2019).

Os peptídeos selecionados foram analisados isoladamente um a um como podem ser observadas nas figuras a seguir numeradas de 11 a 23. Detalhes como o intervalo do tempo de retenção (RT - retention time) expressos em minutos (min) de cada sequência de aminoácidos, o espectro de uma amostra aleatória é mostrado como exemplo, e os cromatogramas gerados a partir do espectro das amostras 01 a 40 indicando a presença ou ausência dos peptídeos.

O PEP1Y (Figura 12) apresenta a sequência de aminoácidos SMIRPPYSSYGYEPMG e esteve presente em 0 amostras $(0 \%)$ do grupo feminino e em 17 amostras (85\%) do grupo masculino, detectado pelo espectrômetro de massas com tempo de retenção variando entre RT: 29.07 - 29.68 min, e a modificação variável observada foi oxidação de M (metionina). A razão m/z: 933.90759 Da, monoisotópica, foi detectada no exemplo apresentado e a proteína de referência encontrada no banco de dados UniProt foi: Isoform 1 of Amelogenin, Y isoform OS=Homo sapiens OX=9606 $G N=A M E L Y$. 
Figuras 12. Espectro e cromatogramas do peptídeo PEP1Y.

\section{PEP1Y}

Sequência de aminoácidos: SMIRPPYSSYGYEPMG

Tempo de retenção (RT): 29.07 - 29.68

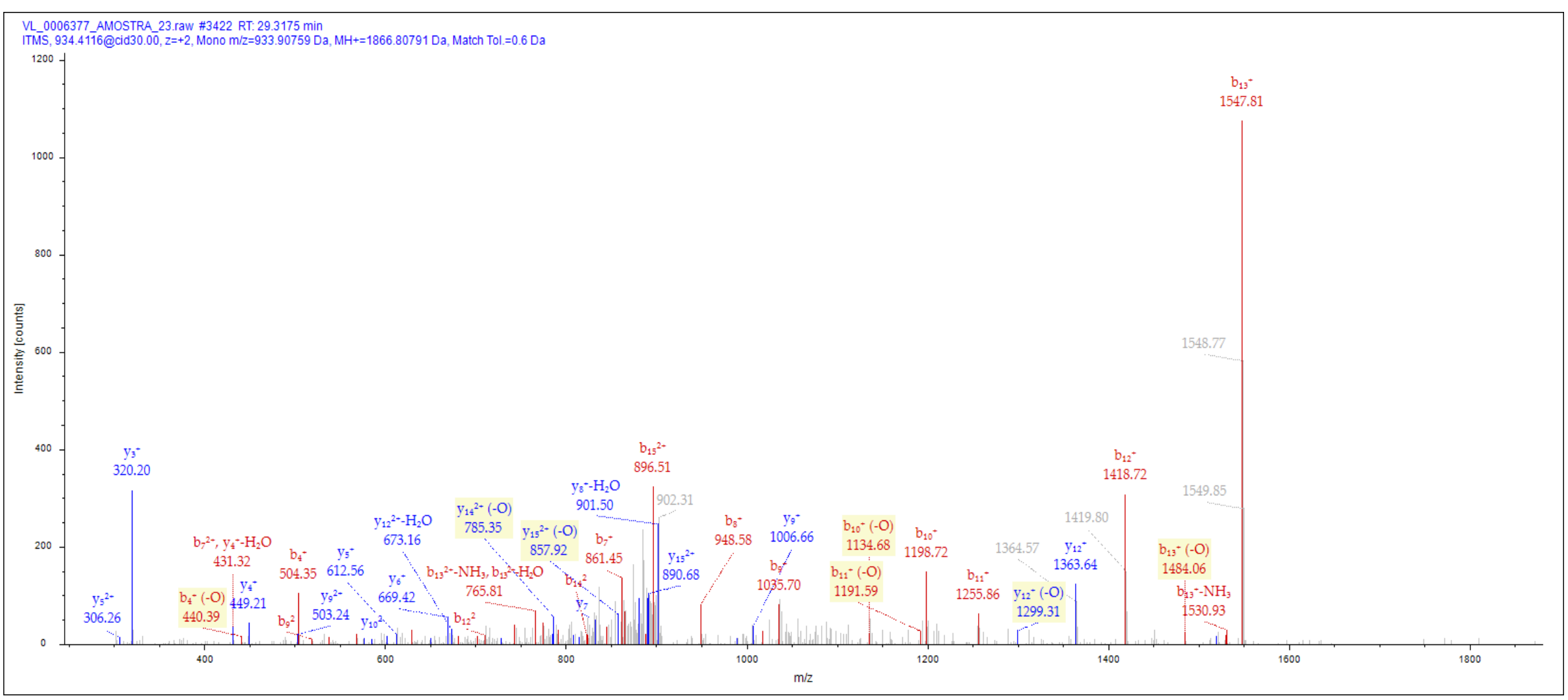


Amostras Femininas - PEP1Y
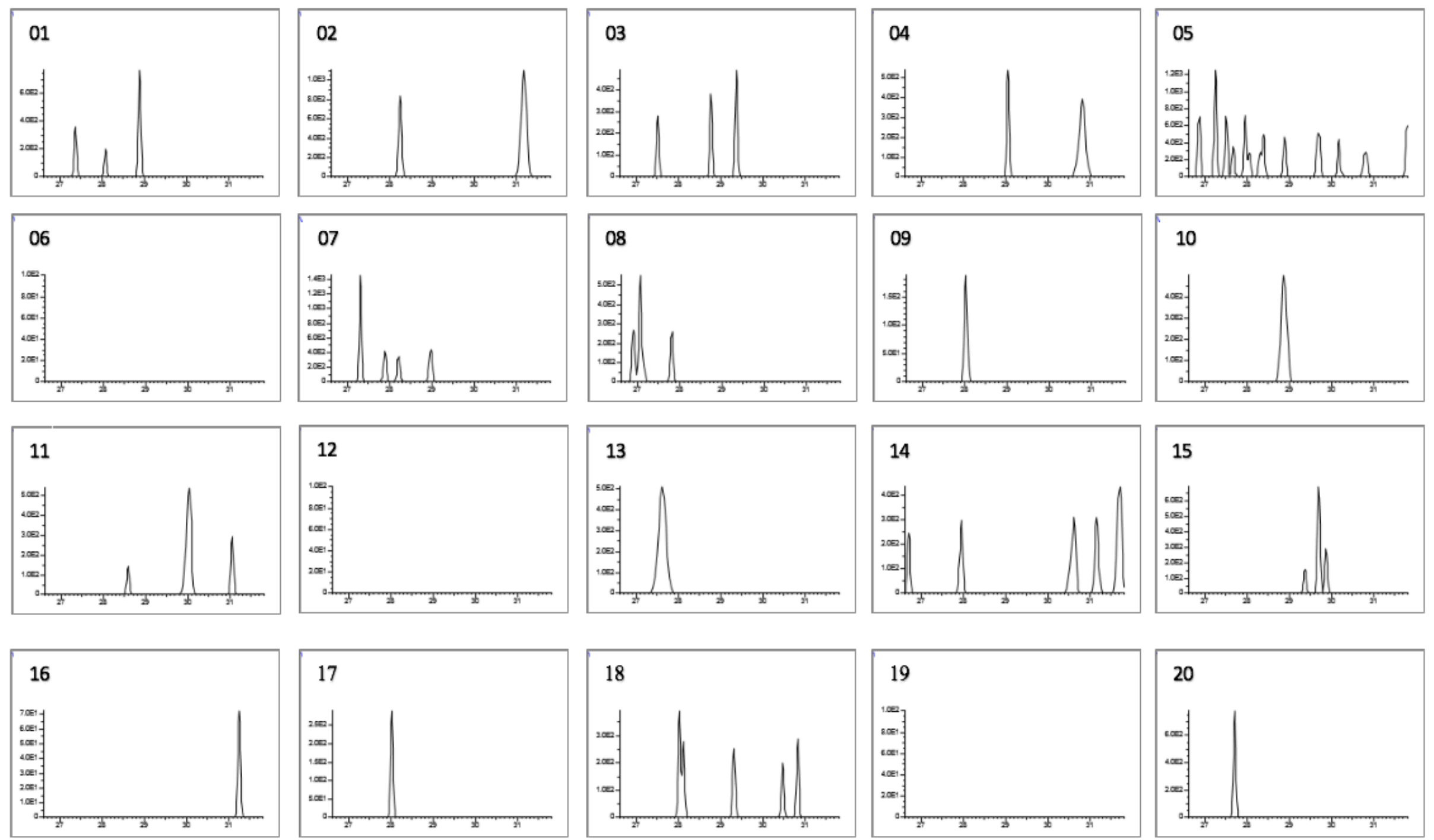
Amostras Masculinas - PEP1Y
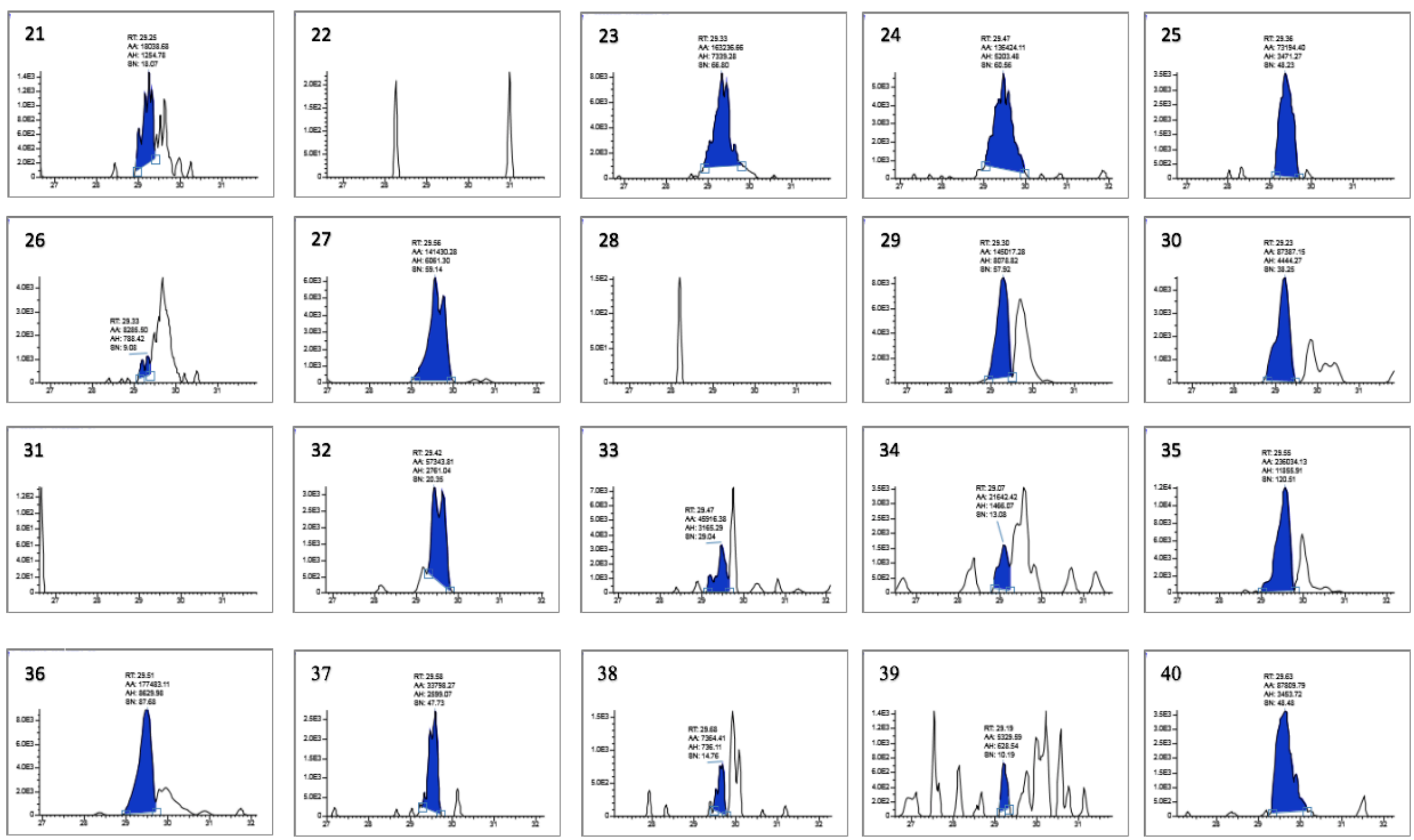
O PEP2Y (Figura 13) apresenta a sequência de aminoácidos SMIRPPYSSYGYEPMGGW e esteve presente em 01 amostra (5\%) do grupo feminino (5\%), e em 11 amostras (55\%) do grupo masculino detectado pelo espectrômetro de massas com tempo de retenção variando entre RT: 39.41 - 39.98 min, e a modificação variável observada foi oxidação de $M$ (metionina). A razão m/z: $1055.45703 \mathrm{Da}$, monoisotópica, foi detectada no exemplo apresentado e a proteína de referência encontrada no banco de dados UniProt foi: Isoform 1 of Amelogenin, $Y$ isoform OS=Homo sapiens $O X=9606 \mathrm{GN}=A M E L Y$. 
Figura 13. Espectro e cromatogramas do peptídeo PEP2Y.

\section{PEP2Y}

Sequência de aminoácidos: SMIRPPYSSYGYEPMGGW

Tempo de retenção (RT): 39.41 - 39.98

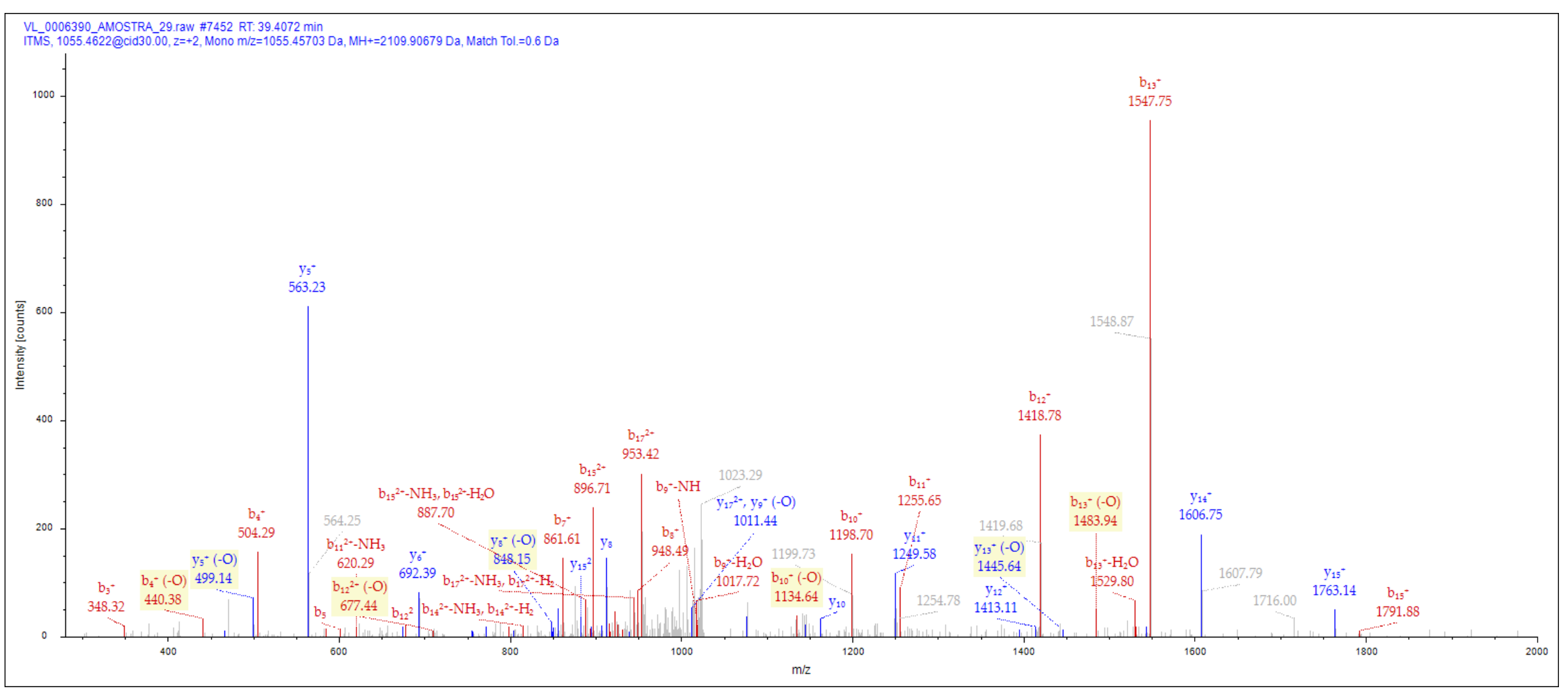


Amostras Femininas - PEP2Y
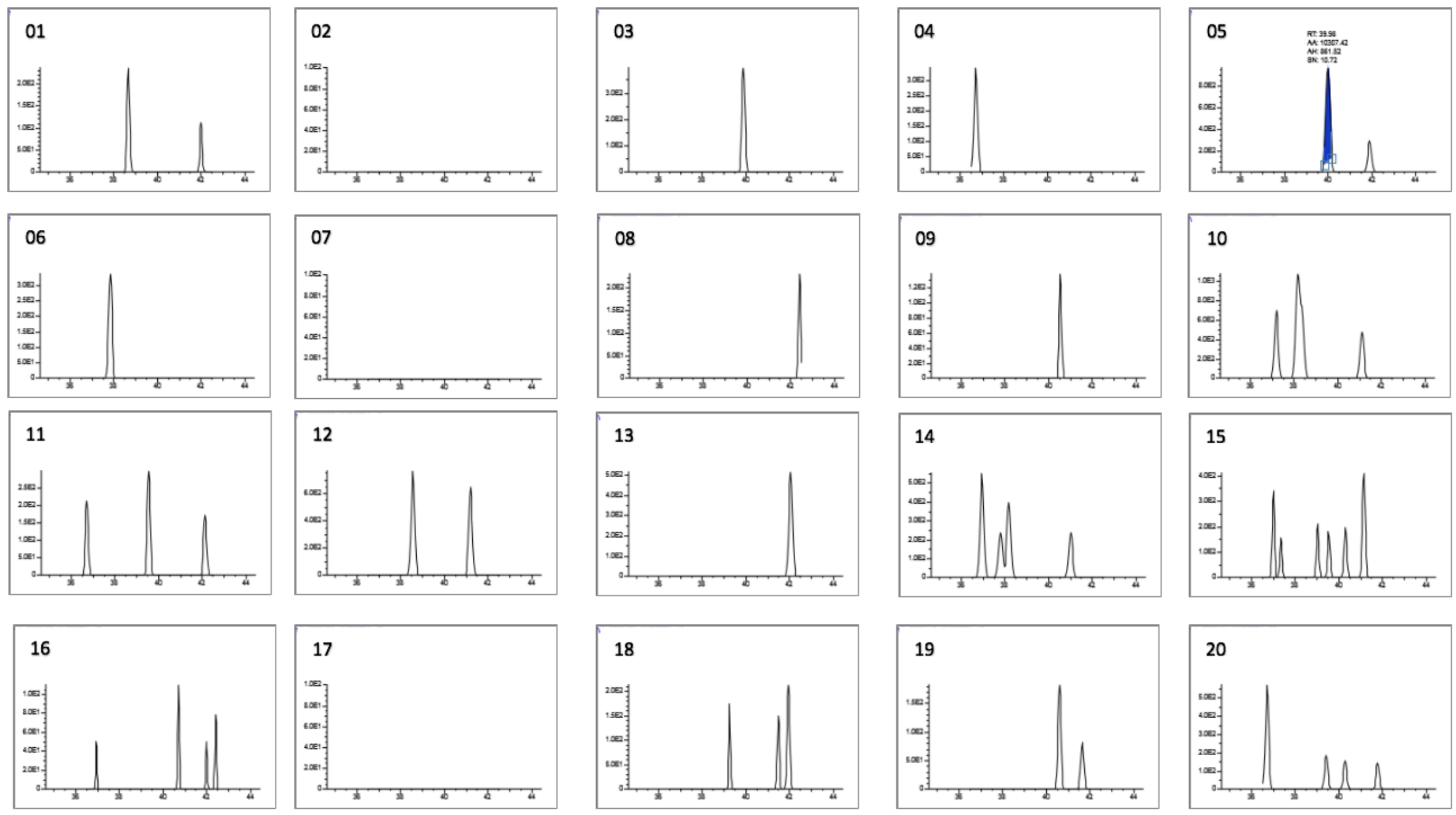
Amostras Masculinas - PEP2Y
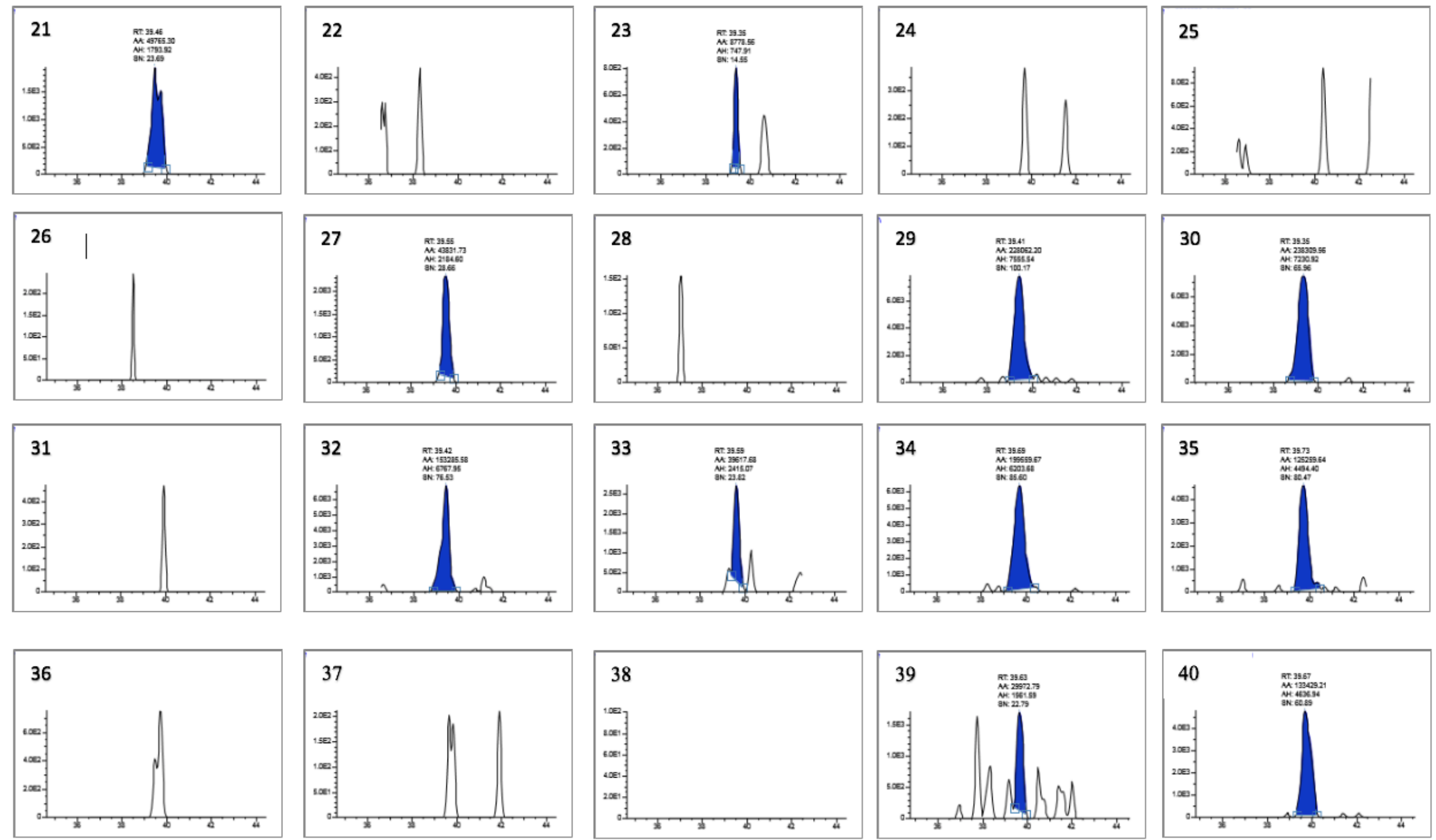
O PEP3Y (Figura 14) apresenta a sequência de aminoácidos SMIRPPYSS e esteve presente em 03 amostras (15\%) do grupo feminino, e em 19 amostras (95\%) do grupo masculino, detectado pelo espectrômetro de massas com tempo de retenção variando entre RT: 19.10 - 19.53 min, e as modificações variáveis observadas foram fosforilação de S (serina) e oxidação de M (metionina). A razão m/z: 567.24042 Da, monoisotópica, foi detectada no exemplo apresentado e a proteína de referência encontrada no banco de dados UniProt foi: Isoform 1 of Amelogenin, $Y$ isoform OS=Homo sapiens $O X=9606$ GN=AMELY. 
Figura 14. Espectro e cromatogramas do peptídeo PEP3Y.

\section{PEP3Y}

Sequência de aminoácidos: SMIRPPYSS

Tempo de retenção (RT): 19.10 - 19.53

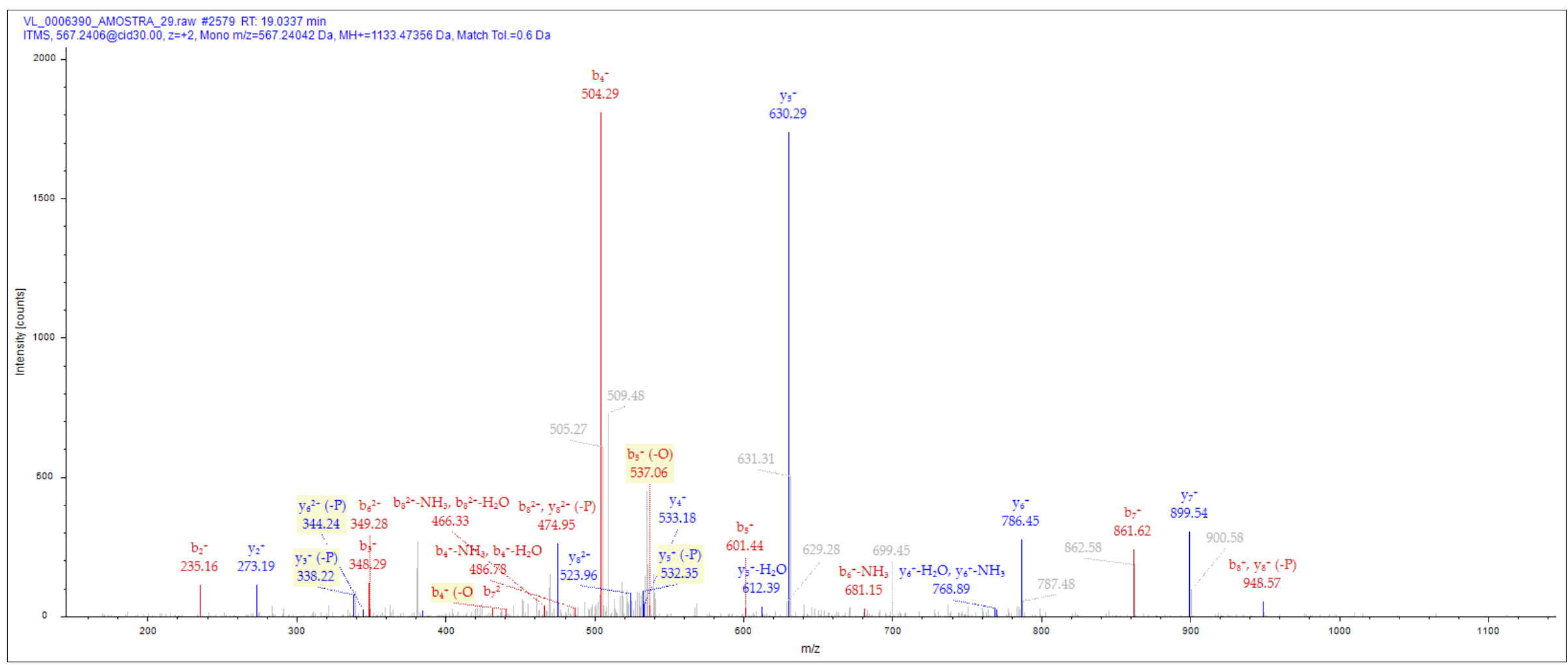


Amostras Femininas - PEP3Y
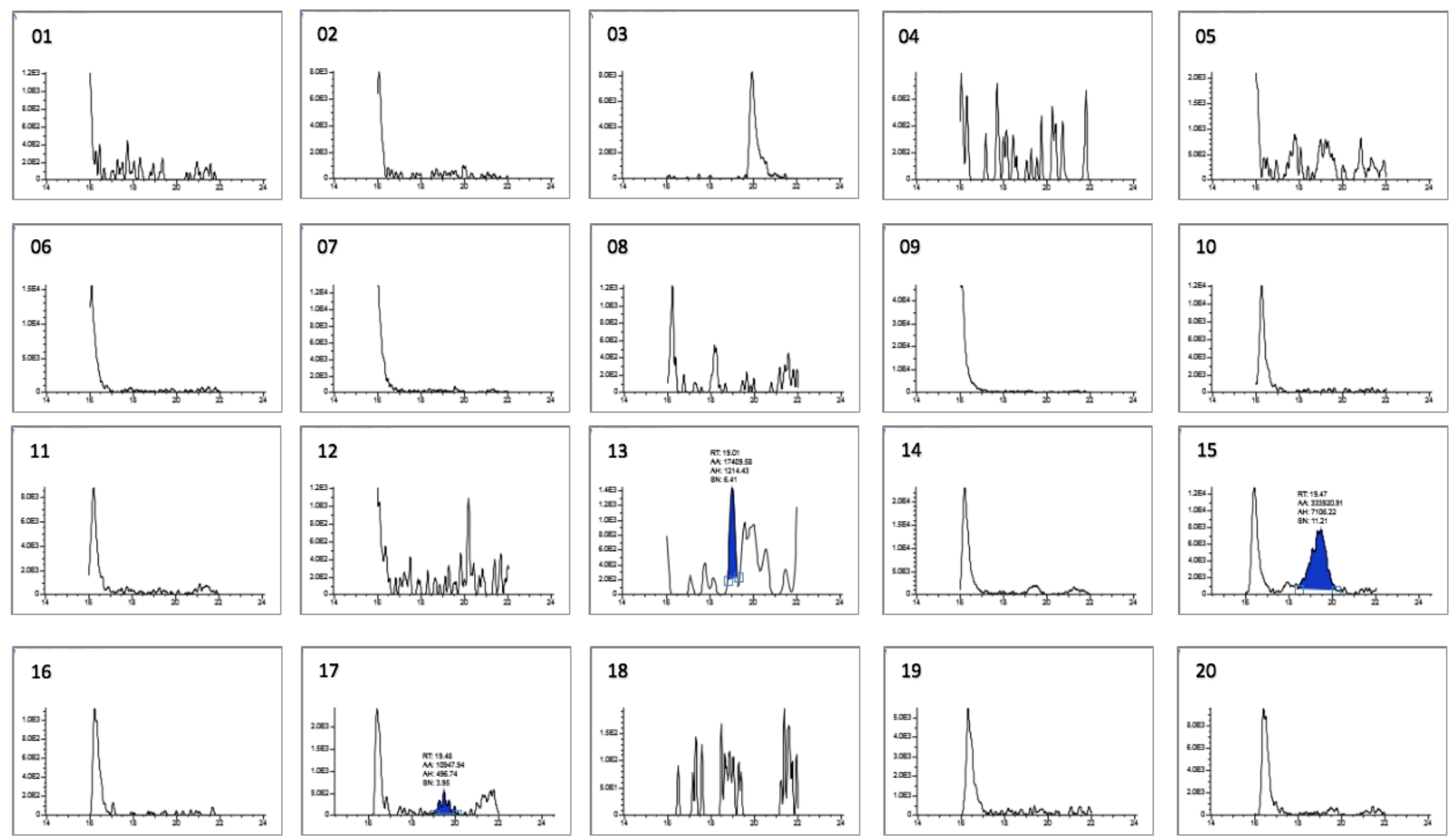
Amostras Masculinas - PEP3Y
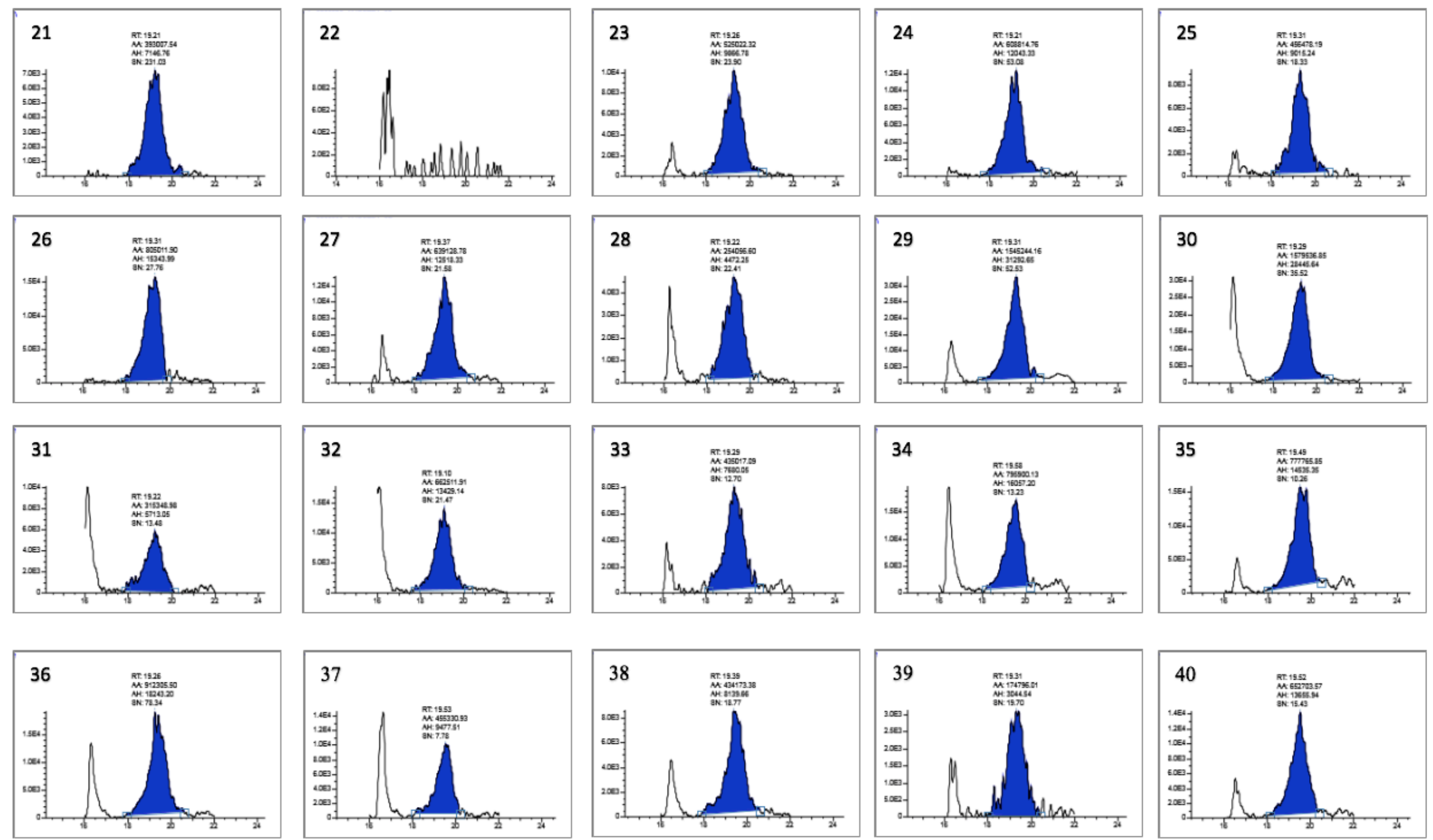
O PEP4Y (Figura 15) apresenta a sequência de aminoácidos YEVLTPLKWYQSM e esteve presente em 02 amostras (10\%) do grupo feminino, e em 12 amostras (60\%) do grupo masculino, detectado pelo espectrômetro de massas com tempo de retenção variando entre RT: 48.88 - 49.35 min, e a modificação variável observada foi oxidação de M (metionina). A razão m/z: 837.41833 Da, monoisotópica, foi detectada no exemplo apresentado e a proteína de referência encontrada no banco de dados UniProt foi: Isoform 1 of Amelogenin, Y isoform OS=Homo sapiens OX=9606 $G N=A M E L Y$. 
Figura 15. Espectro e cromatogramas do peptídeo PEP4Y.

\section{PEP4Y}

Sequência de aminoácidos: YEVLTPLKWYQSM

Tempo de retenção (RT): 48.88 - 49.35

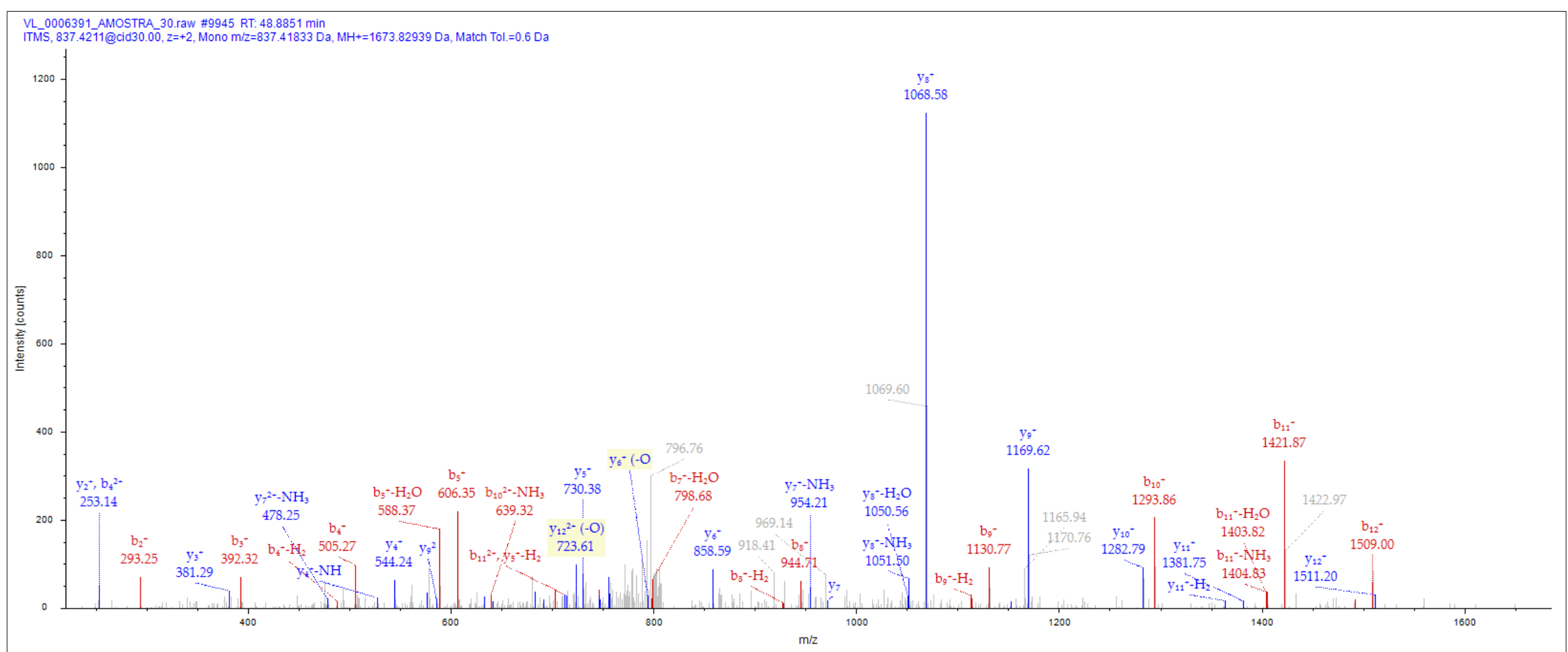


Amostras Femininas - PEP4Y
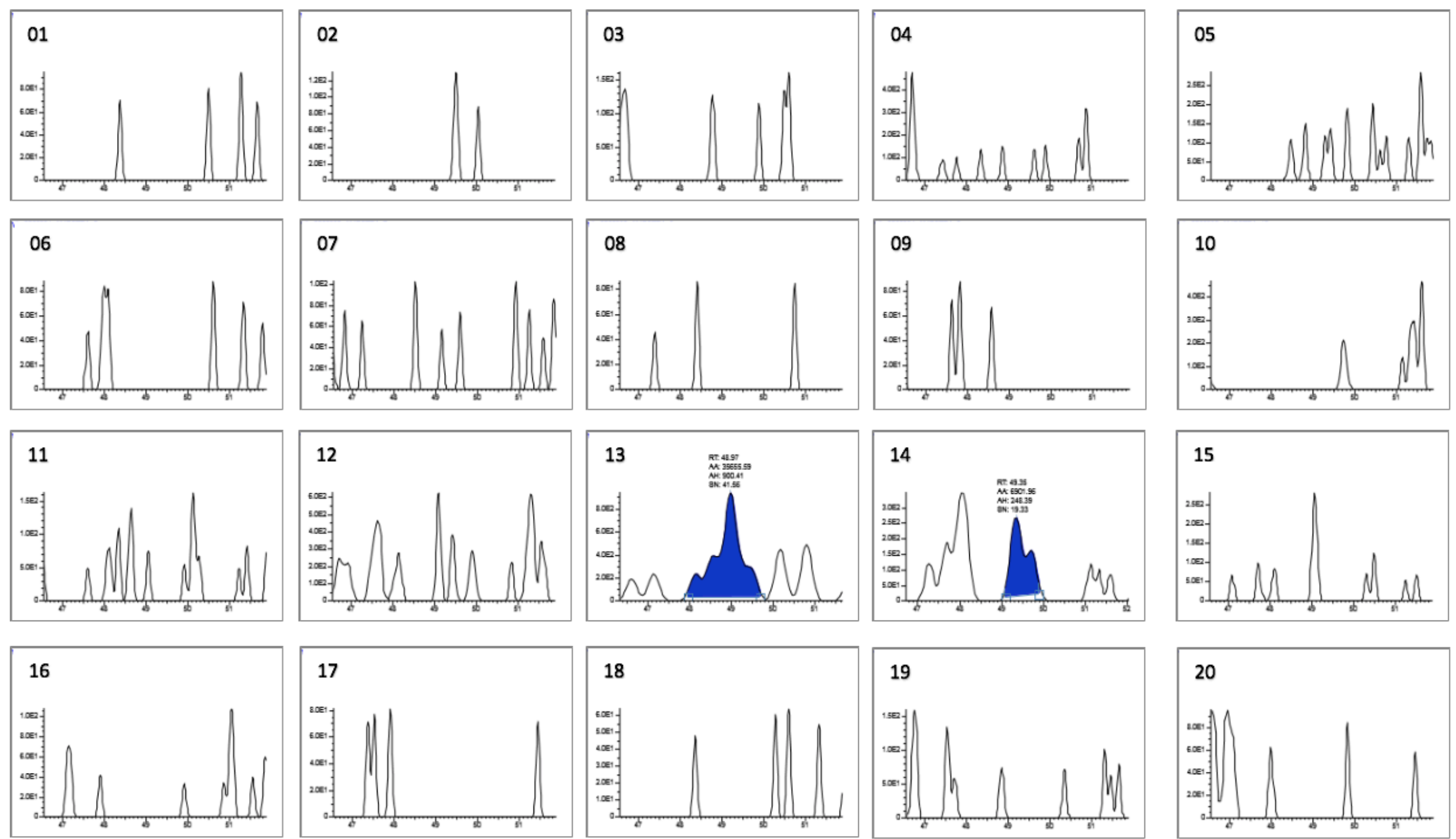
Amostras Masculinas - PEP4Y
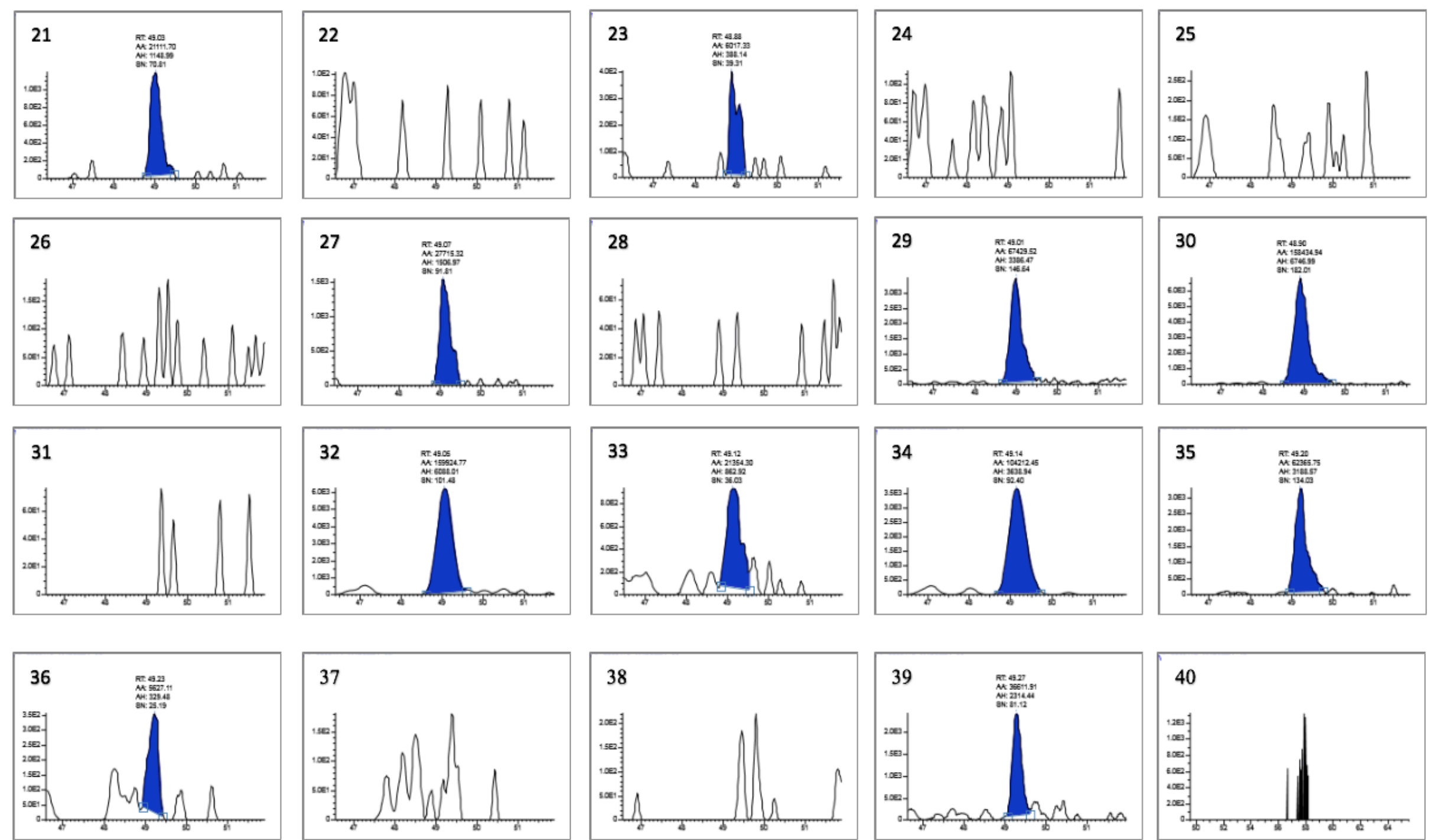
O PEP1X (Figura 16) apresenta a sequência de aminoácidos INFSYEVLTPLK e esteve presente em 19 amostras (95\%) no grupo feminino, e em 20 amostras (100\%) no grupo masculino, detectado pelo espectrômetro de massas com tempo de retenção variando entre RT: 48.52 - 49.24 min, e a modificação variável observada foi fosforilação de S (serina). A razão m/z: $752.37927 \mathrm{Da}$, , monoisotópica, foi detectada no exemplo apresentado e as proteínas de referência encontradas no banco de dados UniProt foram: Isoform 1 of Amelogenin, $Y$ isoform OS=Homo sapiens OX=9606 $G N=A M E L Y$; e Amelogenin, $X$ isoform OS=Homo sapiens $O X=9606$ GN=AMELX. 
Figura 16. Espectro e cromatogramas do peptídeo PEP1X.

\section{PEP1X}

Sequência de aminoácidos: INFSYEVLTPLK

Tempo de retenção (RT): 48.52 - 49.24

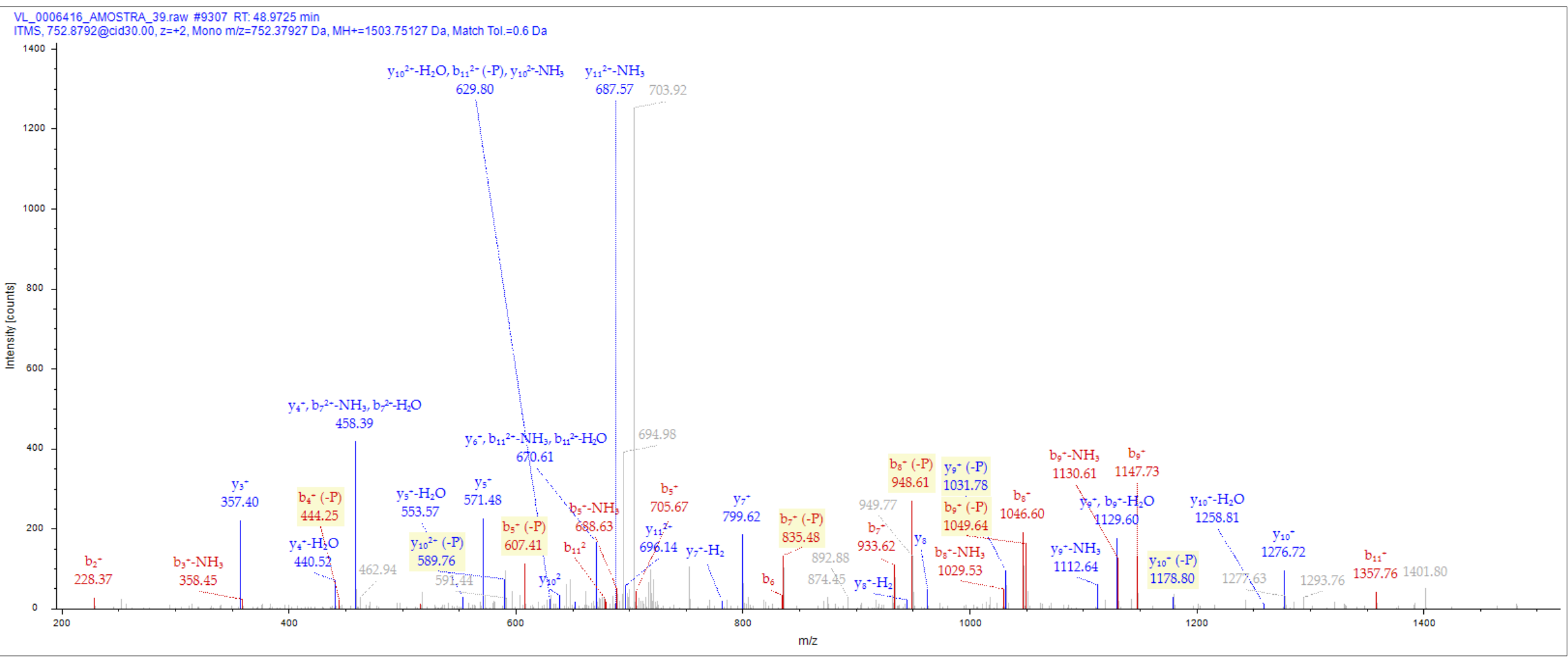




\section{Amostras Femininas - PEP1X}
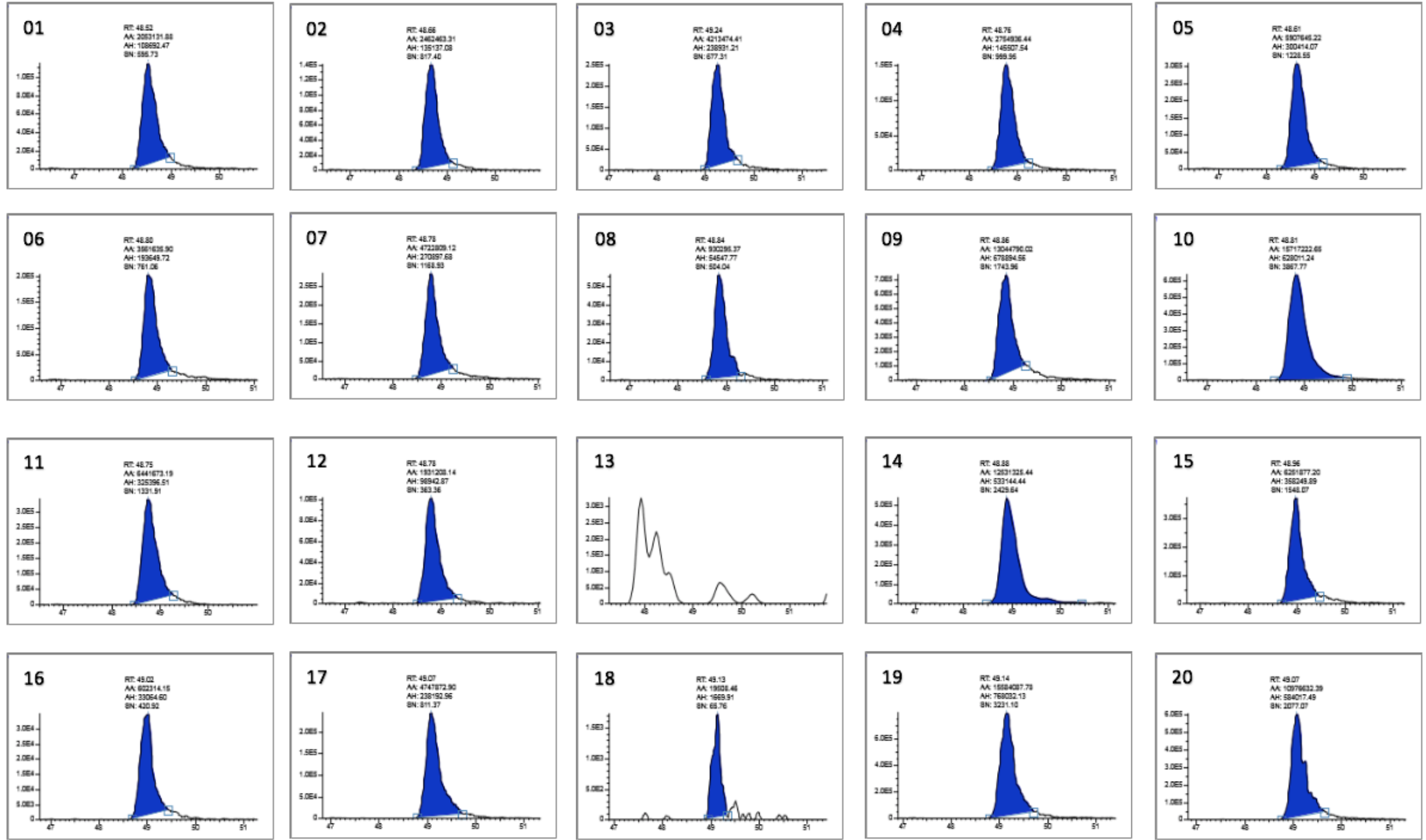
Amostras Masculinas - PEP1X
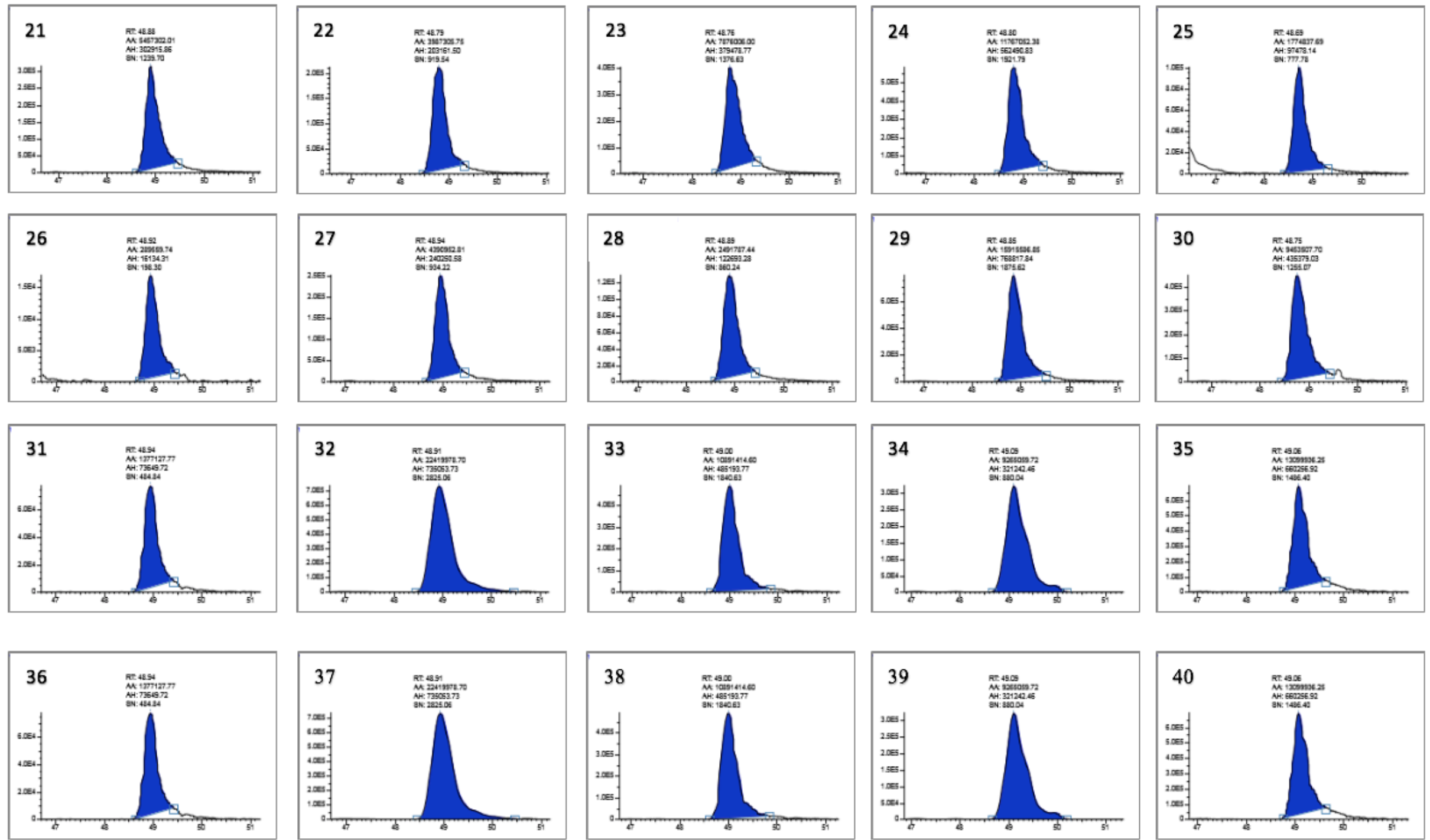
O PEP2X (Figura 17) apresenta a sequência de aminoácidos LPPHPGHPGYINFS e esteve presente em 19 amostras (95\%) do grupo feminino, e em 20 amostras (100\%) do grupo masculino, detectado pelo espectrômetro de massas com tempo de retenção variando entre RT: 32.72 - 35.14 min, e a modificação variável observada foi fosforilação de $S$ (serina). A razão m/z: 806.86853 Da, monoisotópica, foi detectada no exemplo apresentado e as proteínas de referência encontradas no banco de dados UniProt foram: Isoform 3 of Amelogenin, $X$ isoform OS=Homo sapiens OX=9606 GN=AMELX; e Isoform 1 of Amelogenin, $Y$ isoform OS=Homo sapiens $O X=9606$ GN=AMELY. 
Figura 17. Espectro e cromatogramas do peptídeo PEP2X.

PEP2X

Sequência de aminoácidos: LPPHPGHPGYINFS

Tempo de retenção (RT): 32.72 - 35.14

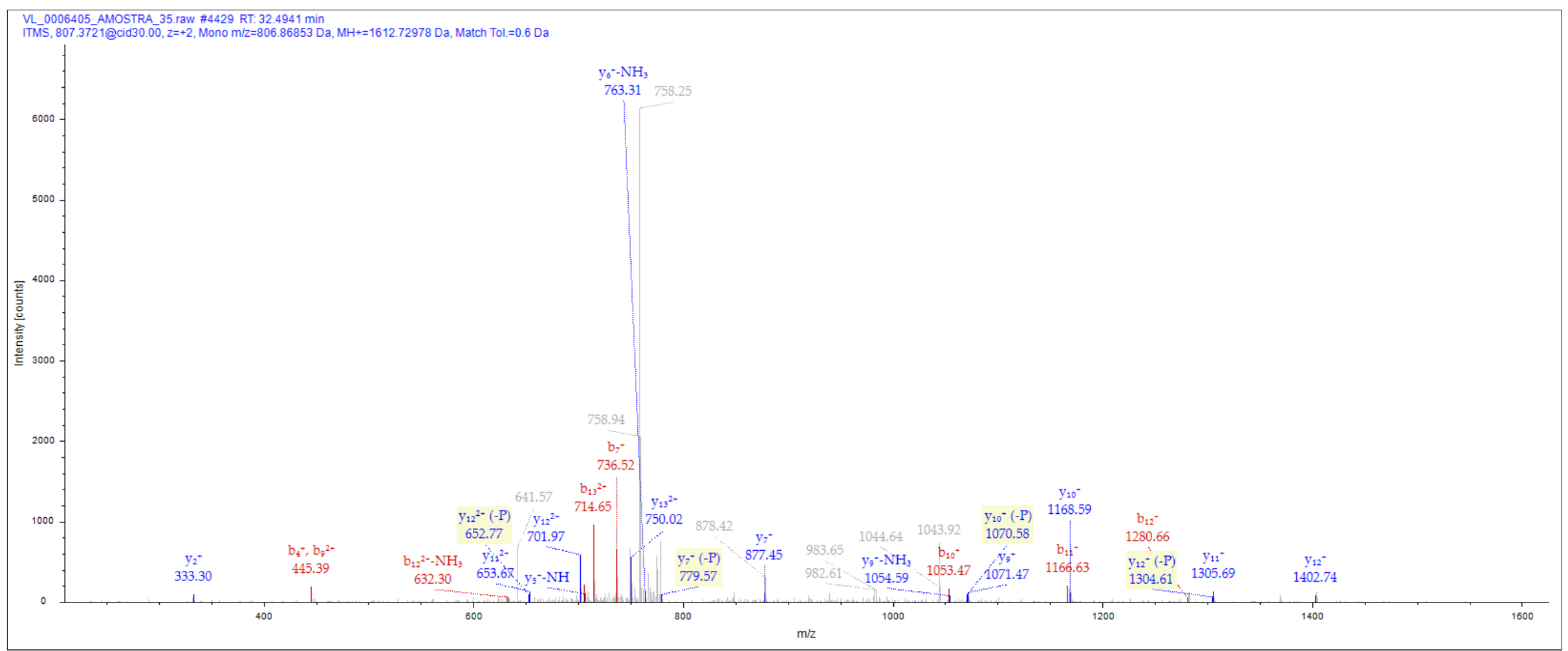


Amostras Femininas - PEP2X
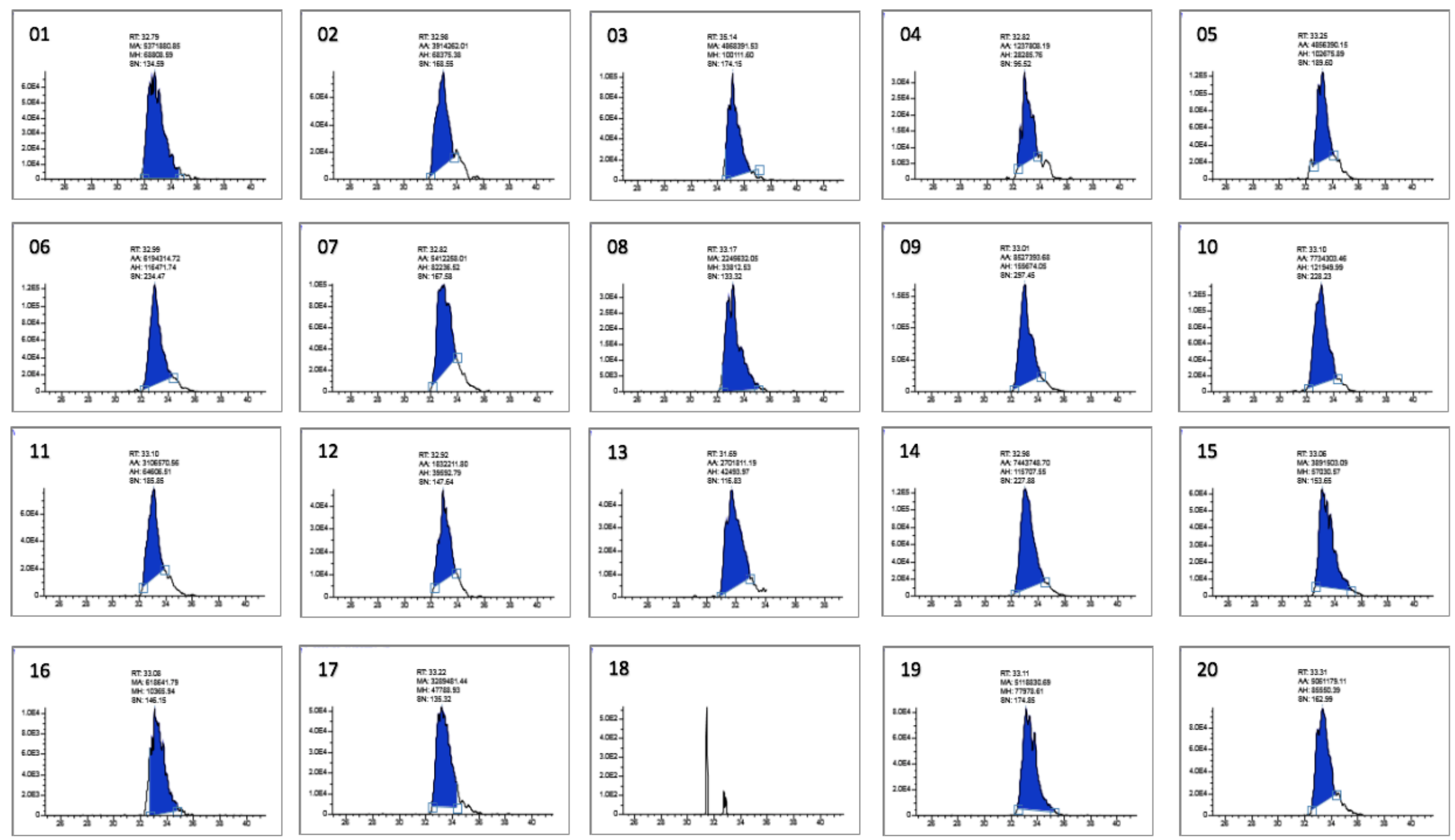
Amostras Masculinas - PEP2X
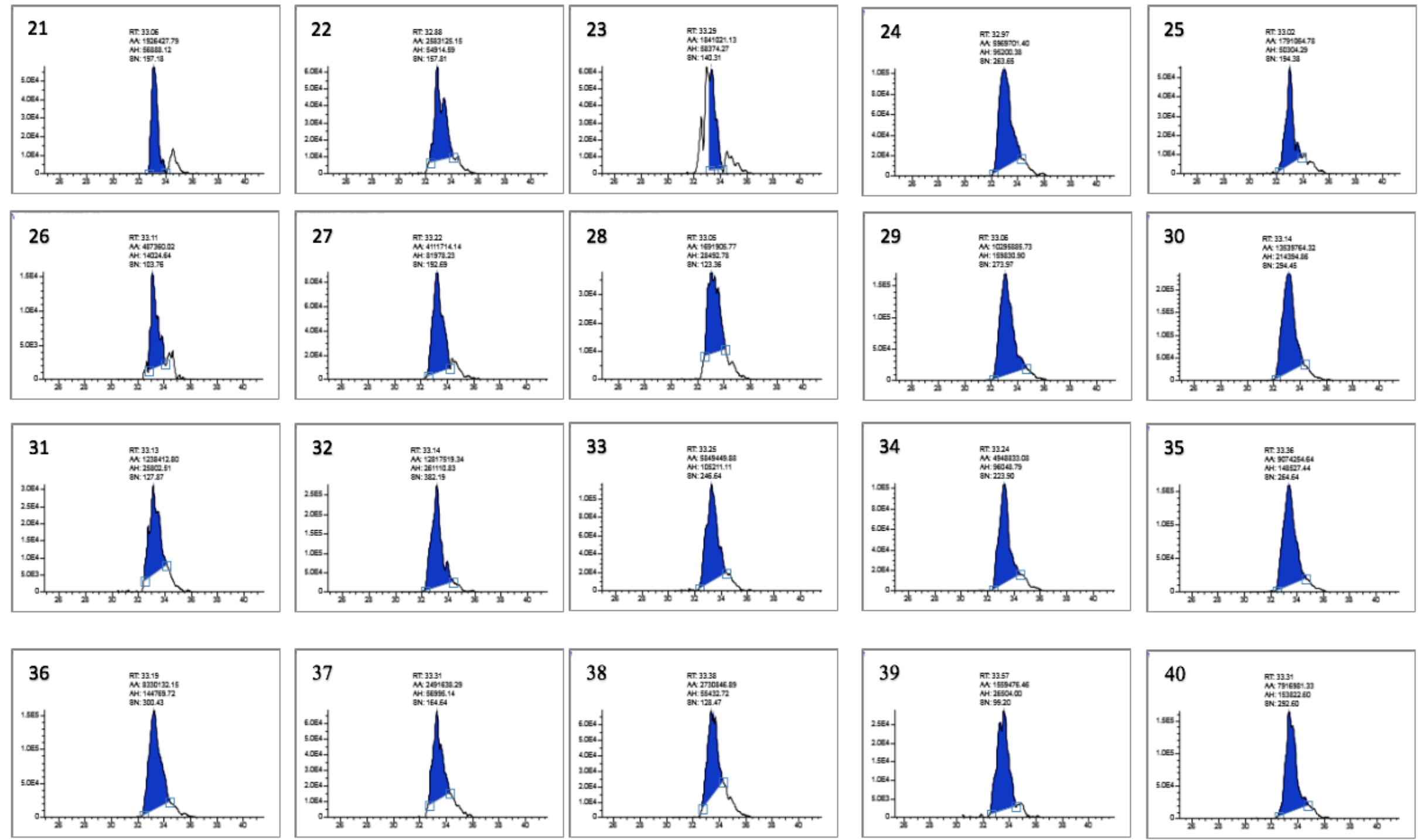
O PEP3X (Figura 18) apresenta a sequência de aminoácidos SIRPPYPSYGYEPMG e esteve presente em 18 amostras (90\%) do grupo feminino, e em 20 amostras (100\%) do grupo masculino, detectado pelo espectrômetro de massas com tempo de retenção variando entre RT: 31.03 - 31.62 min, e a modificação variável observada foi oxidação de M (metionina). A razão m/z: 865.39923 Da, monoisotópica, foi detectada no exemplo apresentado e as proteínas de referência encontradas no banco de dados UniProt foram: Isoform 3 of Amelogenin, $X$ isoform OS=Homo sapiens OX=9606 GN=AMELX; e Amelogenin, $X$ isoform OS=Homo sapiens $O X=9606 \mathrm{GN}=A M E L X$. 
Figura 18. Espectro e cromatogramas do peptídeo PEP3X.

\section{PEP3X}

Sequência de aminoácidos: SIRPPYPSYGYEPMG

Tempo de retenção (RT): 31.03 - 31.62

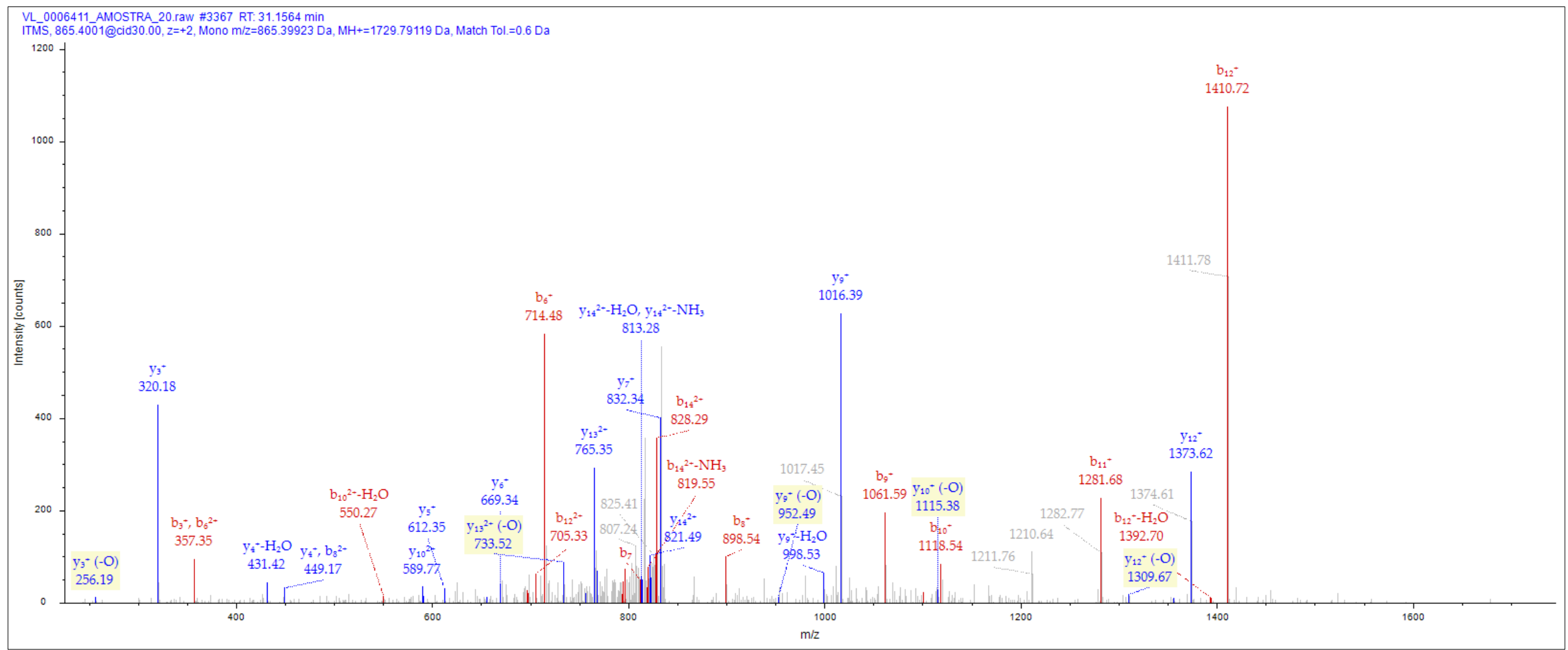


Amostras Femininas - PEP3X
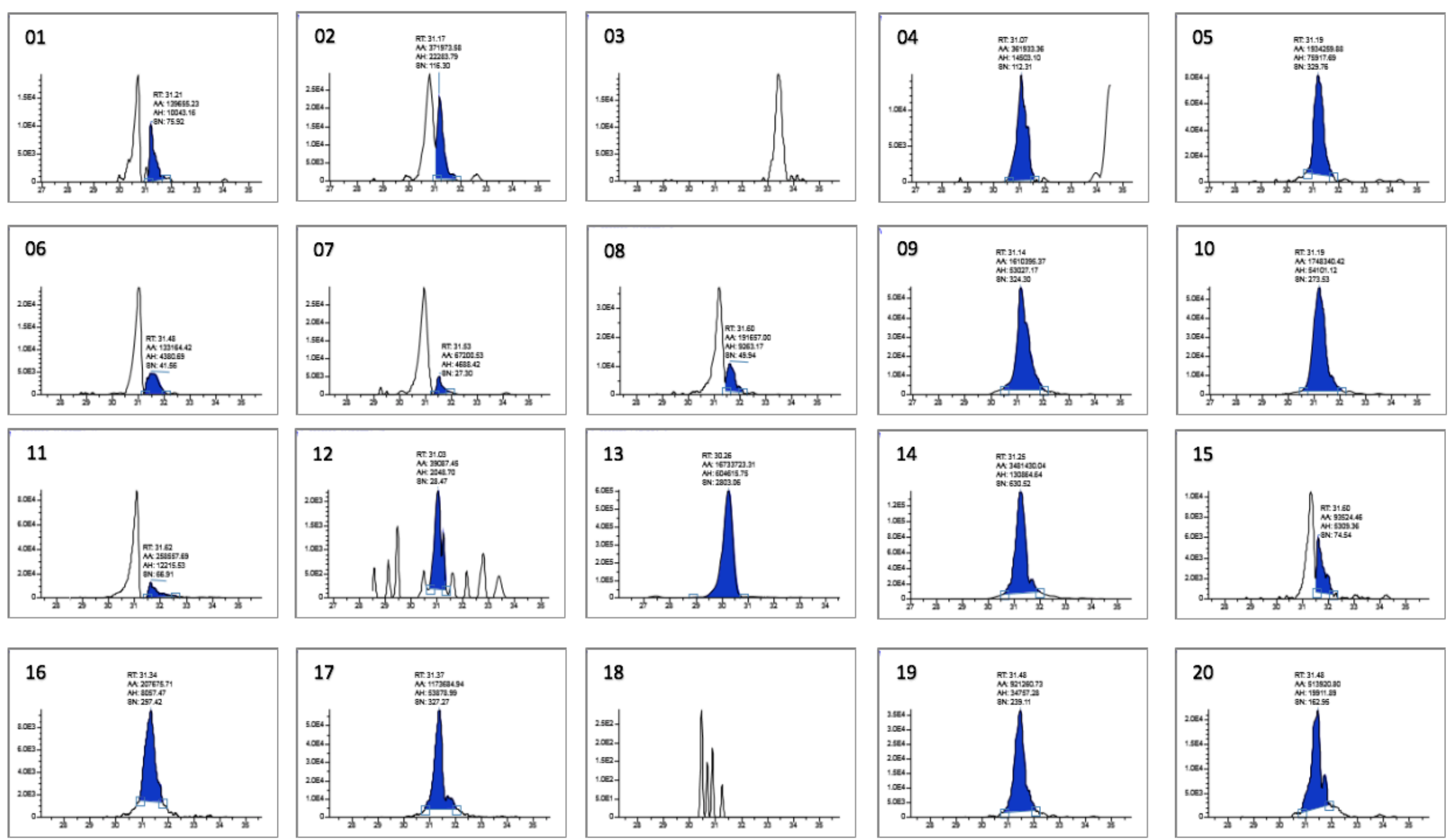
Amostras Masculinas - PEP3X
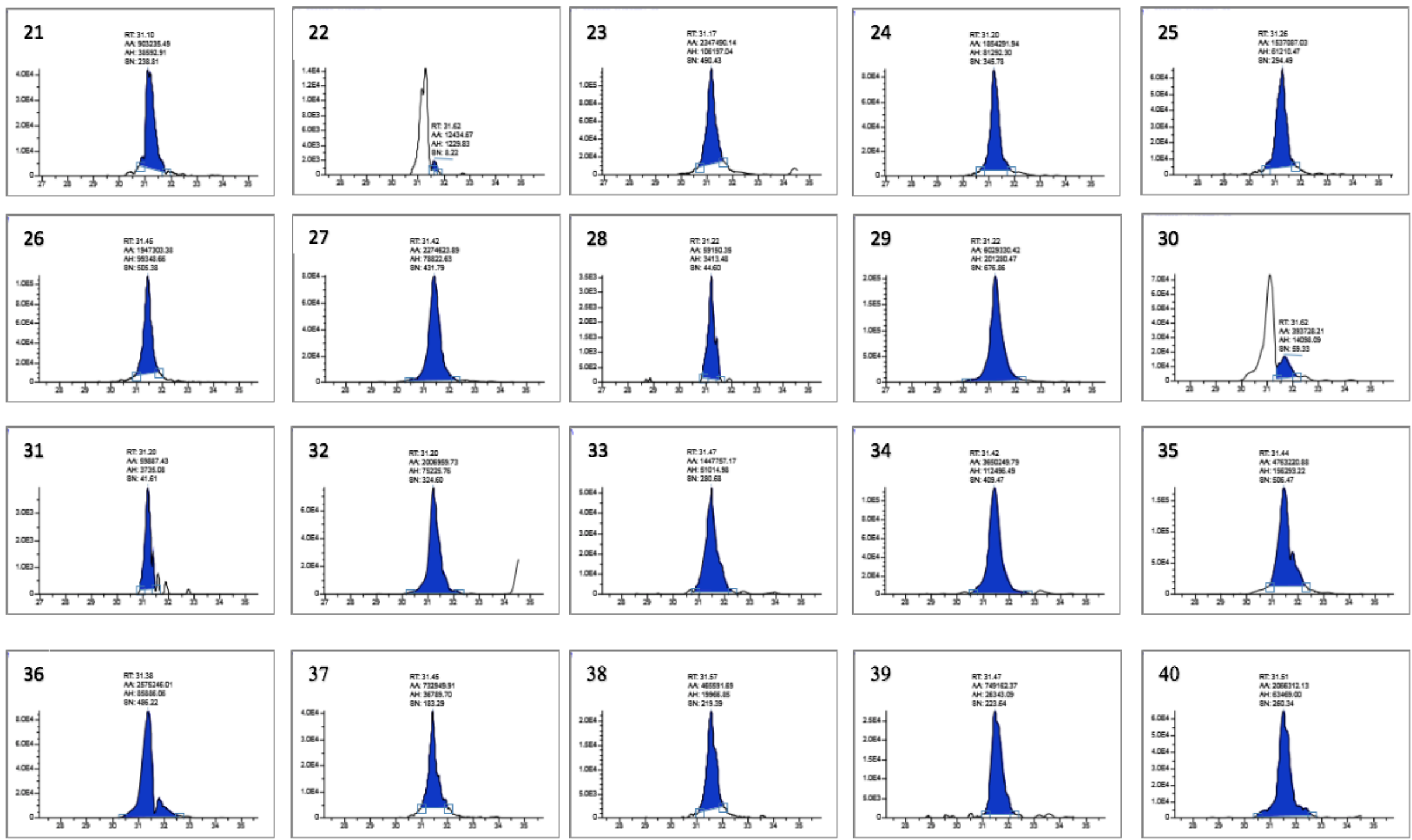
O PEP4X (Figura 19) apresenta a sequência de aminoácidos SIRPPYPSYGYEPM e esteve presente em 17 amostras (85\%) do grupo feminino, e em 20 amostras (100\%) do grupo masculino, detectado pelo espectrômetro de massas com tempo de retenção variando entre RT: 30.79 - 31.61 min, e a modificação variável observada foi oxidação de M (metionina). A razão m/z: 836.88776 Da, monoisotópica, foi detectada no exemplo apresentado e as proteínas de referência encontradas no banco de dados UniProt foram: Isoform 3 of Amelogenin, $X$ isoform OS=Homo sapiens OX=9606 GN=AMELX; e Amelogenin, $X$ isoform OS=Homo sapiens $O X=9606$ GN=AMELX. 
Figura 19. Espectro e cromatogramas do peptídeo PEP4X.

\section{PEP4X}

Sequência de aminoácidos: SIRPPYPSYGYEPM

Tempo de retenção (RT): 30.79 - 31.61

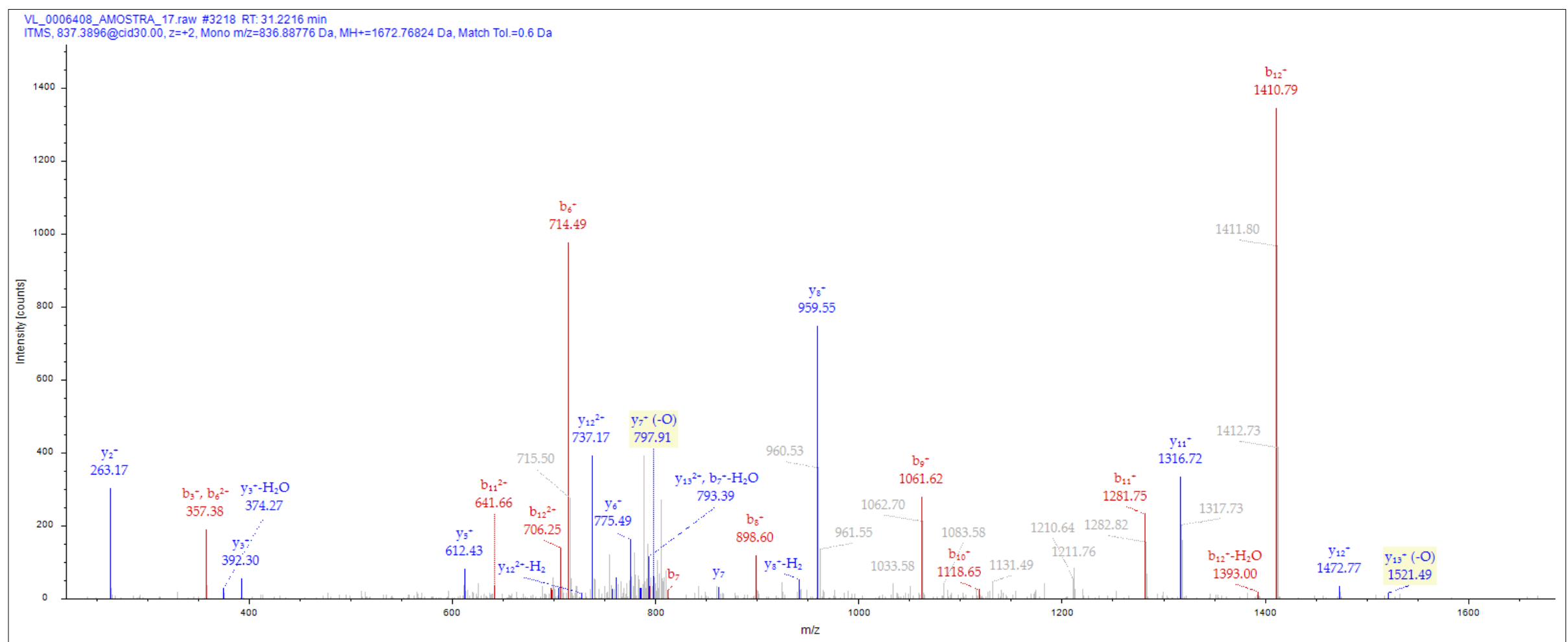


Amostras Femininas - PEP4X
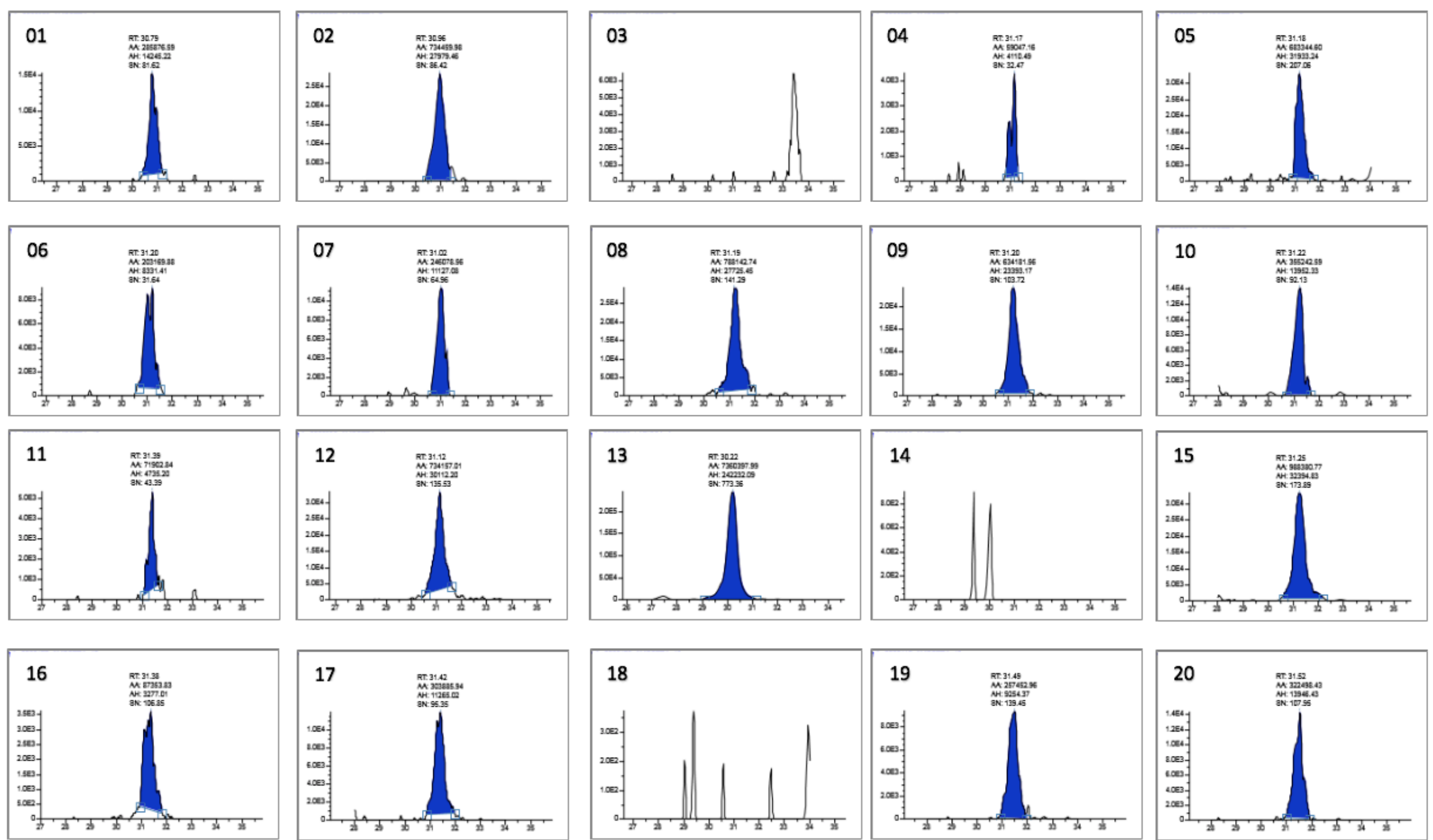
Amostras Masculinas - PEP4X
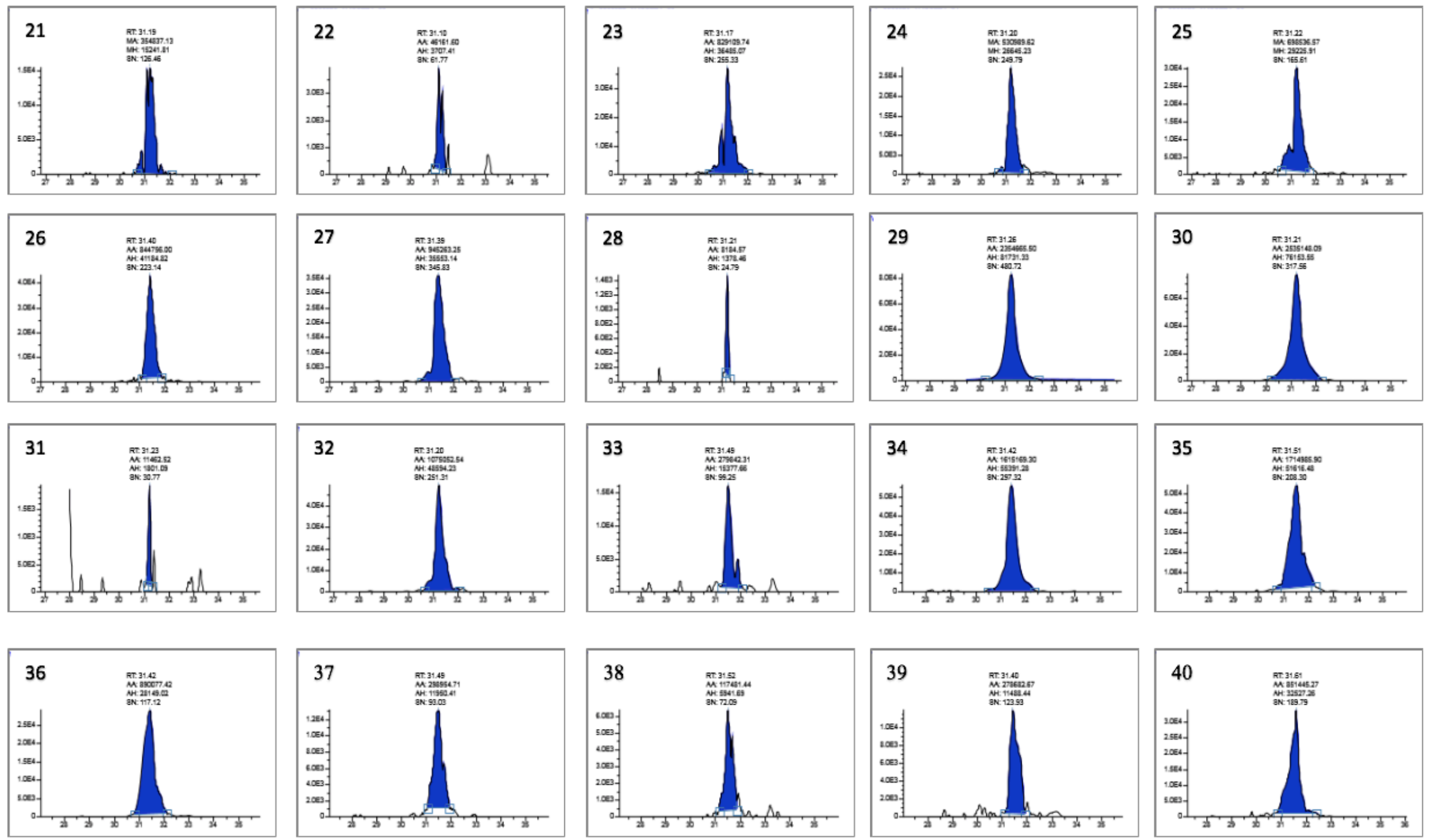
O PEP5X (Figura 20) apresenta a sequência de aminoácidos SYENSHQAINVDR e esteve presente em 17 amostras (85\%) do grupo feminino, e em 19 amostras (95\%) do grupo masculino, detectado pelo espectrômetro de massas com tempo de retenção variando entre RT: 15.86 - 16.55 min, e a modificação variável observada foi fosforilação de $\mathrm{Y}$ (tirosina). A razão m/z: 850.35956 Da, monoisotópica, foi detectada no exemplo apresentado e a proteína de referência encontrada no banco de dados UniProt foi: Isoform 3 of Amelogenin, $X$ isoform OS=Homo sapiens OX=9606 $G N=A M E L X$. 
Figura 20. Espectro e cromatogramas do peptídeo PEP5X.

PEP5X

Sequência de aminoácidos: SYENSHSQAINVDR

Tempo de retenção (RT): 15.86 - 16.55

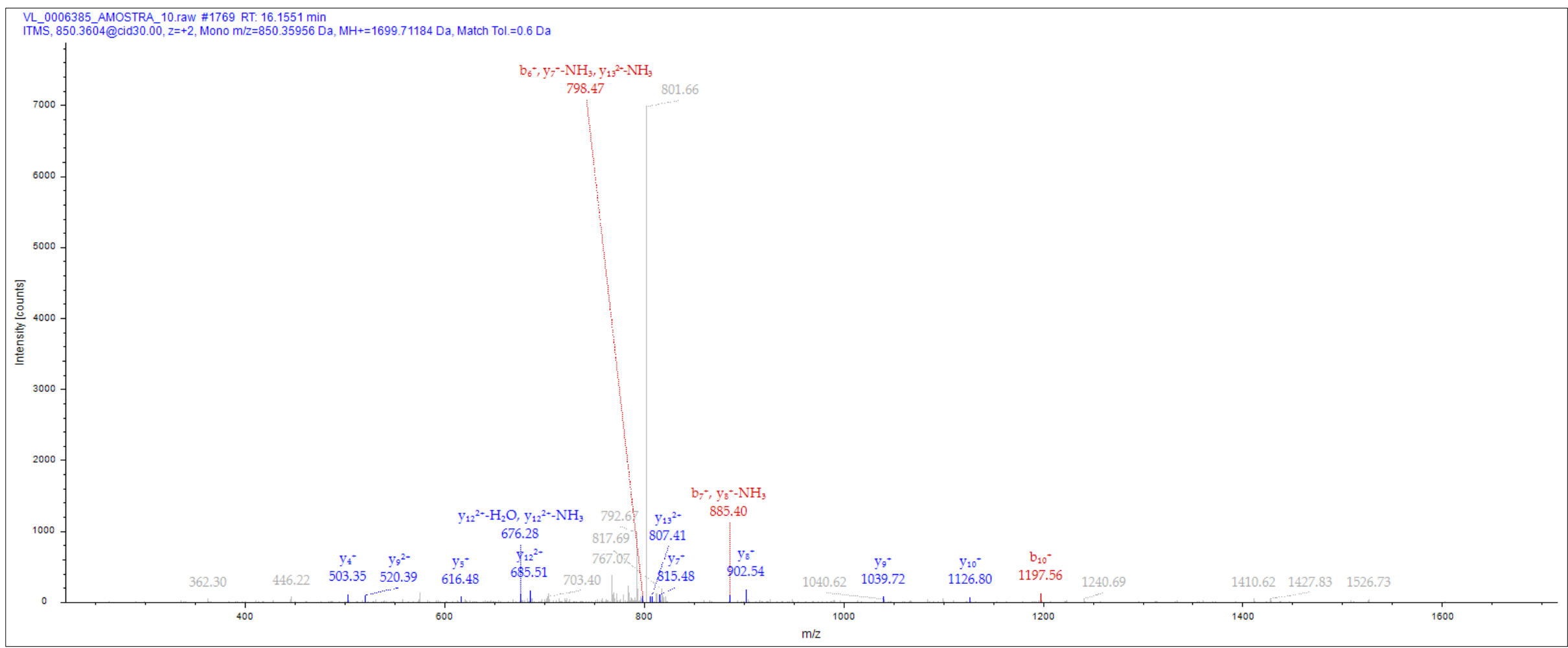


Amostras Femininas - PEP5X
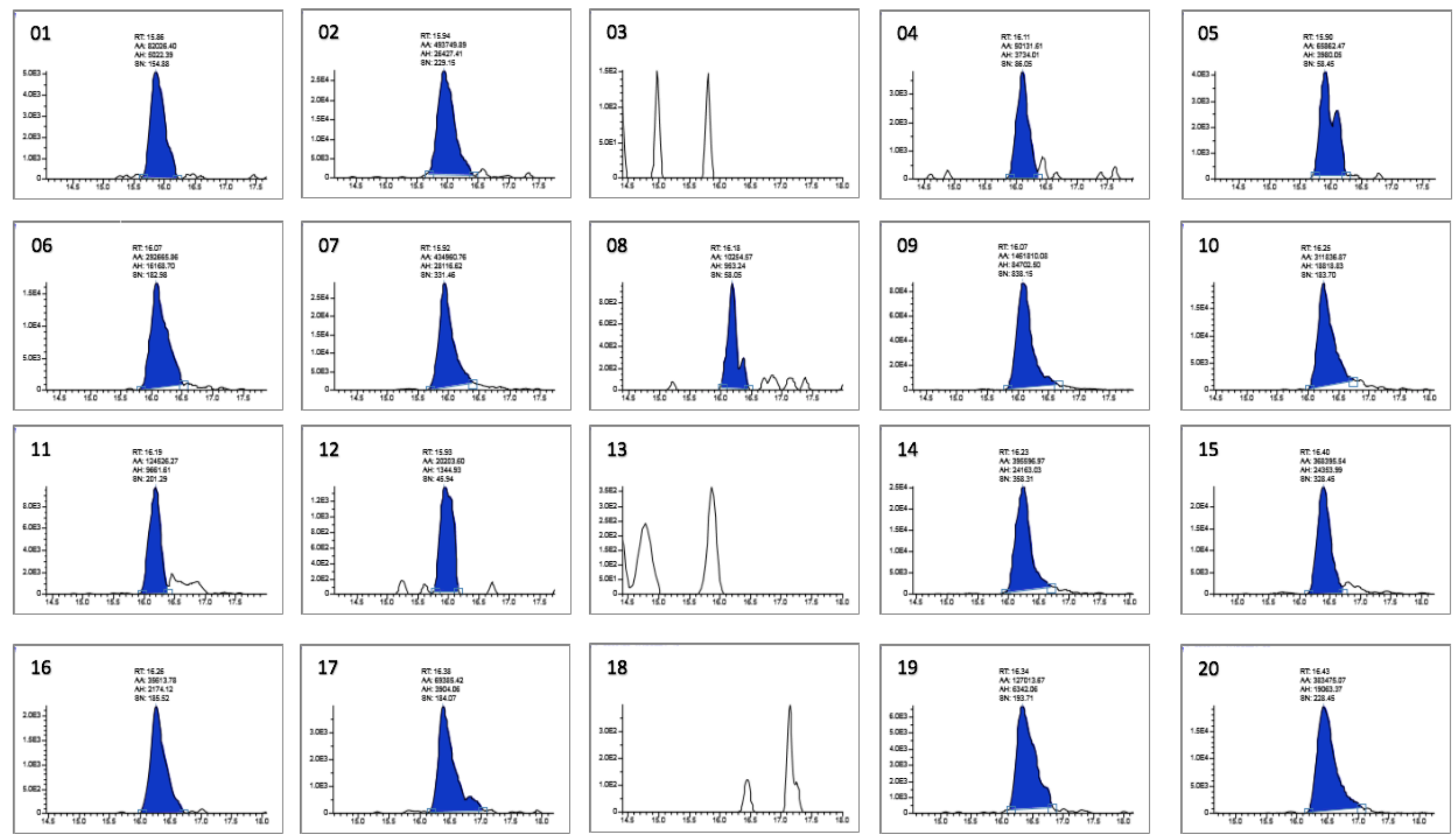
Amostras Masculinas - PEP5X
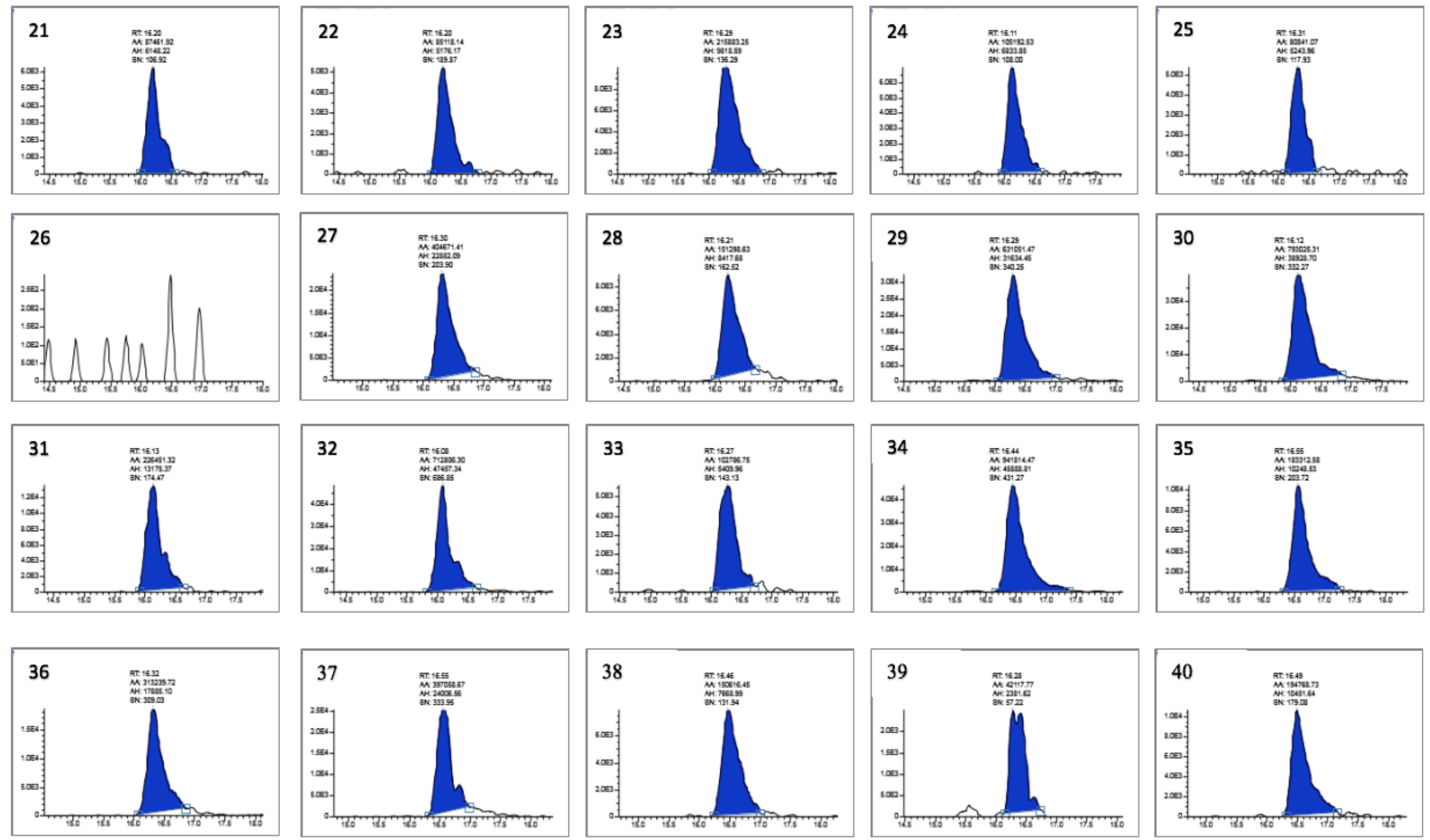
O PEP6X (Figura 21) apresenta a sequência de aminoácidos SIRPPYPSYGYEPMGG e esteve presente em 16 amostras (80\%) do grupo feminino, e em 17 amostras (85\%) do grupo masculino, detectado pelo espectrômetro de massas com tempo de retenção variando entre RT: 29.79 - 30.98 min, e a modificação variável observada foi oxidação de M (metionina). A razão m/z: 893.90741 Da, monoisotópica, foi detectada no exemplo apresentado e as proteínas de referência encontradas no banco de dados UniProt foram: Isoform 3 of Amelogenin, $X$ isoform OS=Homo sapiens OX=9606 GN=AMELX; e Amelogenin, $X$ isoform OS=Homo sapiens $O X=9606$ GN=AMELX. 
Figura 21. Espectro e cromatogramas do peptídeo PEP6X.

\section{PEP6X}

Sequência de aminoácidos: SIRPPYPSYGYEPMGG

Tempo de retenção (RT): 29.79 - 30.98

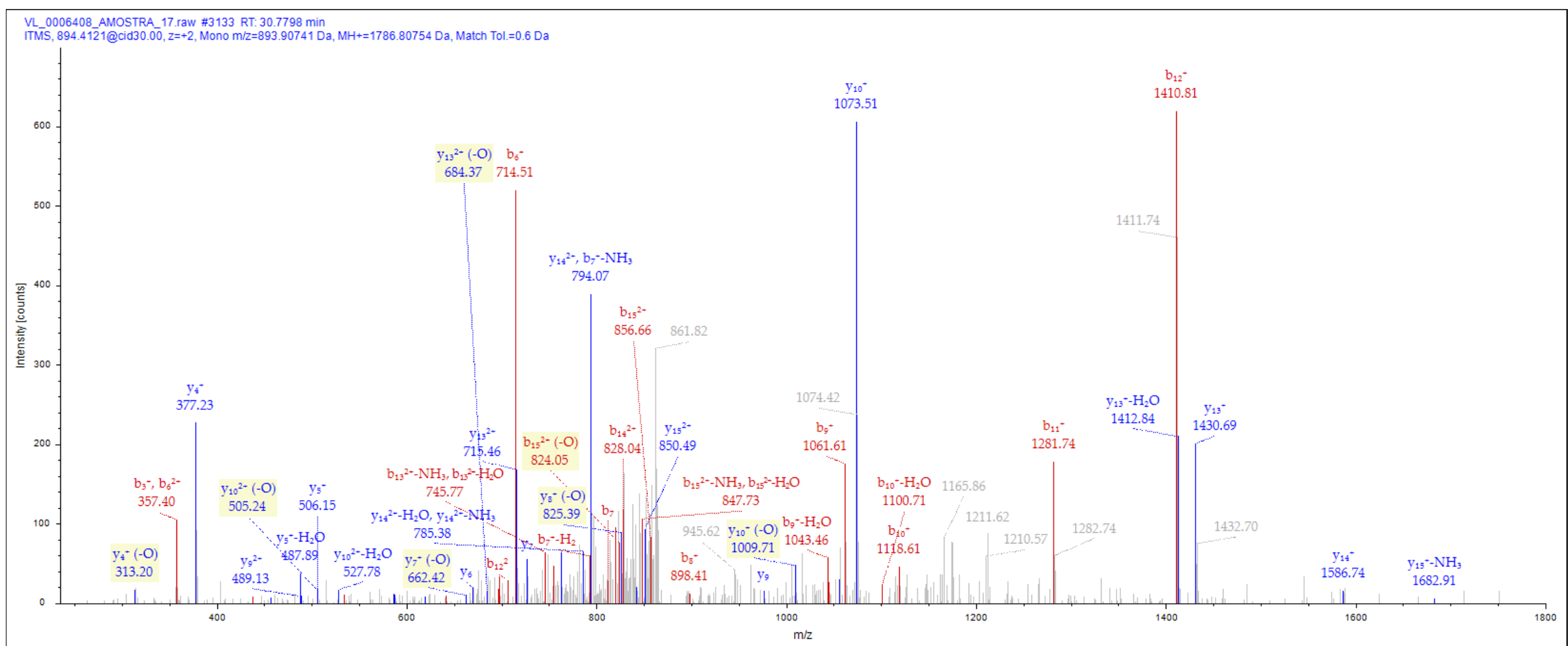


Amostras Femininas - PEP6X
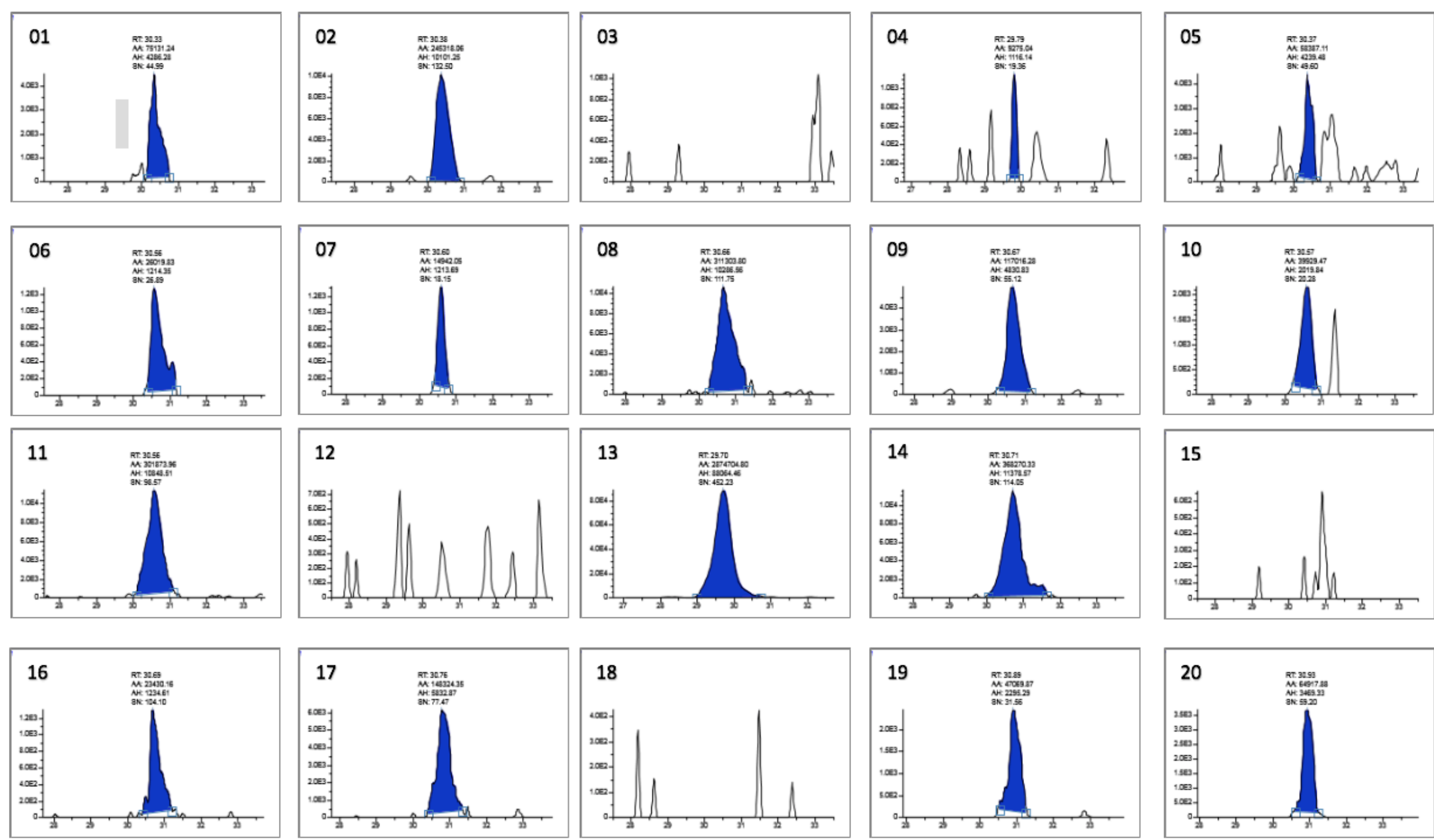
Amostras Masculinas - PEP6X
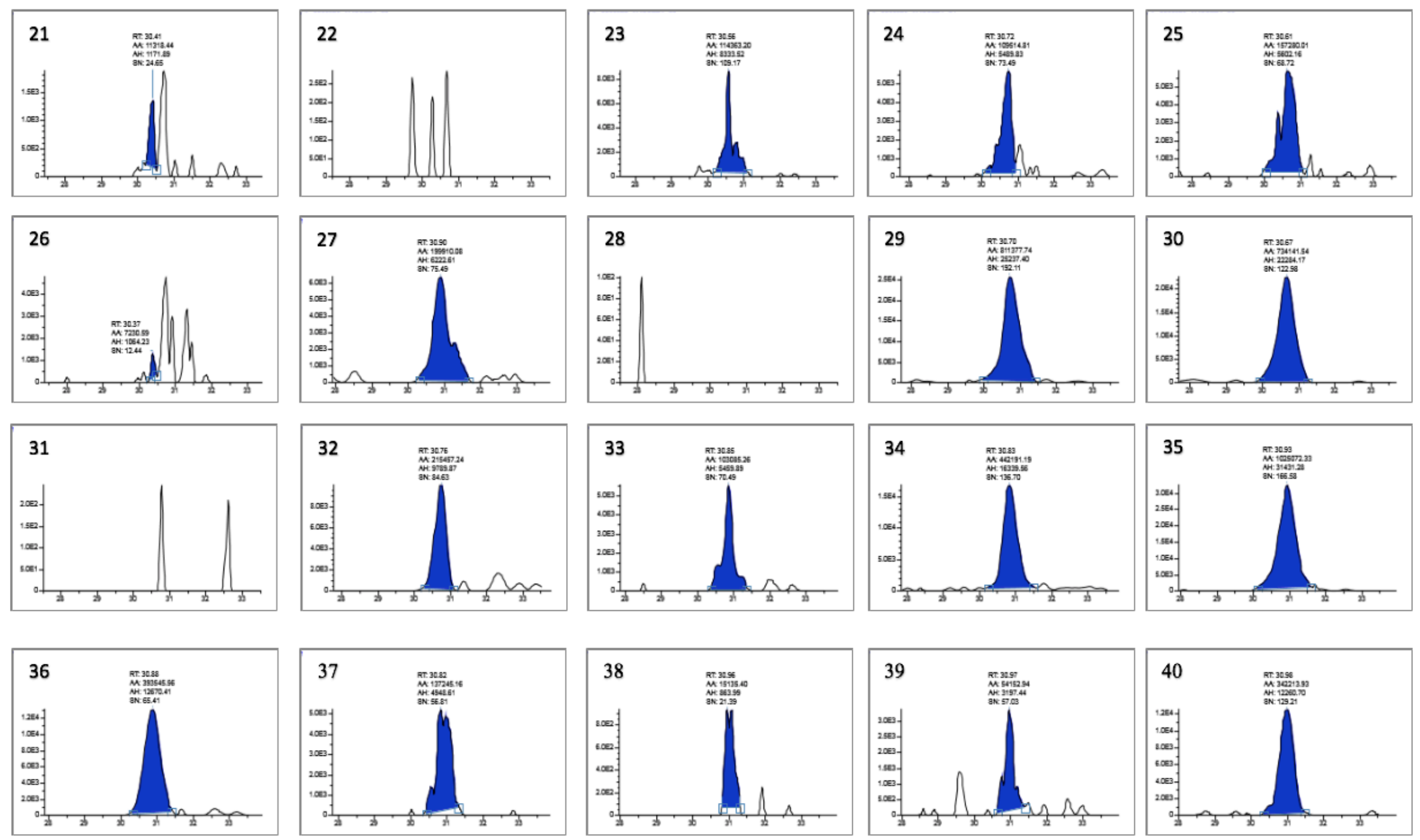
O PEP7X (Figura 22) apresenta a sequência de aminoácidos TDKTKQEEVD e esteve presente em 13 amostras (65\%) do grupo feminino, e em 18 amostras (90\%) do grupo masculino, detectado pelo espectrômetro de massas com tempo de retenção variando entre RT: 7.52 - 7.96 min, sem modificação variável observada. A razão m/z: 596.79108 Da, monoisotópica, foi detectada no exemplo apresentado e a proteína de referência encontrada no banco de dados UniProt foi: Isoform 1 of Amelogenin, $Y$ isoform OS=Homo sapiens $O X=9606 G N=A M E L Y$, apesar dessa sequência estar presente em todas as isoformas da amelogenina conforme o quadro 5 apresentado. 
Figuras 22. Espectro e cromatogramas do peptídeo PEP7X.

\section{PEP7X}

Sequência de aminoácidos: TDKTKQEEVD

Tempo de retenção (RT): 7.52 - 7.96

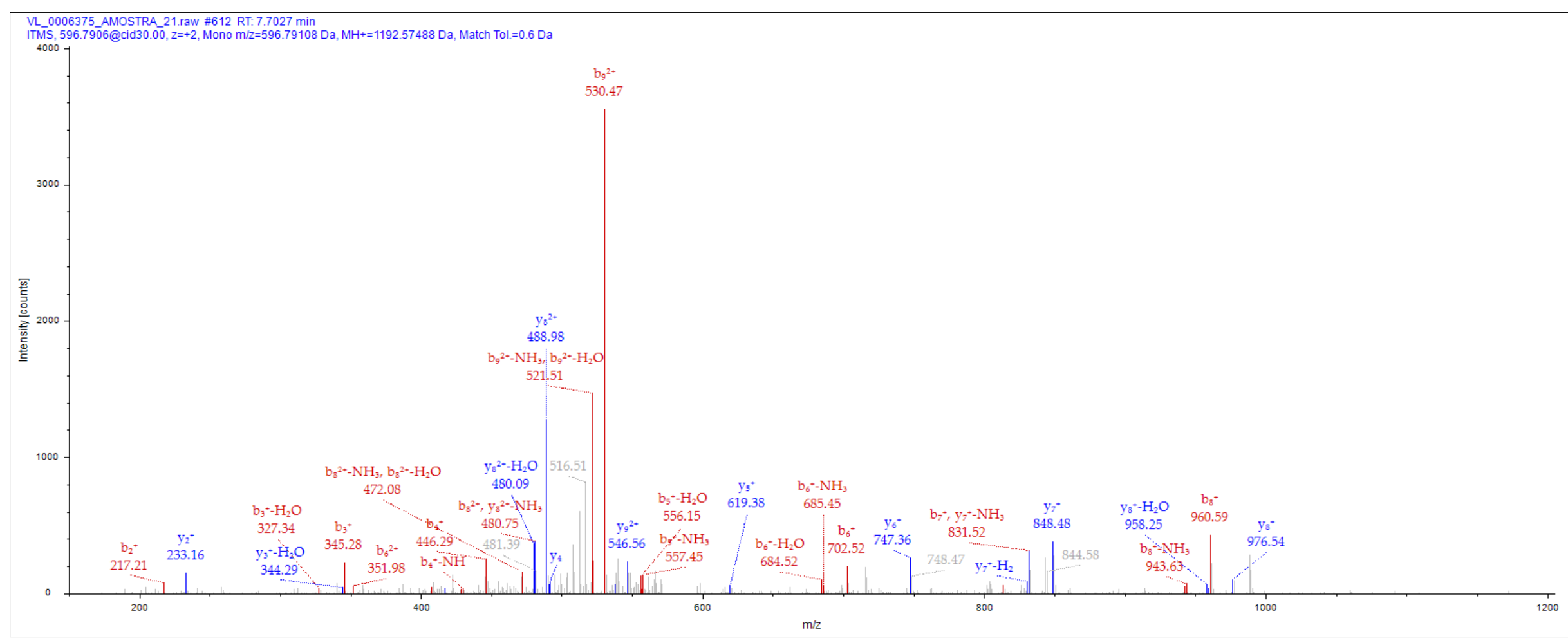




\section{Amostras Femininas - PEP7X}
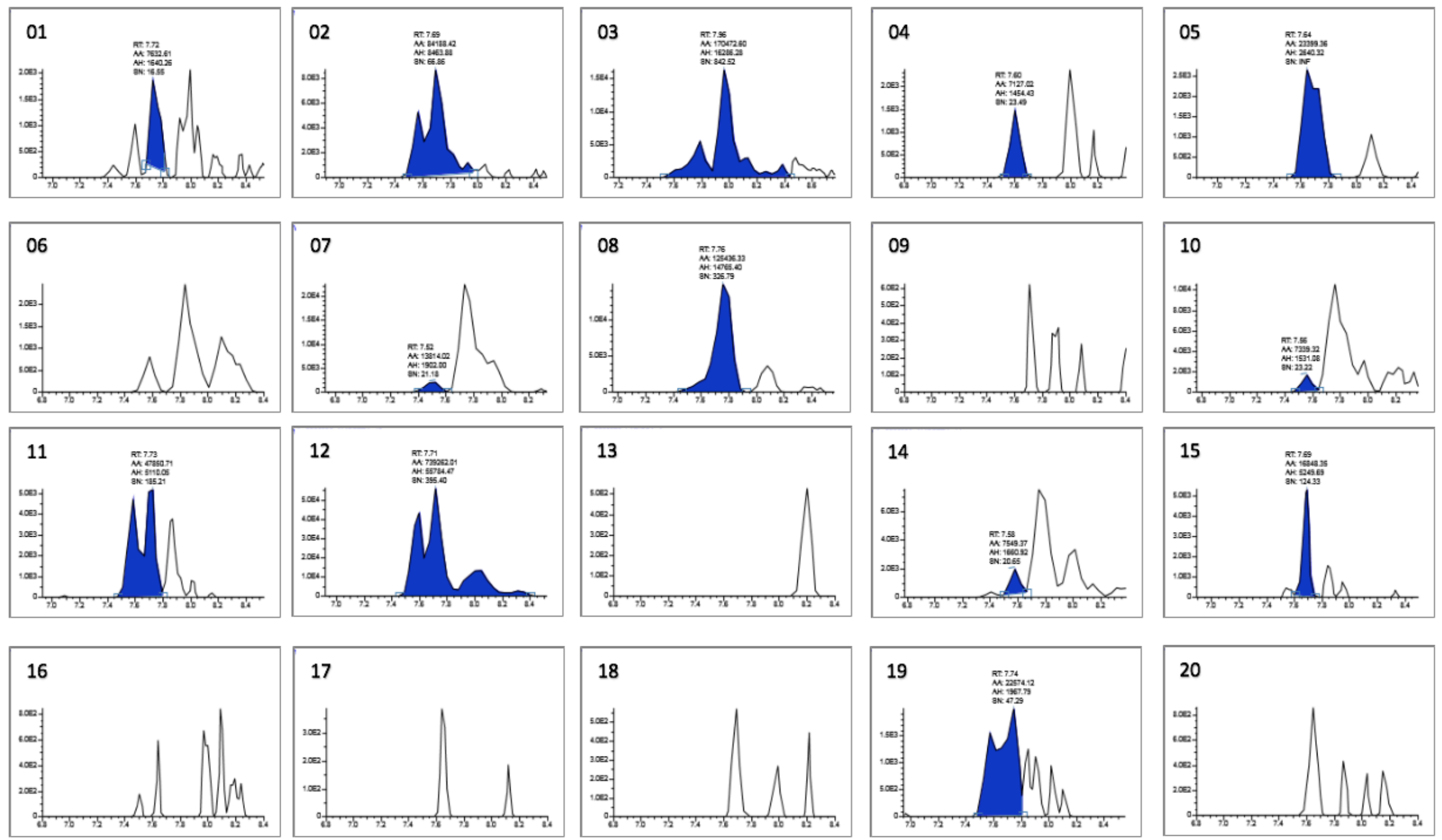
Amostras Masculinas - PEP7X
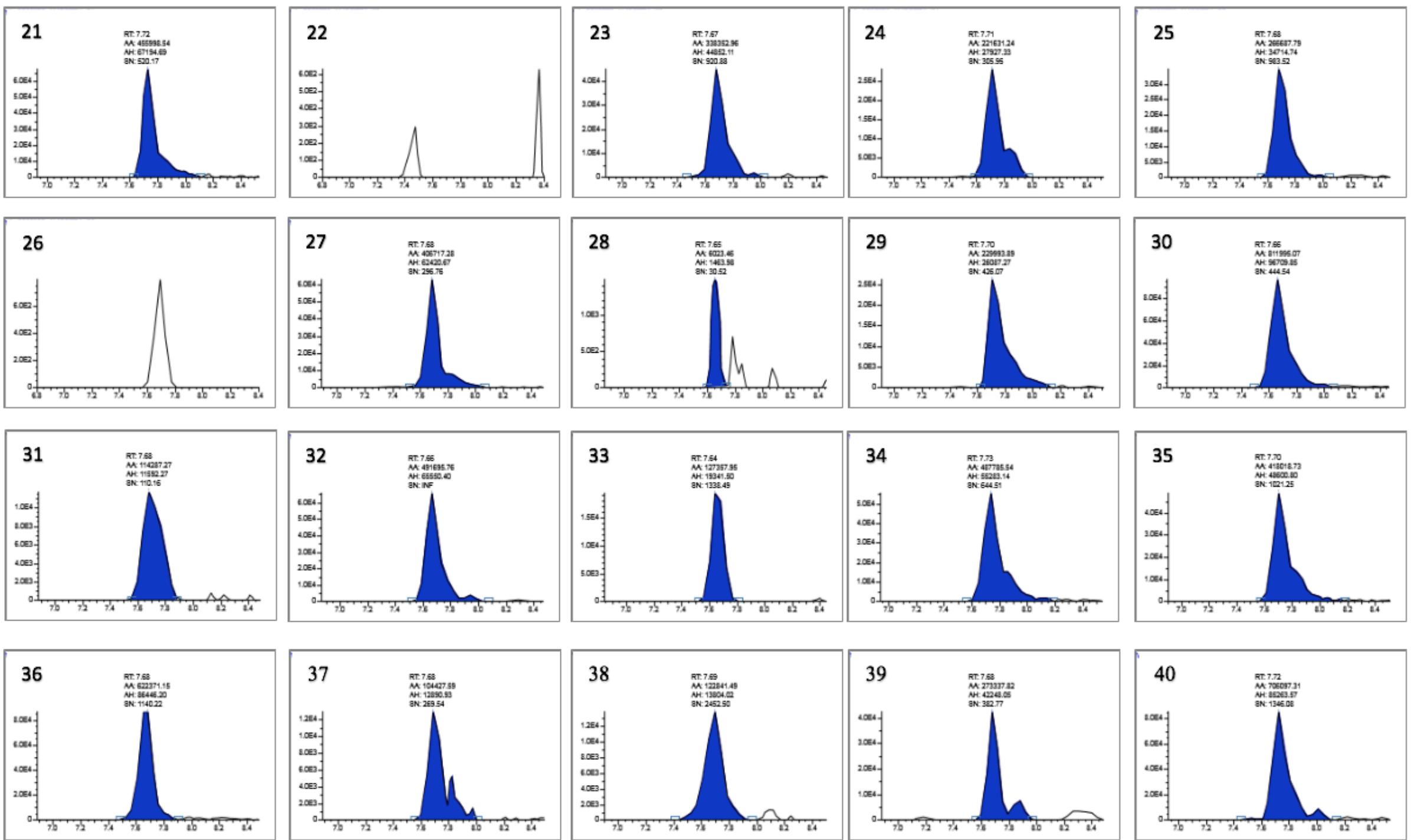
O PEP8X (Figura 23) apresenta a sequência de aminoácidos SIRPPYPSYGYEPMGGW e esteve presente em 14 amostras (70\%) do grupo feminino, e em 15 amostras (75\%) do grupo masculino, detectado pelo espectrômetro de massas com tempo de retenção variando entre RT: 40.71 - 41.44 min, e a modificação variável observada foi oxidação de $M$ (metionina). A razão $\mathrm{m} / \mathrm{z}$ : 986.95123 Da, monoisotópica, foi detectada no exemplo apresentado e as proteínas de referência encontradas no banco de dados UniProt foram: Isoform 3 of Amelogenin, $X$ isoform OS=Homo sapiens OX=9606 GN=AMELX; e Amelogenin, $X$ isoform OS=Homo sapiens $O X=9606 \mathrm{GN}=A M E L X$. 
Figura 23. Espectro e cromatogramas do peptídeo PEP8X.

\section{PEP8X}

Sequência de aminoácidos: SIRPPYPSYGYEPMGGW

Tempo de retenção (RT): 40.71 - 41.44

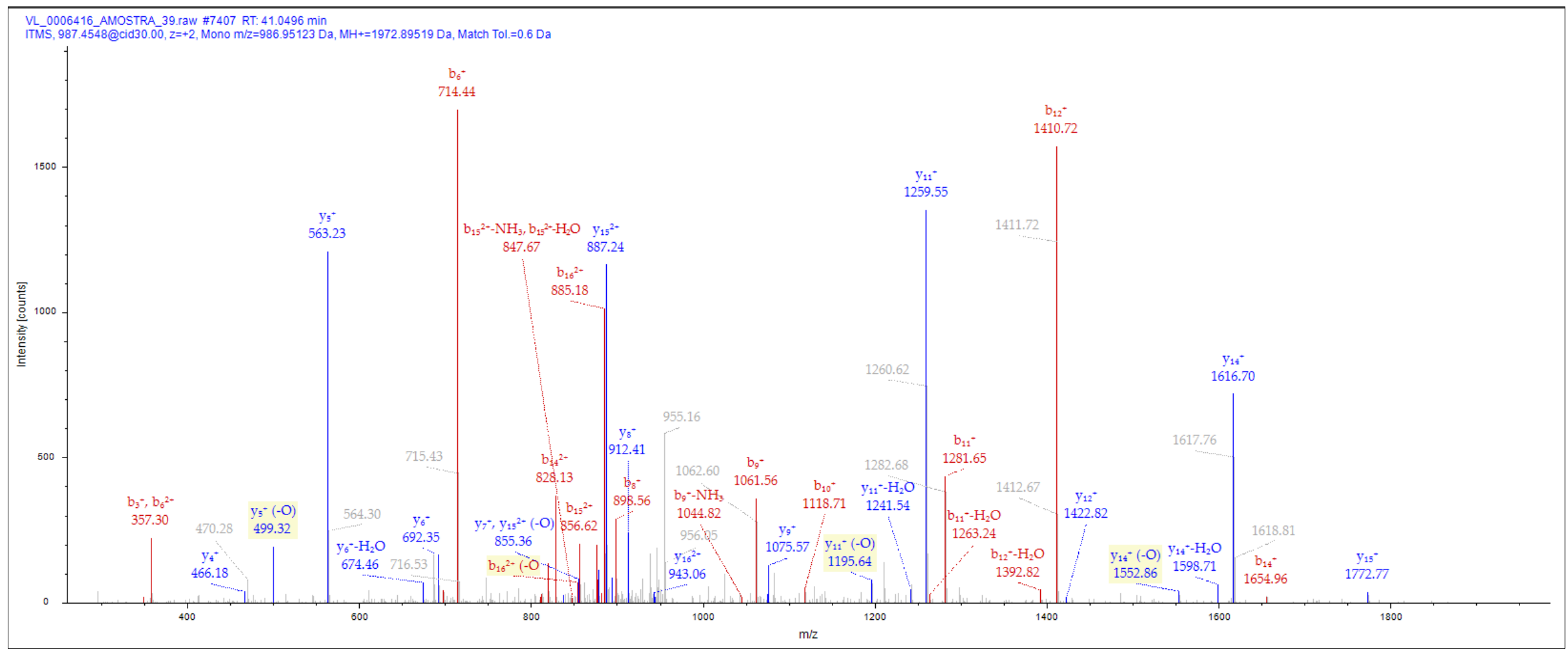


Amostras Femininas - PEP8X
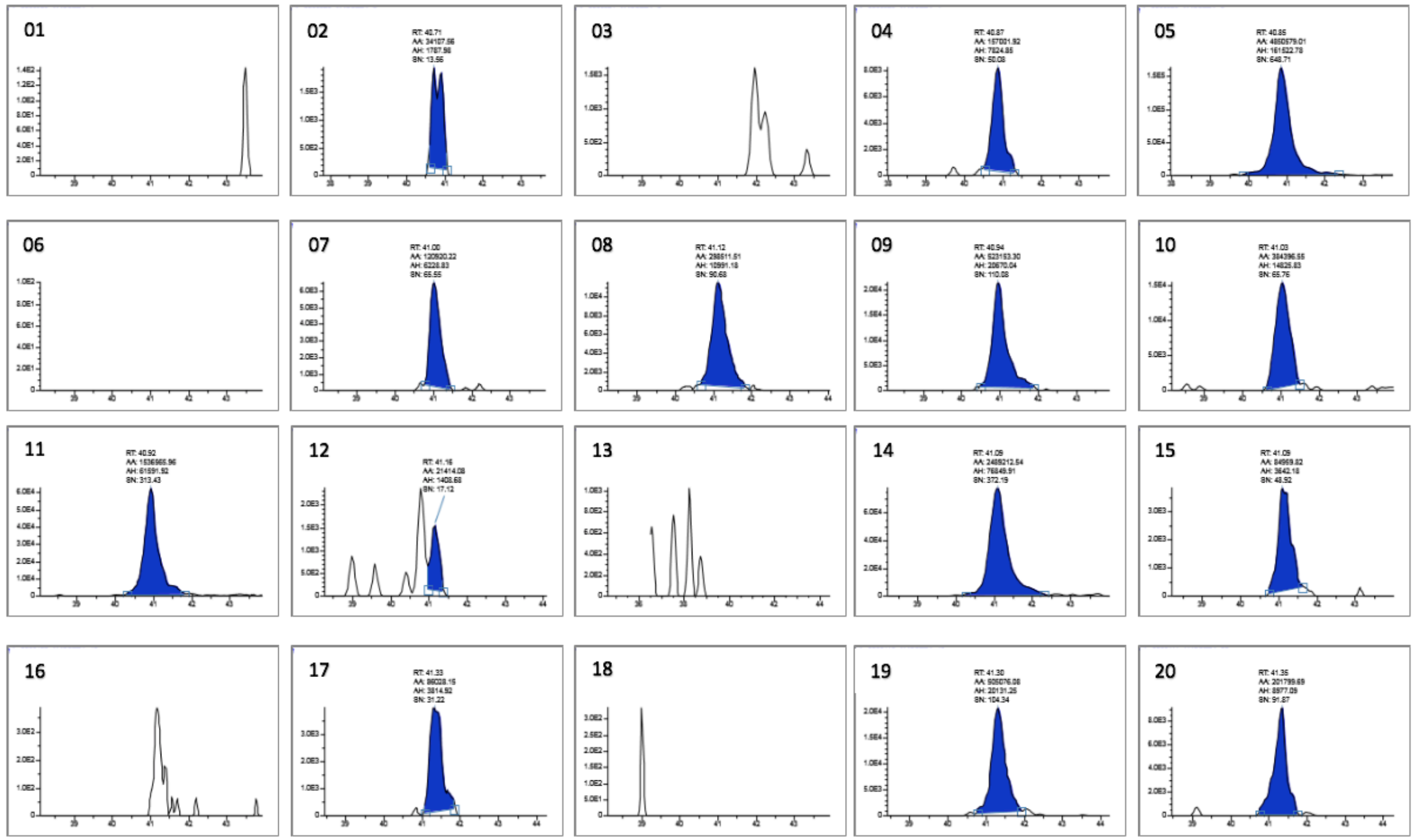
Amostras Masculinas - PEP8X
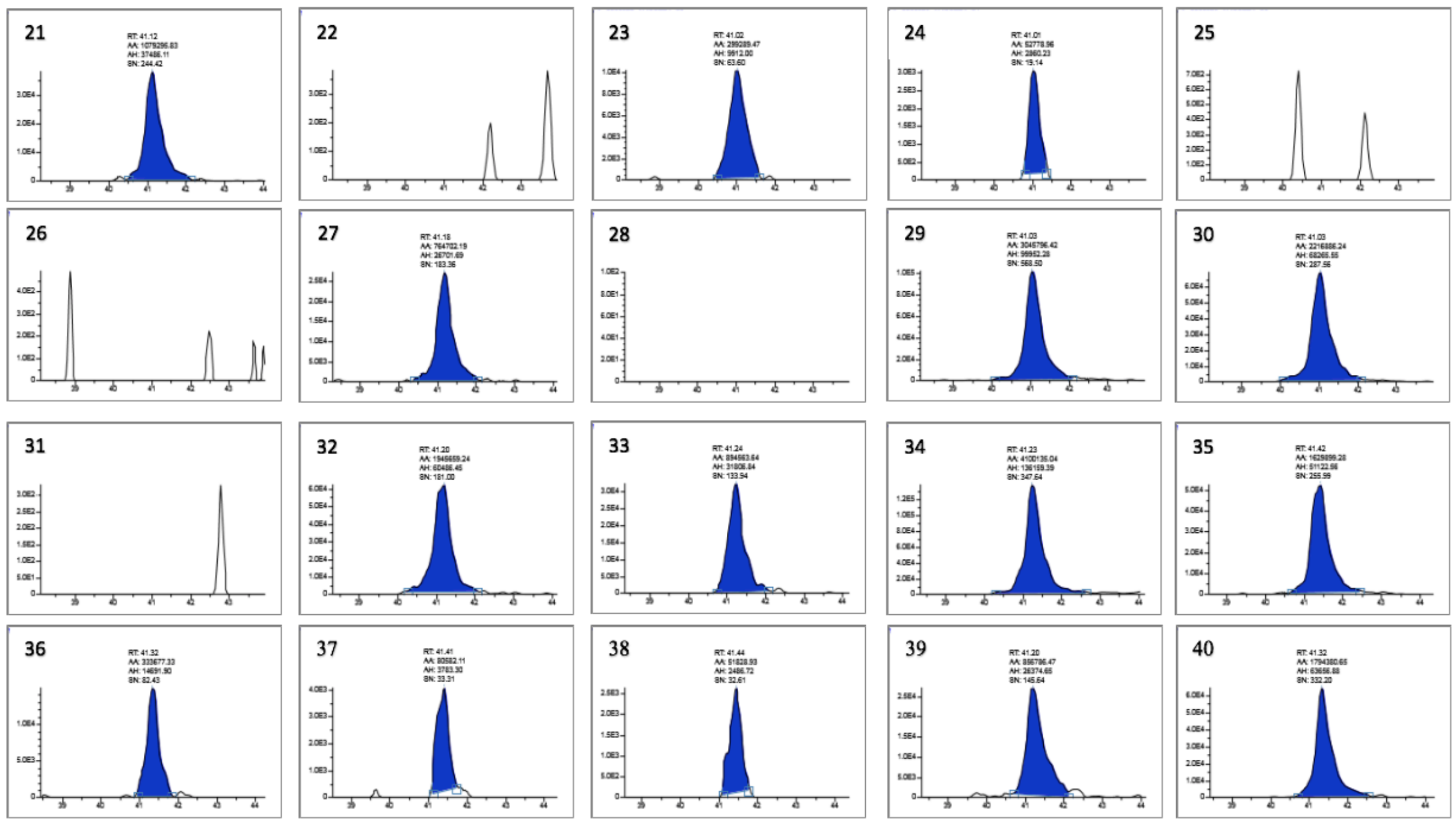
O PEP9X (Figura 24) apresenta a sequência de aminoácidos GHPGYINFSYEVLTPLK e esteve presente em 14 amostras (70\%) do grupo feminino, e em 14 amostras (70\%) do grupo masculino, detectado pelo espectrômetro de massas com tempo de retenção variando entre RT: 49.90 - 50.63 min, e a modificação variável observada foi fosforilação de $Y$ (tirosina). A razão m/z: 1007.98975 Da, monoisotópica, foi detectada no exemplo apresentado e as proteínas de referência encontradas no banco de dados UniProt foram: Isoform 1 of Amelogenin, $Y$ isoform OS=Homo sapiens OX=9606 GN=AMELY; e Amelogenin, $X$ isoform OS=Homo sapiens $O X=9606 \mathrm{GN}=A M E L X$. 
Figura 24. Espectro e cromatogramas do peptídeo PEP9X.

\section{PEP9X}

Sequência de aminoácidos: GHPGYINFSYEVLTPLK

Tempo de retenção (RT): 49.90 - 50.63

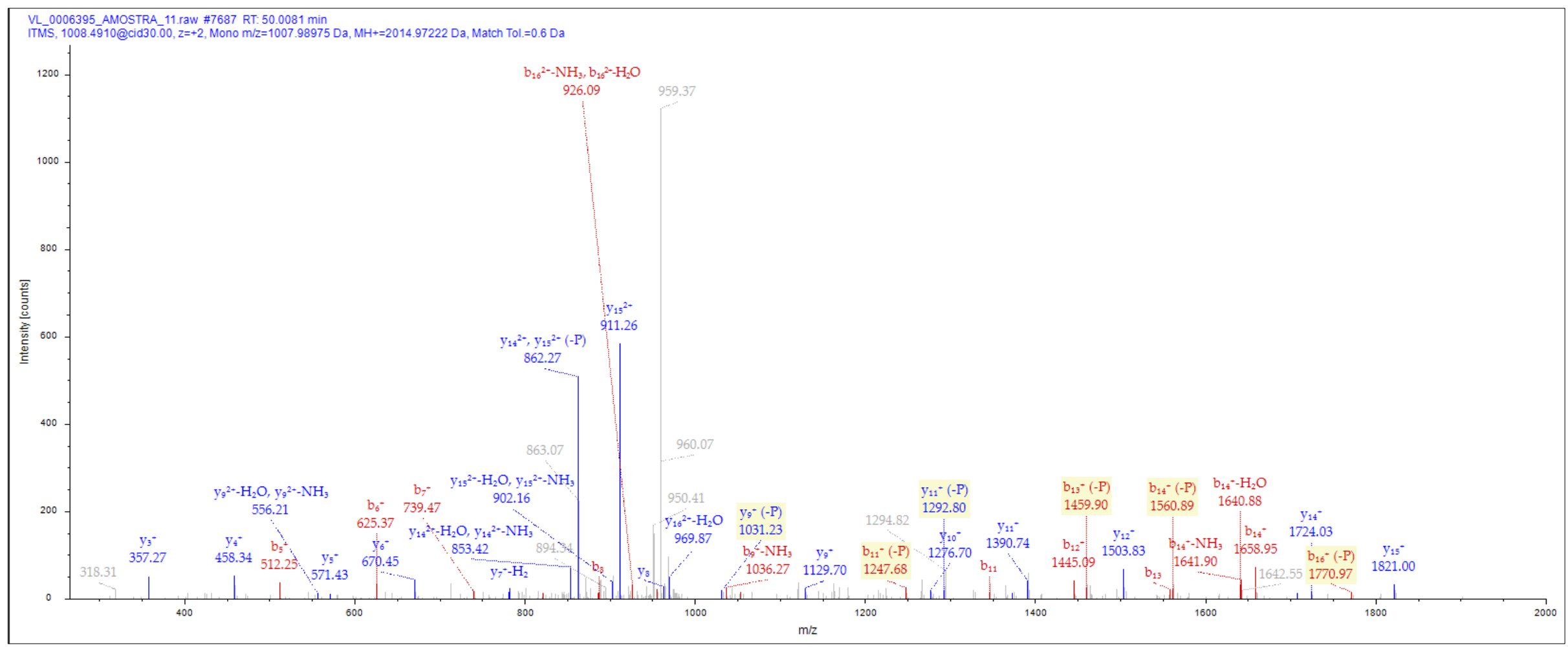


Amostras Femininas - PEP9X
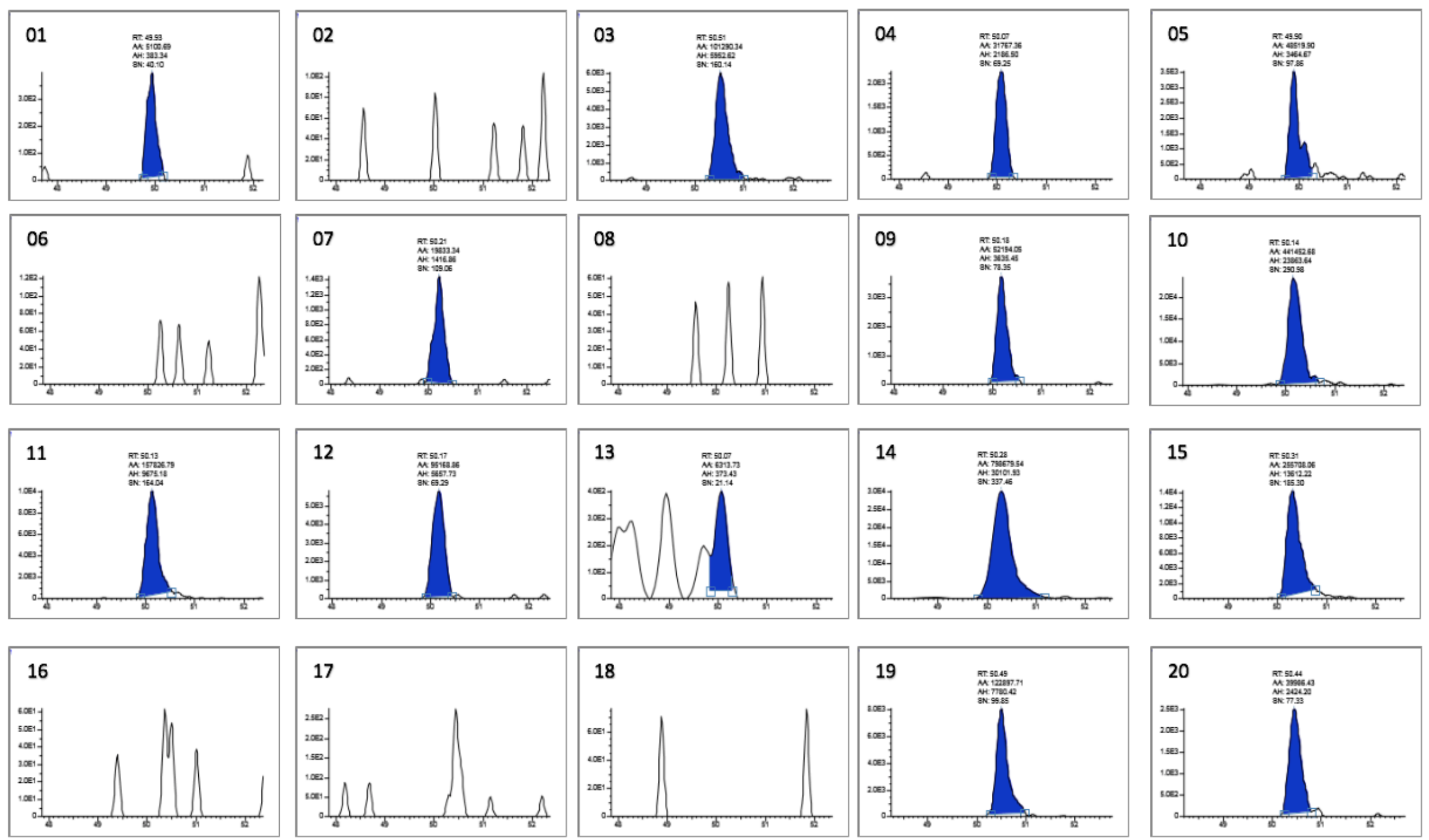
Amostras Masculinas - PEP9X
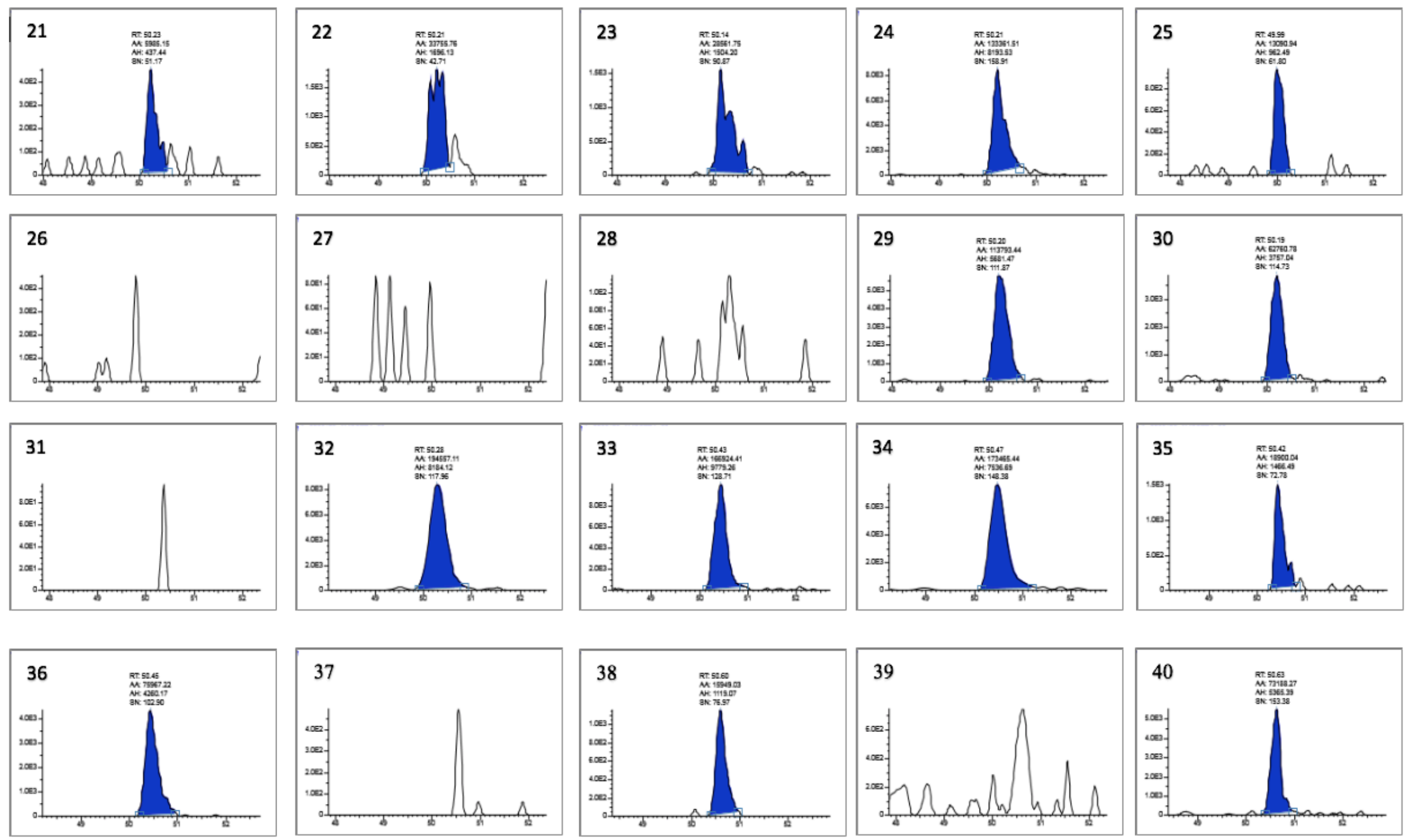
A tabela 1 a seguir resume a frequência absoluta e relativa desses peptídeos observados anteriormente nos cromatogramas, indicando a presença ou ausência, a quantidade de amostras em que foram detectados e o percentual total, tanto nas amostras masculinas quanto nas amostras femininas com $n=40$ (Tabela 1).

Tabela 1 - Frequências absoluta e relativa de cada peptídeo na amostra total $(n=40)$.

\begin{tabular}{|c|c|c|c|}
\hline Variável & Classe & Quantidade & $\%$ \\
\hline \multirow{2}{*}{ PEP1Y } & Ausente & 23 & 57,5 \\
\hline & Presente & 17 & 42,5 \\
\hline \multirow{2}{*}{ PEP2Y } & Ausente & 28 & 70 \\
\hline & Presente & 12 & 30 \\
\hline \multirow{2}{*}{ PEP3Y } & Ausente & 18 & 45 \\
\hline & Presente & 22 & 55 \\
\hline \multirow{2}{*}{ PEP4Y } & Ausente & 26 & 65 \\
\hline & Presente & 14 & 35 \\
\hline \multirow{2}{*}{ PEP1X } & Ausente & 1 & 2,5 \\
\hline & Presente & 39 & 97,5 \\
\hline \multirow{2}{*}{ PEP2X } & Ausente & 1 & 2,5 \\
\hline & Presente & 39 & 97,5 \\
\hline \multirow{2}{*}{ PEP3X } & Ausente & 2 & 5 \\
\hline & Presente & 38 & 95 \\
\hline \multirow{2}{*}{ PEP4X } & Ausente & 3 & 7,5 \\
\hline & Presente & 37 & 92,5 \\
\hline \multirow{2}{*}{ PEP5X } & Ausente & 4 & 10 \\
\hline & Presente & 36 & 90 \\
\hline \multirow{2}{*}{ PEP6X } & Ausente & 7 & 17,5 \\
\hline & Presente & 33 & 82,5 \\
\hline \multirow{2}{*}{ PEP7X } & Ausente & 9 & 22,5 \\
\hline & Presente & 31 & 77,5 \\
\hline \multirow{2}{*}{ PEP8X } & Ausente & 11 & 27,5 \\
\hline & Presente & 29 & 72,5 \\
\hline \multirow{2}{*}{ PEP9X } & Ausente & 12 & 30 \\
\hline & Presente & 28 & 70 \\
\hline
\end{tabular}

Fonte: Oliveira, L. D. B. (2019).

A tabela 02 separou por sexo a presença ou ausência de cada peptídeo encontrado, onde como classe 0 significa ausência e 1 significa a presença do peptídeo, seguido das frequências absoluta e relativa nas amostras femininas e masculinas. Os valores de $p$ indicam o resultado do Teste de associação Exato da Fisher onde quanto menor o valor de $p$, maior a evidência da não concordância da ausência ou presença da AMELY e AMELX nas amostras. Portanto, fica evidente que 
há uma baixa concordância da presença dos peptídeos da AMELY na amostra total com valores de $p$ variando entre 0,001 e 0,003, visto serem peptídeos exclusivos do sexo masculino. Já os peptídeos da AMELX, os valores de $p$ variaram entre 0,13 a 1 , sugerindo maior concordância da presença desses peptídeos na amostra total pois estes estão presentes em todas as amostras (Tabela 2).

Tabela 2 - Frequências absoluta e relativa de cada peptídeo por sexo $(n=20)$.

\begin{tabular}{|c|c|c|c|c|c|c|}
\hline \multirow{3}{*}{ Variável } & \multirow{3}{*}{ Classe } & \multicolumn{4}{|c|}{ Sexo_Real } & \multirow{3}{*}{ Valor $\mathrm{p}^{*}$} \\
\hline & & \multicolumn{2}{|c|}{ Feminino } & \multicolumn{2}{|c|}{ Masculino } & \\
\hline & & Quantidade & $\%$ & Quantidade & $\%$ & \\
\hline \multirow{2}{*}{ PEP1Y } & 0 & 20 & 100 & 3 & 15 & \multirow{2}{*}{0,001} \\
\hline & 1 & 0 & 0 & 17 & 85 & \\
\hline \multirow{2}{*}{ PEP2Y } & 0 & 19 & 95 & 9 & 45 & \multirow{2}{*}{0,002} \\
\hline & 1 & 1 & 5 & 11 & 55 & \\
\hline \multirow{2}{*}{ PEP3Y } & 0 & 17 & 85 & 1 & 5 & \multirow{2}{*}{0,001} \\
\hline & 1 & 3 & 15 & 19 & 95 & \\
\hline \multirow{2}{*}{ PEP4Y } & 0 & 18 & 90 & 8 & 40 & \multirow{2}{*}{0,003} \\
\hline & 1 & 2 & 10 & 12 & 60 & \\
\hline \multirow{2}{*}{ PEP1X } & 0 & 1 & 5 & 0 & 0 & \multirow{2}{*}{1} \\
\hline & 1 & 19 & 95 & 20 & 100 & \\
\hline \multirow{2}{*}{ PEP2X } & 0 & 1 & 5 & 0 & 0 & \multirow{2}{*}{1} \\
\hline & 1 & 19 & 95 & 20 & 100 & \\
\hline \multirow{2}{*}{ PEP3X } & 0 & 2 & 10 & 0 & 0 & \multirow{2}{*}{0,468} \\
\hline & 1 & 18 & 90 & 20 & 100 & \\
\hline \multirow{2}{*}{ PEP4X } & 0 & 3 & 15 & 0 & 0 & \multirow{2}{*}{0,23} \\
\hline & 1 & 17 & 85 & 20 & 100 & \\
\hline \multirow{2}{*}{ PEP5X } & 0 & 3 & 15 & 1 & 5 & \multirow{2}{*}{0,598} \\
\hline & 1 & 17 & 85 & 19 & 95 & \\
\hline \multirow{2}{*}{ PEP6X } & 0 & 4 & 20 & 3 & 15 & \multirow{2}{*}{1} \\
\hline & 1 & 16 & 80 & 17 & 85 & \\
\hline \multirow{2}{*}{ PEP7X } & 0 & 7 & 35 & 2 & 10 & \multirow{2}{*}{0,13} \\
\hline & 1 & 13 & 65 & 18 & 90 & \\
\hline \multirow{2}{*}{ PEP8X } & 0 & 6 & 30 & 5 & 25 & \multirow{2}{*}{1} \\
\hline & 1 & 14 & 70 & 15 & 75 & \\
\hline \multirow{2}{*}{ PEP9X } & 0 & 6 & 30 & 6 & 30 & 1 \\
\hline & 1 & 14 & 70 & 14 & 70 & 1 \\
\hline
\end{tabular}

\section{*Teste de associação Exato da Fisher}

Fonte: Oliveira, L. D. B. (2019).

A tabela 3 exibe a quantificação dos peptídeos na amostra total $(n=40)$ e por sexo $(n=20)$. São apresentados os valores mínimos e máximos, a mediana, a média, os valores interquartis e o desvio padrão, assim como o $n$ indicando o número de 
amostras em que se obteve essa quantificação. De uma forma geral da quantificação, dois pontos nos chamou bastante a atenção. O primeiro deles foi a presença dos peptídeos PEP2Y em 1 (uma) amostra do grupo feminino, do PEP3Y em 3 amostras do grupo feminino e do PEP4Y em 2 amostras do grupo feminino, visto serem peptídeos exclusivos do sexo masculino. E o segundo ponto foi a presença do PEP7X encontrado em 13 (treze) amostras femininas e 18 (dezoito) amostras masculinas, sendo identificada a proteína de referência no banco de dados UniProt como: Isoform 1 of Amelogenin, $Y$ isoform OS=Homo sapiens $O X=9606$ GN=AMELY.

Tabela 3 - Quantificação dos peptídeos na amostra total $(n=40)$ e por sexo $(n=20)$.

\begin{tabular}{|c|c|c|c|c|c|c|c|c|c|}
\hline Variável & Amostra & Mínimo & $1^{\circ}$ Quartil & Mediana & Média & $3^{\circ}$ Quartil & Máximo & Desvio Padrão & $\mathrm{n}$ \\
\hline & Geral & 5330 & 21640 & 73190 & 85040 & 141400 & 236000 & 70152,08 & 17 \\
\hline \multirow[t]{3}{*}{ PEP1YQ } & Feminino & NA & NA & NA & NA & NA & NA & NA & 0 \\
\hline & Masculino & 5330 & 21640 & 73190 & 85040 & 141400 & 236000 & 70152,08 & 17 \\
\hline & Geral & 8779 & 37210 & 87510 & 105000 & 164900 & 238300 & 85455,49 & 12 \\
\hline \multirow[t]{3}{*}{ PEP2YQ } & Feminino & 10310 & 10310 & 10310 & 10310 & 10310 & 10310 & NA & 1 \\
\hline & Masculino & 8779 & 41720 & 125300 & 113600 & 176400 & 238300 & 83990,55 & 11 \\
\hline & Geral & 10950 & 348700 & 490800 & 581100 & 749000 & 1580000 & 399188 & 22 \\
\hline \multirow[t]{3}{*}{ PEP3YQ } & Feminino & 10950 & 14180 & 17410 & 120800 & & 333900 & 184631,5 & 3 \\
\hline & Masculino & 174800 & 434600 & 608800 & 653800 & 786800 & 1580000 & 375798,4 & 19 \\
\hline & Geral & 5627 & 21170 & 130 & 58030 & & 159900 & 53378,75 & 14 \\
\hline \multirow[t]{3}{*}{ PEP4YQ } & Feminino & 6902 & 14090 & 21280 & 21280 & 28470 & 35660 & 20331,88 & 2 \\
\hline & Masculino & 5627 & 21290 & 49490 & 64160 & 100400 & 159900 & 55165,51 & 12 \\
\hline & Geral & 19510 & 2623000 & 5457000 & 7285000 & 11370000 & 22420000 & 5816854 & 39 \\
\hline \multirow[t]{3}{*}{ PEP1XQ } & Feminino & 19510 & 2258000 & 4723000 & 6024000 & 8709000 & 15720000 & 5064618 & 19 \\
\hline & Masculino & 289600 & 3733000 & 7074000 & 8483000 & 12100000 & 22420000 & 6345874 & 20 \\
\hline & Geral & 487400 & 2086000 & 4112000 & 4743000 & 6082000 & 13540000 & 3219251 & 39 \\
\hline \multirow[t]{3}{*}{ PEP2XQ } & Feminino & 618600 & 3081000 & 4856000 & 4409000 & 5392000 & 85270 & 69587 & 19 \\
\hline & Mascl & 487400 & 1829 & 342 & 5060000 & 000 & 13540 & 6360 & 20 \\
\hline & Geral & 12430 & 220400 & 912200 & 1733000 & 1992000 & 16730000 & 2858428 & 38 \\
\hline \multirow[t]{3}{*}{ PEP3XQ } & Feminino & 39090 & 152700 & 367000 & 1666000 & 1501000 & 16730000 & 3869561 & 18 \\
\hline & Masculino & 12430 & 666100 & 1696000 & 1794000 & 2293000 & 6029000 & 1582926 & 20 \\
\hline & Geral & 8185 & 257500 & 531000 & 821500 & 851400 & 7360000 & 1258135 & 37 \\
\hline \multirow[t]{3}{*}{ PEP4XQ } & Feminino & 59050 & 246100 & 322500 & 830300 & 734200 & 7360000 & 1706407 & 17 \\
\hline & Masculino & 8185 & 279600 & 763800 & 814000 & 977700 & 2535000 & 739591,9 & 20 \\
\hline & Geral & 10250 & & & 293000 & & 1462000 & 304979,7 & 36 \\
\hline \multirow[t]{3}{*}{ PEP5XQ } & Feminino & 10250 & $65 \varepsilon$ & 127 & 278100 & & 1462000 & 47237 & 17 \\
\hline & Masculino & 42120 & 104 & & 306300 & & 941 & 0712 & 19 \\
\hline & Geral & 7231 & 47070 & 117000 & 290900 & 311300 & 2875000 & 524238,6 & 33 \\
\hline \multirow[t]{3}{*}{ PEP6XQ } & Feminino & 9275 & 36450 & 70020 & 295400 & 259500 & 2875000 & 697910,4 & 16 \\
\hline & Masculino & 7231 & 103100 & 157300 & 286700 & 393500 & 1025000 & 304920,7 & 17 \\
\hline & Geral & 6023 & 22990 & 127400 & 241300 & 412400 & 812000 & 244179,3 & 31 \\
\hline \multirow[t]{3}{*}{ PEP7XQ } & Feminino & 7127 & 7633 & 22570 & 97960 & 84190 & 739300 & 199516 & 13 \\
\hline & Masculino & 6023 & 150900 & 305800 & 344800 & 479800 & 812000 & 223773,5 & 18 \\
\hline & Geral & 21410 & 120900 & 505100 & 1050000 & 1630000 & 4851000 & 1269943 & 29 \\
\hline \multirow[t]{3}{*}{ PEP8XQ } & Feminino & 21410 & 94750 & 250200 & 806700 & 518600 & 4851000 & 1354100 & 14 \\
\hline & Masculino & 51830 & 316500 & 894600 & 1276000 & 1870000 & 4100000 & 1186916 & 15 \\
\hline & Geral & 5101 & 26380 & 67970 & 117400 & 139500 & 798700 & 163768,4 & 28 \\
\hline \multirow[t]{2}{*}{ PEP9XQ } & Feminino & 5101 & 33820 & 73680 & 155500 & 149100 & 798700 & 219648,2 & 14 \\
\hline & Masculino & 5985 & 21320 & 67970 & 79300 & 128500 & 194600 & 65827,67 & 14 \\
\hline
\end{tabular}

Fonte: Oliveira, L. D. B. (2019). 
O box plot a seguir descreve a distribuição da quantificação de cada peptídeo AMELY nas amostras masculinas (Figura 25), destacando o PEP3Y como o peptídeo encontrado em maior quantidade nas amostras e grande homogeneidade. Não foi possível fazer um gráfico de distribuição dos peptídeos AMELY nas amostras femininas devido a presença desses peptídeos ser inferior a quantidade necessária de observações para construir um box plot. Foram observados dois valores acima da mediana, porém valores atípicos foram desprezados, levando em consideração apenas a mediana.

Figura 25. Quantificação dos peptídeos AMELY nas amostras masculinas.

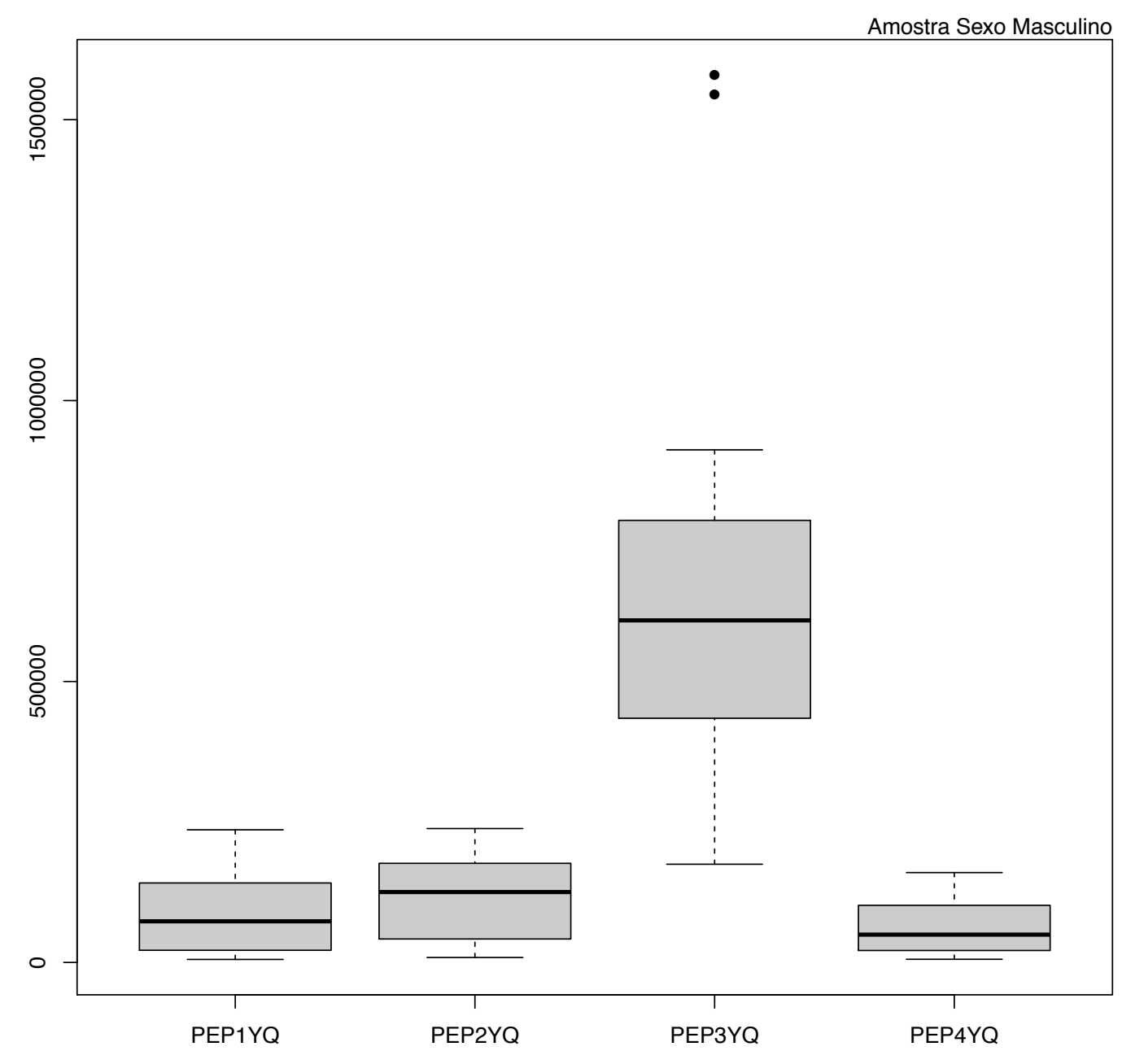

Fonte: Oliveira, L. D. B. (2019).

O box plot apresentado na figura 26 , representa a distribuição da quantificação de cada peptídeo AMELX nas amostras femininas, destacando os PEP1X e o PEP2X 
como expressos em maior quantidade além de uma maior desigualdade na distribuição dos peptídeos apresentando diversos valores atípicos (Figura 26).

Figura 26. Quantificação dos peptídeos AMELX nas amostras femininas.

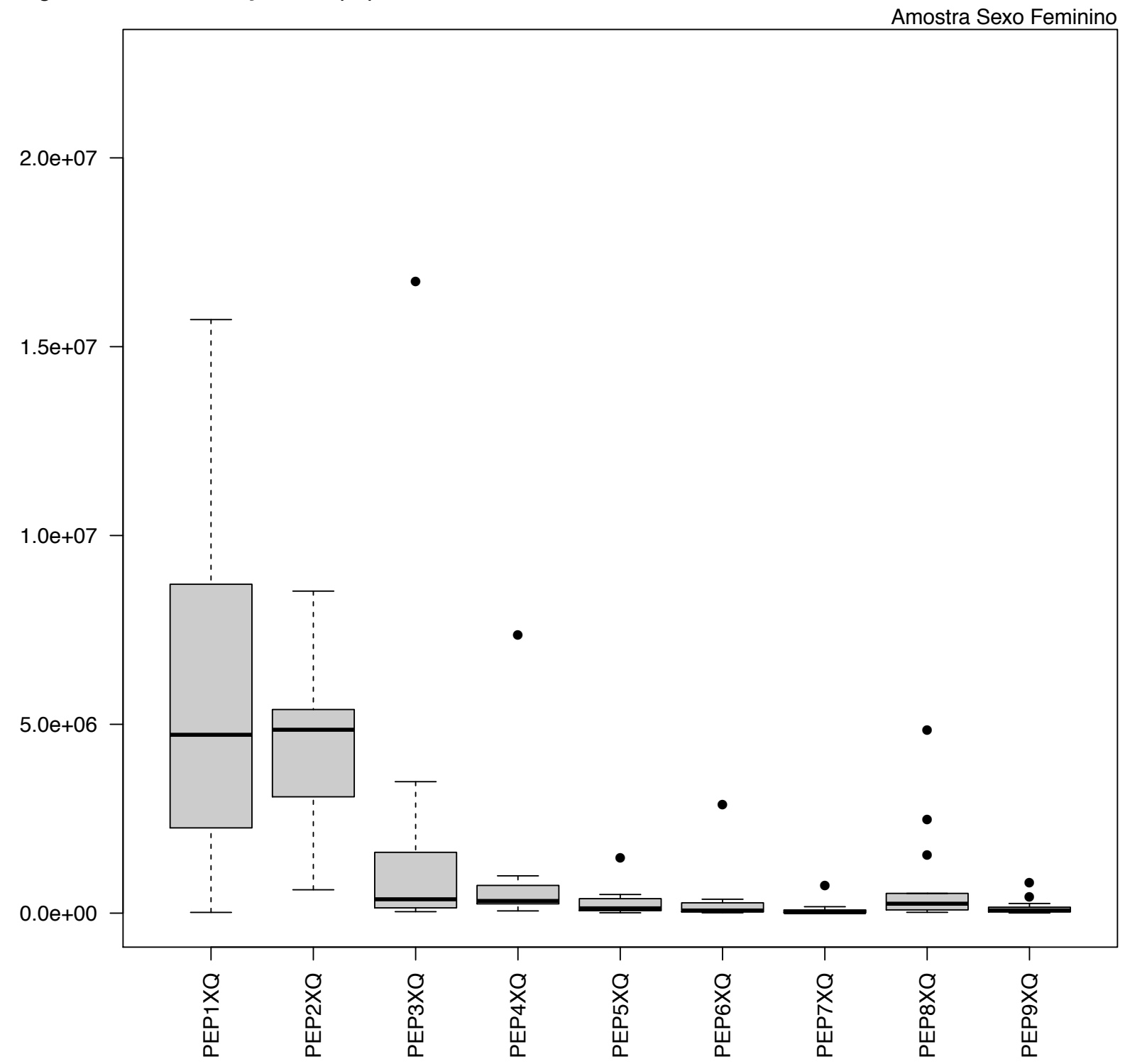

Fonte: Oliveira, L. D. B. (2019).

O box plot a seguir (Figura 27) representa a distribuição da quantificação de cada peptídeo AMELX nas amostras masculinas, destacando-se que os PEP1X e o PEP2X também foram expressos em maior quantidade, e também demonstraram que os valores encontrados foram acima dos observados nas amostras femininas, sugerindo serem expressos em maior quantidade no sexo masculino. Foi também observado que as amostras masculinas apresentaram uma menor quantidade de valores atípicos, sugerindo serem mais iguais em sua distribuição. 
Figura 27. Quantificação dos peptídeos AMELX nas amostras masculinas.

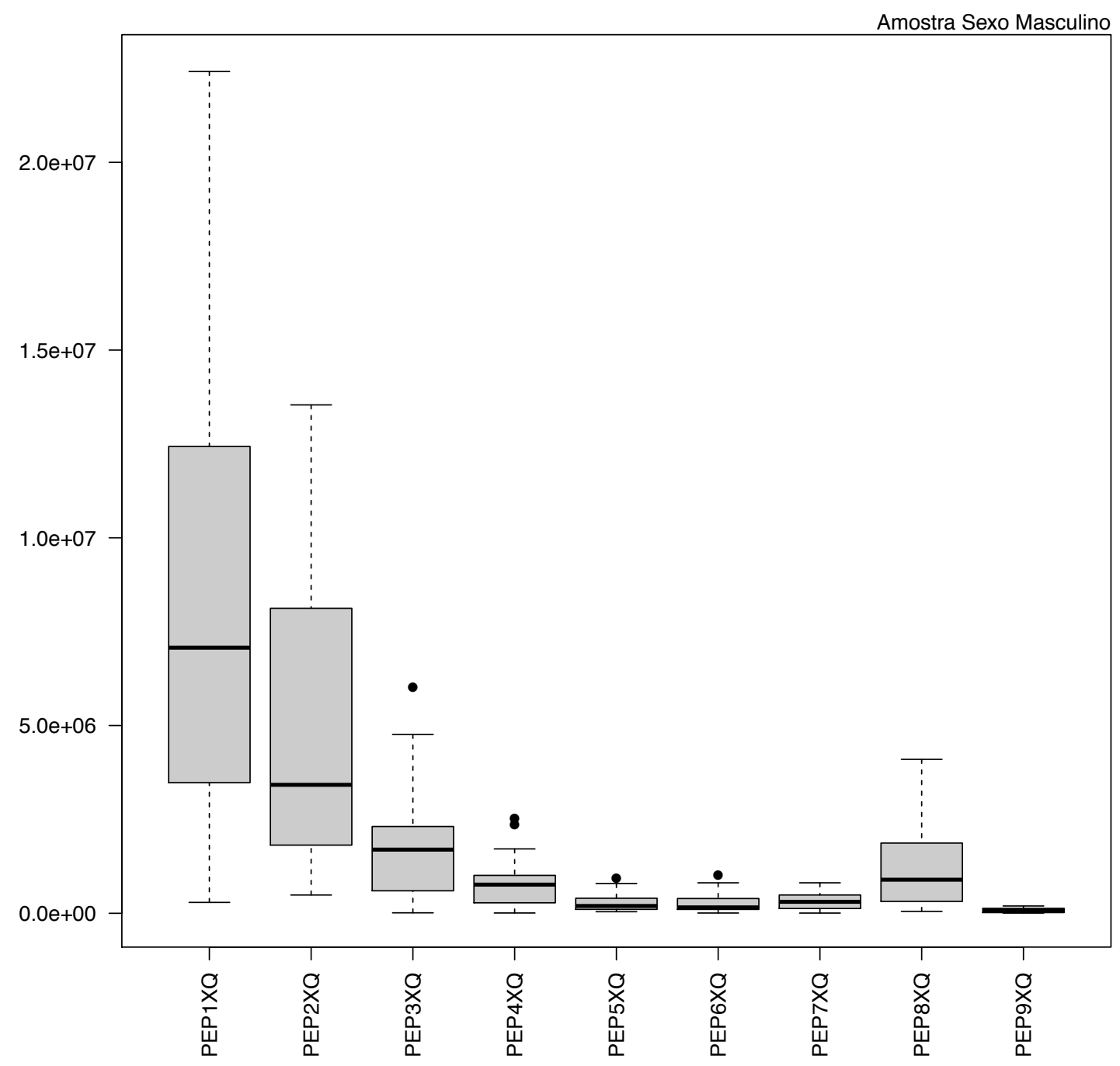

Fonte: Oliveira, L. D. B. (2019).

A tabela 4 apresenta um resumo dos dados obtidos após realizado o confronto do sexo real e o sexo estimado através da análise por cromatografia líquida e espectrometria de massas LC-MS/MS, evidenciando que das 20 amostras do grupo feminino analisado houve concordância em todas elas entre os sexos real e o estimado, enquanto que nas 20 amostras masculinas analisadas, houve concordância em 19 amostras entre os sexos real e o estimado (Tabela 4).

Tabela 4 - Concordância entre o sexo real e o sexo estimado por LC-MS/MS

\begin{tabular}{ccc}
\hline \multirow{2}{*}{ Sexo_Real } & \multicolumn{2}{c}{ Sexo_Estimado } \\
\cline { 2 - 3 } & Feminino & Masculino \\
\hline Feminino & 15 & 5 \\
Masculino & 1 & 19 \\
\hline
\end{tabular}

Fonte: Oliveira (2019). 
Díscussão 


\section{DISCUSSÃO}

Estudos realizados anteriormente demonstraram que peptídeos originados do esmalte, extraídos por meio de ataque ácido da coroa dental podem ser identificados através da cromatografia líquida acoplada à espectrometria de massas (PARKER et al., 2019; STEWART et al., 2016, 2017). Tais peptídeos identificados são originados dos cromossomos sexuais, o que os torna úteis para a estimativa do sexo de indivíduos.

A presente pesquisa demonstrou a possibilidade de análise de peptídeos do esmalte dental para a estimativa de sexo em esqueletos subadultos, especificamente em crianças entre 6 e 8 anos de vida. O motivo da seleção dessa população específica é devido ao fato de que a estimativa de sexo por métodos antropológicos tem sido realizada com relativa acurácia variando entre 70 e 95\% em esqueletos adultos (CAPITANEANU; WILLEMS; THEVISSEN, 2017; CHRISTENSEN; PASSALACQUA, 2018; KLALES, 2016; PHENICE, 1969) e 54 a $88 \%$ em esqueletos subadultos (CAPITANEANU; WILLEMS; THEVISSEN, 2017; LUNA; ARANDA; SANTOS, 2017; OLIVARES; AGUILERA, 2016; SCHEUER, 2002), o que depende de fatores como a preservação do esqueleto, o grau do dimorfismo sexual influenciado por hormônios e metabolismo, a idade, fatores ambientais e a variação populacional (BIANCHI, 2007; BONJOUR et al., 2012; CHRISTENSEN; PASSALACQUA, 2018; LOTH; HENNEBERG, 2001; LUNA; ARANDA; SANTOS, 2017; MANIFOLD, 2014; OLIVARES; AGUILERA, 2016; PILLI et al., 2018; STEWART et al., 2017; UBELAKER; DEGAGLIA, 2017). Sendo assim, diante dos obstáculos enfrentados pela antropologia forense em esqueletos de crianças, viu-se uma importante aplicação e necessidade de pesquisas na área.

O desenvolvimento do esmalte, chamado de amelogênese, pode ser dividido em quatro estágios definidos: pré-secretório, secretório, de transição e maturação (BARTLETT, 2013). Os estágios são definidos dependendo da morfologia e função dos ameloblastos, células formados do esmalte dental.

$\mathrm{Na}$ fase secretória, os ameloblastos alongam-se em células colunares altas e formam os processos de Tomes em suas extremidades apicais mais próximas do esmalte em formação onde proteínas da matriz de esmalte são secretadas. Os ameloblastos secretam 4 diferentes proteínas na matriz de esmalte (BARTLETT, 2013). As três proteínas estruturais são amelogenina, ameloblastina e enamelina, e 
foram detectadas e identificadas pela análise por cromatografia líquida e pela espectrometria de massas como as proteínas mais abundantes encontradas nas amostras.

Além das proteínas estruturais, também são secretadas classes de proteinases com função essencial para o resultado deste estudo. Pesquisas iniciais sugeriram que, à medida que o esmalte dental em formação passa pelo estágio secretório e entra no estágio de maturação do desenvolvimento, as proteinases sofrem uma alteração no seu perfil enzimático, onde a metaloproteinase 20 (MMP-20) esteve presente durante o estágio secretório até o estágio inicial de maturação, e a calicreína 4 (KLK4) foi expressa na transição do estágio de maturação do desenvolvimento do esmalte (BARTLETT, 2013; NAGANO et al., 2009). Até o momento, essas são as únicas duas proteinases conhecidas secretadas na matriz do esmalte.

Para o contexto desta pesquisa, o fato dessas proteases atuarem no interior do esmalte dental durante a fase de maturação, a maioria das proteínas são processadas por elas, metaloproteinase 20 (MMP-20) e calicreína 4 (KLK4) (BARTLETT, 2013), resultando em peptídeos de vários comprimentos, os quais permanecem no interior do esmalte maduro (STEWART et al., 2016; PORTO et al., 2011). Graças à evolução das técnicas de fragmentação e detecção de proteínas e peptídeos, foi possível obter dados de grande relevância das amostras através da cromatografia líquida e da espectrometria de massas.

Sabe-se que a amelogenina, abundantemente expressa pelos ameloblastos durante o desenvolvimento dentário, é originada do gene do cromossomo sexual. Os cromossomos $\mathrm{X}$ e $\mathrm{Y}$ humanos compartilham significativa similaridade de sequência, provavelmente devido à sua origem revolucionária, a partir de um par de cromossomos homólogos ancestrais comuns (SALIDO et al., 1992). Salido et al. (1992) caracterizou os genes AMELY e AMELX nos braços curtos dos cromossomos $Y$ e $X$ humanos que codificam as amelogeninas. $O$ fato desta informação estar relacionada ao cromossomo sexual a torna confiável, visto não se alterar ao longo da vida, trazendo segurança para o método mesmo diante de influências externas, ambientais ou fatores relacionados a uma variação populacional.

Diante de tais descobertas acerca da ação das proteases e da possibilidade de extração de proteínas e peptídeos em busca do sexo de um indivíduo no esmalte dental, foi utilizada a metodologia de ataque ácido para a extração de peptídeos do esmalte dental desenvolvida e sugerida por Stewart et al. 2016 e aplicada em 40 
amostras de dentes decíduos de igual quantidade para cada sexo, $n=20$. Conforme sugestão de Olivares (2016), a distribuição amostral de meninos e meninas de um indicador específico deve ser igual para se calcular de forma a mostrar a probabilidade de ser feminina ou masculina determinada amostra.

O ataque ácido foi realizado na porção de interesse da coroa dental utilizando apenas uma pequena área do esmalte, evitando a contaminação com o colágeno da dentina (PORTO et al. 2011; STEWART et al., 2016; STEWART et al., 2017). A concentração do $\mathrm{HCl}$ utilizado a $10 \%$ indicou que a técnica de condicionamento superficial do esmalte testada foi satisfatória na geração de amostras adequadas para análises de MS, conforme Stewart et al. 2016 e 2017.

$\mathrm{O}$ fato da amelogenina se encontrar fragmentada no interior do esmalte dental pelas proteases MMP-20 e KLK4 do esmalte, excluiu-se a necessidade do uso de enzimas para a digestão da amostra. Essas duas enzimas são fundamentais na formação do esmalte dental, pois mutações pontuais que alteram a sequência de aminoácidos da amelogenina humana causam amelogênese imperfeita ( $\mathrm{Al})$ e também alteram a suscetibilidade da proteína à proteólise (BARTLETT, 2013; BARTLETT et al., 2006; SALIDO et al., 1992). As formas de fragmentação dominantes dependem da técnica de ionização aplicada, que neste estudo foi realizada por ESI, dependem do analisador de massas, no caso presente, foi utilizados o Orbitrap Velos e da estrutura peptídica da AMELY e AMELX.

Os padrões de fragmentação da sequência dimórfica exibidos aqui foram muito semelhantes às pesquisas apresentadas previamente (NAGANO et al., 2009; PARKER et al., 2019; PORTO et al., 2011b, 2011a; STEWART et al., 2016b, 2017), na AMELY foram observadas clivagens nos pontos após G (glicina), M (metionina), Q (glutamina), S (serina) e W (triptofano), e na AMELX foram observadas clivagens após A (alanina), F (fenilalanina), G (glicina), K (lisina), M (metionina), P (prolina), Q (glutamina), R (arginina), S (serina), W (triptofano) e $\mathrm{Y}$ (tirosina). Porém, no presente estudo não foram observadas clivagens em $\mathrm{H}$ (histidina) conforme relatado por Nagano et al. (2009) ao isolar e identificar os padrões de fragmentação pelas MMP20 e KLK4 da amelogenina em dentes de suínos, observou que a MMP-20 é expressa no início da formação do esmalte, é a única atividade proteolítica significativa no espaço extracelular durante o estágio secretório, enquanto a KLK4 não é expressa até os estágios de transição e maturação. 
Essas enzimas processam as amelogeninas em um grupo de produtos gerados pelas clivagens, ou seja, peptídeos de tamanhos variados, que acumulam e são degradados apenas lentamente pela MMP-20. Os peptídeos de amelogenina ricos em tirosina $(Y)$ e leucina $(L)$ se acumulam pois a MMP-20 tem pouca atividade para fragmentá-los. Nos resultados desta pesquisa, em concordância, não foram observadas fragmentações após $L$ (leucina), porém houve fragmentação após tirosina (Y) antecedendo o PEP1X. A KLK4 não pode ser ativa durante o estágio secretório, pois impediria seu acúmulo e não contribui para o processamento da amelogenina, mas dedica-se à sua degradação durante os estágios de transição e maturação (NAGANO et al., 2009). Mais estudos devem ser realizados para um maior entendimento dos padrões específicos de fragmentação dessas proteases durante os estágios secretórios e de maturação do esmalte de dentes decíduos pois foram observadas, apesar de exibirem semelhanças no padrão, algumas fragmentações em pontos distintos.

A sequência de amelogenina no cromossomo $Y$ foi transcrita, embora em um nível muito inferior ao de seu homólogo $X$, os transcritos $Y$ representam $10 \%$ do total de transcritos de amelogenina, independentemente da comparação entre os fragmentos. Embora a similaridade geral da sequência entre os cDNAs AMELY e AMELX seja de $91 \%$, ela varia significativamente entre as regiões codificantes e não codificantes (SALIDO et al., 1992). A semelhança entre o gene da AMELY e o gene da AMELX sugere que os transcritos da amelogenina sofrem splicing alternativo (BARTLETT, 2013; NAGANO et al., 2009), onde as proteínas traduzidas do RNAm que sofreram o splicing alternativo serão diferentes quanto às suas sequencias de aminoácidos e em certos casos até mesmo quanto às suas funções biológicas, apresentando substituições nas sequências dos aminoácidos em pontos específicos, o que gera isoformas de amelogeninas diferentes (BARTLETT, 2013; NAKAYAMA et al., 2018). Nos trabalhos de Salido et al. (1992), os RNAs masculino e feminino deram os mesmos produtos de PCR quando os iniciadores específicos para $X$ foram utilizados, enquanto que na amplificação por PCR do mRNA masculino usando os primers específicos de $\mathrm{Y}$ produziu um fragmento que estava ausente quando os primers específicos de $\mathrm{X}$ foram utilizados.

$\mathrm{Na}$ presente estudo, a identificação dos peptídeos pelo Tracefinder $^{\mathrm{TM}}$, foi realizada contra o banco de dados UniProt (Proteome ID UP000005640, Taxonomia 9606 - Homo Sapiens) que identificou isoformas da amelogenina. As isoformas da 
amelogenina encontradas na aqui foram a isoforma 1 da AMELY (Q99218-1) com 192 aminoácidos, e as isoformas 1 (Q99217-1) com 191 aminoácidos e 3 da AMELX (Q99217-3) com 205 aminoácidos, e não foram observadas a isoforma 2 da AMELY e a isoforma 2 da AMELX em nenhuma das amostras analisadas.

De todo o universo de peptídeos encontrados, foram selecionadas 4 (quatro) sequências da AMELY que estavam presentes no maior número de amostras, dentre elas PEP1Y, PEP2Y, PEP3Y e PEP4Y (Quadro 3). As sequências dimórficas da AMELY nas amostras analisadas foram compostas por 9 a 24 aminoácidos. As sequências de aminoácidos indicadas pelas setas na primeira coluna possuem como proteína de referência no banco de dados UniProt a isoforma 1 da amelogenina, AMELY-1 (Q99218-1), ou seja, são peptídeos específicos desta, os quais são encontrados exclusivamente no sexo masculino, com exceção da sequência TDKTKQEEVD (PEP7X) que será discutida mais adiante.

Os peptídeos PEP2Y, PEP3Y e PEP4Y, se mostraram presentes em 3 amostras que estavam no grupo feminino, com mediana de quantificação de 10310 , 172400 e 6902 respectivamente, que representa uma quantidade abaixo quando comparados com a quantificação mediana do grupo masculino que foram 125300 , 608800 e 49490, respectivamente. A presença de um peptídeo dimórfico do sexo masculino em uma amostra feminina pode estar relacionada a problemas como: a atribuição incorreta da sequência de aminoácidos pelos algoritmos matemáticos (a partir dos espectros que estão em pequenas quantidades com sinais muito baixos). Outra possibilidade é que haja mesmo amostras trocadas (por ex. amostras de meninos que estão no grupo de meninas). As amostras usadas foram obtidas em escolas, e doadas pelos pais ou responsáveis pela criança, podendo ter sido trocadas (com amostras de outras crianças da mesma casa). Há também a possibilidade de contaminação cruzada da amostra, fato descartado ao revisar a sequência dos Vials colocados no cromatógrafo líquido pois em os grupos foi realizada a limpeza da coluna cromatográfica; ou também uma possível variação genética, metabólica ou química da criança, visto ainda não terem pesquisas de aplicação da proteômica na detecção de peptídeos relacionados a síndromes e doenças dos cromossomos $\mathrm{Y}$ e $\mathrm{X}$ (STEWART et al., 2017), além da possibilidade de co-eluição pseudoisobárica, que significa a detecção pelo aparelho de uma massa muito próxima da massa do peptídeo procurado. Os métodos que dependem de análise de dados direcionada do peptídeo fornecem informações quantitativas de praticamente qualquer íon precursor 
de peptídeo. No entanto, eles exibem alto ruído químico devido à co-eluição de peptídeos de alta e baixa abundância ao rastrear toda a faixa de massa em amostras complexas. Esse fenômeno limita a faixa dinâmica desses métodos e resulta em sinais que geralmente contêm interferências de outros íons peptídicos (BORRÀS; SABIDÓ, 2017). Porém, foi utilizado a fragmentação do tipo MS/MS onde a probabilidade de dois fragmentos peptídicos possuindo a mesma massa, derivando de dois peptídeos isobáricos diferentes, e exibindo exatamente o mesmo tempo de retenção, é baixa. Portanto, a estratégia de aquisição direcionada empregada aos íons da AMELY e AMELX é altamente específica, beneficiando de baixo ruído químico, resultando em medições de alta sensibilidade e pode detectar proteínas em amostras complexas tão baixas quanto em poucas cópias por célula para moléculas selecionadas (BORRÀS; SABIDÓ, 2017). Tais hipóteses necessitam melhores estudos para esclarecimentos dos achados nessas amostras. Entre as 20 (vinte) amostras do grupo masculino, em uma não pode ser observado nenhum peptídeo da AMELY. Nesta mesma amostra $(n=22)$, foi realizada uma repetição da análise que não alterou o resultado, comprovando a eficiência e sensibilidade da metodologia, o que nos fez levantar as mesmas hipóteses destacadas anteriormente. Nas demais amostras, os peptídeos estavam presentes e dentro da média de quantificação.

A quantificação mostrou que o peptídeo AMELY mais abundante e homogêneo nas amostras masculinas foi O PEP3Y (Figura 24) e pode-se observar que a abundância dos peptídeos AMELX nas amostras masculinas foi maior do que nas amostras femininas. Os genes AMELY e AMELX são funcionalmente únicos, pois podem representar o único par de genes $X$ ou $Y$ no qual a inativação de $X$ pode atuar no locus $X$, de modo que no sexo masculino têm mais produto genético do que no sexo feminino (SALIDO et al., 1992). Os produtos transcricionais dos loci X e $Y$ são qualitativamente e quantitativamente diferentes (SALIDO et al., 1992), o que pode justificar a expressão e quantificação diversa entre as AMELY e AMELX, apresentando valores maiores nos peptídeos AMELX nas amostras masculinas analisadas, com exceção dos PEP2XQ e PEP9XQ valores não muito discrepantes (Tabela 1). A quantificação obteve valores de certa forma suficientes para se ter um padrão, porém mais estudos são necessários para análise dessa expressão e correlacionar com a presença ou ausência nas amostras.

As sequências dimórficas da AMELX nas amostras analisadas foram compostas por 10 a 24 aminoácidos (Quadro 3). Foram listadas todas as sequências 
peptídicas encontradas, tendo como proteínas de referência no banco de dados UniProt apenas a isoforma 1 da AMELY, e as isoformas AMELX-1 e AMELX-3. Não foram observadas as isoformas 2, tanto da AMELY quanto da AMELX. Apesar do peptídeo PEP7X - TDKTKQEEVD ter sido encontrado no banco de dados UniProt como sendo a proteína de referência AMELY, ele se mostrou presente em 18 amostras masculinas (90\%) e 13 amostras femininas (65\%), fato controverso com o cadastro do banco de dados UniProt. Para sanar tal dúvida, foi analisada no programa BLAST https://blast.ncbi.nlm.nih.gov/Blast.cgi a sequência peptídica PEP7X que se mostrou presente tanto na AMELY quanto na AMELX, esta mesma sequência se mostrou presente em todas as isoformas da amelogenina, fato controverso com o cadastro do banco de dados UniProt.

Observamos também modificações fixas e variáveis dos peptídeos dos dentes decíduos, dentre elas a oxidação (M e P) e fosforilação (ST e STY) como modificações variáveis e carbamidometilação de cisteína como modificação fixa, fato sustentado por trabalhos anteriores (BARTLETT, 2013; GREEN et al., 2019; PARKER et al., 2019; STEWART et al., 2016, 2017), tanto em amostras recentes quanto em amostras arqueológicas. As modificações se não forem especificadas como possíveis durante a pesquisa no banco de dados, não serão identificadas (MEDZIHRADSZKY; CHALKLEY, 2015).

Além de peptídeos não específicos do esmalte dental como colágeno, albumina e hemoglobina, foram identificados provavelmente pelo contato com os tecidos bucais e manuseio quando da doação dos dentes decíduos para a pesquisa, dados também encontrados nos estudos de Stewart et al. 2016 e 2017. Pelo fato das análises serem muito sensíveis, qualquer tipo de contaminante será detectado, o que gera uma demora maior para a obtenção dos resultados, além de aumentar as chances de erro na corrida da amostra, destacando assim, a importância da extração dos peptídeos do esmalte em ambiente o mais limpo possível. Mesmo com a realização em capela de fluxo laminar, foram observados muitos contaminantes externos aos componentes do esmalte dental, porém estes não interferiram nos resultados.

Uma suposta forma de se diminuir o tempo e a detecção de proteínas contaminantes seria realizar as análises por espectrometria de massas em target, ou seja, a varredura dos íons peptídicos são direcionados para o que se procura, o espectrômetro de massa é programado para detectar íons peptídicos específicos derivados de proteínas de interesse, objetivando diminuir o tempo de análise e 
monitorar algumas poucas proteínas de interesse com alta sensibilidade, reprodutibilidade e precisão quantitativa (DOERR, 2013).

O uso da espectrometria de massas de precisão pode reduzir bastante o custo computacional das pesquisas no banco de dados, aproveitando as medições precisas de massa do precursor para eliminar uma proporção maior dos peptídeos dos banco de dados. A busca realizada por sequenciamento peptídico de novo é uma alternativa rápida à busca no banco de dados, embora possa produzir resultados menos precisos (FRANK et al., 2007).

Vale destacar que a técnica permitiu a preservação da coroa dental conservando-a, podendo a mesma ser empregada para novas pesquisas ou utilizadas como arquivo, fato de grande relevância na ciência forense e / ou arqueológica (PORTO et al., 2011b; STEWART et al., 2016), até mesmo para repetição da análise em casos de dúvidas. Mostrou-se também mais vantajosa diante das técnicas utilizadas hoje para a estimativa de sexo em esqueletos infantis, por sugerir ser mais resistente a influências externas ou endógenas e fatores taxonômicos, pois a informação parece estar protegida e conservada no interior do esmalte dos dentes decíduos. A técnica laboratorial é de fácil manuseio, simples e rápida. Em contextos forenses, poder ser uma alternativa diante de casos em esqueletos onde não se encontram DNA suficientes ou em boa qualidade para exames genéticos de sexagem, pois a técnica é realizada apenas no esmalte, não dependendo de matéria orgânica encontrada na polpa como o DNA.

Como todos os métodos possuem limitações, a escassez de amostras é um fator relevante para o desenvolvimento de mais pesquisas, devido a cultura do nosso país pelo apego e guarda dos dentes decíduos pelos pais, impossibilitando muitas vezes o desenvolvimento de pesquisas que precisem de mais de um dente da mesma criança, como exemplo. O alto custo do aparelho e a qualificação técnica de pessoas na área, também foram obstáculos enfrentados, visto ainda ser uma área relativamente nova, principalmente dentro da Antropologia Forense. Mais pesquisas direcionadas a públicos-alvo, com faixas etárias mais específicas e estreitas, além de aumento do número de amostras para as análises são necessárias para responder lacunas na literatura.

Vale também salientar que a metodologia descrita identifica peptídeos originários de isoformas da amelogenina ligadas ao cromossomo sexual e não foram encontradas pesquisas na literatura, utilizando a mesma técnica aqui descrita, 
aplicadas em amostras com alterações cromossômicas ou doenças relacionadas a cromossomos sexuais, como por exemplo, a hemofilia, a Síndrome de Morris (Síndrome da Insensibilidade Androgênica) ou aneuploidias 47, XXY ou 47, XYY. Em um estudo realizado por indivíduos com um cromossomo $X$ extra - por exemplo, indivíduos como 47, XXX mulheres e 47, XXY homens - apresentaram esmalte mais espesso do que homens e mulheres normais, sugerindo que o cromossomo $X$ extra pode ser ativo em amelogênese (ALVESALO; TAMMISALO; THERMAN, 1987).

Embora os genes no cromossomo $X$ humano influenciem a morfologia da coroa dental, pouco se sabe sobre os sistemas de ativação ou inativação do cromossomo $X$ relevantes para as variações morfológicas. Investigações anteriores indicaram que a aberração do cromossomo $X$ tem um impacto significativo na coroa dentária e na morfologia radicular em mulheres. Nakayama et al. (2018) avaliou as relações entre o tamanho da coroa dental e as características morfológicas da coroa em mulheres com Síndrome de Turner, cujas variantes incluem ausência completa de um cromossomo $X$, falta do braço curto ou duplicação dos braços longos, e em seguida, avaliou o processo de inativação unilateral do cromossomo $X$ durante o desenvolvimento da coroa dental. Os cariótipos da Síndrome de Turner variaram no número de regiões ativas em seus braços curtos e longos do cromossomo $X$, que regulam 0 desenvolvimento do germe dentário no estágio inicial da odontogênese humana (NAKAYAMA et al., 2018). A identificação e quantificação dos peptídeos nesses casos específicos, pode auxiliar em estudos futuros e justificar uma investigação mais aprofundada.

Os peptídeos encontrados neste estudo mostraram-se semelhantes aos obtidos no estudo de Stewart et al. 2016 e 2017 e Parker et al. (2019). Os resultados demonstraram que foi possível obter material proteico suficiente para uso em MS e MS / MS, produzindo sinais muito bons de peptídeos da amelogenina em dentes decíduos. Além da capacidade de estimar o sexo de crianças no contexto forense, a pesquisa também indica a possibilidade de se ter importantes informações dos primeiros estágios do desenvolvimento infantil (ainda intra-útero e primeiros meses de vida) na forma de moléculas biológicas. Isso poderá mudar as abordagens atuais de estudos nas áreas de pediatria, endocrinologia e ginecologia infantil, em diagnóstico clínico com repercussões subsequentes no crescimento, desenvolvimento, fertilidade e epidemiologia. 
Conclusão 


\section{CONCLUSÃO}

Concluiu-se que o método aplicado através da análise por nLC-MS/MS dos peptídeos dimórficos da amelogenina presentes em dentes decíduos podem ser utilizados de forma segura para a estimativa do sexo biológico em esqueletos de crianças entre 6 e 8 anos de idade na prática forense. Pela cromatografia líquida e espectrometria de massas foi possível identificar nos dentes decíduos analisados, peptídeos relacionados as isoformas da amelogenina, AMELY e AMELX, com concordância entre os sexos real e o sexo estimado das crianças em 19 amostras masculinas e 15 amostras femininas, além da rapidez de coleta e preparo das amostras, o método é não destrutivo o que possibilita o seu armazenamento para outras análises, revelando um futuro promissor para as Ciências Forenses em especial, a Antropologia Forense em esqueletos subadultos. Esta aplicação tornará a estimativa do sexo de crianças uma atividade auxiliar, confiável e rotineira na antropologia forense para casos de identificação humana onde se é necessário traçar o perfil biológico de restos mortais infantis sobressaindo de forma confiável e vantajosa às metodologias morfométricas antropológicas aplicadas nos dias atuais. 


\section{Referências}




\section{REFERÊNCIAS}

ALVESALO, L.; TAMMISALO, E.; THERMAN, E. 47,XXX females, sex chromosomes, and tooth crown structure. Human Genetics, 1987.

ANDERUNG, C. et al. Fishing for ancient DNA. Forensic Science International: Genetics, v. 2, p. 105-107, 2008.

BANSAL, A. K. et al. Amelogenin: A novel protein with diverse applications in genetic and molecular profiling. Journal of Oral and Maxillofacial Pathology, 2012.

BARTLETT, J. D. et al. Protein-Protein Interactions of the Developing Enamel Matrix. Current Topics in Developmental Biology, v. 74, n. 06, p. 57-115, 2006.

BARTLETT, J. D. Dental Enamel Development: Proteinases and Their Enamel Matrix Substrates. ISRN Dentistry, 2013.

BIANCHI, M. L. Osteoporosis in children and adolescentsBone, 2007.

BLACK, T. K. Sexual dimorphism in the tooth-crown diameters of the deciduous teeth. American Journal of Physical Anthropology, 1978.

BONJOUR, J. P. et al. Peak Bone Mass and its Regulation. In: Pediatric Bone. [s.l: s.n.]. p. $189-221$.

BORRÀS, E.; SABIDÓ, E. What is targeted proteomics? A concise revision of targeted acquisition and targeted data analysis in mass spectrometry. Proteomics, 2017.

CANCER, G. et al. Fragmentation pathways of protonated peptides. Mass Spectrometry Reviews, v. 24, p. 508-548, 2005.

CAPITANEANU, C.; WILLEMS, G.; THEVISSEN, P. A systematic review of odontological sex estimation methods. The Journal of forensic odontostomatology, v. 2, n. 35, p. 1-19, 2017.

CAPPELLINI, E.; COLLINS, M. J.; GILBERT, M. T. P. Unlocking ancient protein palimpsestsScience, 2014.

CARDOSO, H. F. V. Sample-specific (universal) metric approaches for determining the sex of immature human skeletal remains using permanent tooth dimensions. Journal of Archaeological Science, 2008.

CARDOSO, H. F. V. Testing discriminant functions for sex determination from deciduous teeth. Journal of Forensic Sciences, 2010.

CATTANEO, C. Forensic anthropology: developments of a classical discipline in the new millennium. Forensic Science International, 2007. 
CHRISTENSEN, A. M.; PASSALACQUA, N. V. Sex Estimation. In: A Laboratory Manual for Forensic Anthropology. [s.I.] 2018, 2018. p. 113-126.

COTTRELL, J. S. Protein identification using MS / MS data. Journal of Proteomics, v. 74, n. 6, p. 1842-1851, 2011.

DARMAWAN, M. F. et al. Comparison on three classification techniques for sex estimation from the bone length of Asian children below 19 years old: An analysis using different group of ages. Forensic Science International, 2015.

DE VITO, C.; SAUNDERS, S. R. A Discriminant Function Analysis of Deciduous Teeth to Determine Sex. Journal of Forensic Sciences, 1990.

DEMARCHI, B. et al. Protein sequences bound to mineral surfaces persist into deep time. eLife, 2016.

DOERR, A. Mass spectrometry-based targeted proteomicsNature Methods, 2013.

DUTTA, P. et al. Amelogenin gene - The pioneer in gender determination from forensic dental samples. Journal of Clinical and Diagnostic Research, v. 11, n. 2, p. ZC56-ZC59, 2017.

FRANK, A. M. et al. De novo peptide sequencing and identification with precision mass spectrometry. Journal of Proteome Research, 2007.

GREEN, D. R. et al. Mapping the Tooth Enamel Proteome and Amelogenin Phosphorylation Onto Mineralizing Porcine Tooth Crowns. Frontiers in Physiology, 2019.

HIGBY SCHWEITZER, M. Molecular paleontology: some current advances and problems. Annales de Paléontologie, 2004.

HUNT, E. E.; GLEISER, I. The estimation of age and sex of preadolescent children from bones and teeth. American Journal of Physical Anthropology, 1955.

IŞCAN, M. Y. Forensic anthropology of sex and body size. Forensic Science International, 2005.

KLALES, A. R. Secular Change in Morphological Pelvic Traits used for Sex Estimation. Journal of Forensic Sciences, v. 61, n. 2, p. 295-301, 2016.

LEWIS, M. E. The bioarchaeology of children. In: The Bioarchaeology of Children, 2009.

LINDSKOG, C. The potential clinical impact of the tissue-based map of the human proteomeExpert Review of Proteomics, 2015.

LÓPEZ-LÁZARO, S. et al. Sexual dimorphism of the first deciduous molar: A 
geometric morphometric approach. Forensic Science International, v. 290, p. 94102, 2018.

LOTH, S. R.; HENNEBERG, M. Sexually dimorphic mandibular morphology in the first few years of life. American Journal of Physical Anthropology, 2001.

LUNA, L. H.; ARANDA, C. M.; SANTOS, A. L. New Method for Sex Prediction Using the Human Non-Adult Auricular Surface of the llium in the Collection of Identified Skeletons of the University of Coimbra. International Journal of Osteoarchaeology, v. 27, n. 5, p. 898-911, 2017.

MANIFOLD, B. M. Bone mineral density in children from anthropological and clinical sciences: A review. Anthropological Review, v. 77, n. 2, p. 111-135, 2014.

MASON, K. E. et al. Protein-based forensic identification using genetically variant peptides in human bone. Forensic Science International, 2018.

MEDZIHRADSZKY, K. F.; CHALKLEY, R. J. Lessons in de novo peptide sequencing by tandem mass spectrometry. Mass Spectrometry Reviews, 2015.

MILLER, J. Z. et al. The relationship of bone mineral density and anthropometric variables in healthy male and female children. Bone and Mineral, 1991.

MJÖR, I. A.; FEJERSKOV, O. Embriologia e histologia oral humana. São Paulo: Panamericana, 1990.

MOLLESON, T.; CRUSE, K.; MAYS, S. Some sexually dimorphic features of the human juvenile skull and their value in sex determination in immature skeletal remains. Journal of Archaeological Science, 1998.

MUÑOZ, J.; HECK, A. J. R. From the human genome to the human proteome. Angewandte Chemie - International Edition, 2014.

NAGANO, T. et al. Mmp-20 and Klk4 cleavage site preferences for amelogenin sequences. Journal of Dental Research, 2009.

NAKAYAMA, M. et al. Influence of long and short arms of $X$ chromosome on maxillary molar crown morphology. PLoS ONE, 2018.

OLIVARES, J.; AGUILERA, I. Validation of the sex estimation method elaborated by Schutkowski in the Granada Osteological Collection of identified infant and young children: Analysis of the controversy between the different ways of analyzing and interpreting the results. International Journal of Legal Medicine, v. 130, n. 6, p. 1623-1632, 2016.

$\mathrm{OU}, \mathrm{X}$. et al. Null alleles of the $\mathrm{X}$ and $\mathrm{y}$ chromosomal amelogenin gene in a Chinese population. International Journal of Legal Medicine, v. 126, n. 4, p. 513-518, 2012.

PAKNAHAD, M.; VOSSOUGHI, M.; AHMADI ZEYDABADI, F. A radio-odontometric 
analysis of sexual dimorphism in deciduous dentition. Journal of Forensic and Legal Medicine, 2016.

PAPAYANNOPOULOS, I. A. The interpretation of collision-induced dissociation tandem mass spectra of peptidesMass Spectrometry Reviews, 1995.

PARKER, G. J. et al. Unambiguous assignment of male sex to a human tooth: Use of proteomics when DNA is unavailable for sex assignment. American Journal of Physical Anthropology, v. 159, p. 248, 2016.

PARKER, G. J. et al. Sex estimation using sexually dimorphic amelogenin protein fragments in human enamel. Journal of Archaeological Science, v. 101, n. May 2018, p. 169-180, 2019.

PATEL, E. et al. A proteomic approach for the rapid, multi-informative and reliable identification of blood. Analyst, v. 141, n. 1, p. 191-198, 2016.

PHENICE, T. W. A newly developed visual method of sexing the os pubis. American Journal of Physical Anthropology, 1969.

PILLI, E. et al. Neither femur nor tooth : Petrous bone for identifying archaeological bone samples via forensic approach. Forensic Science International, v. 283, p. 144-149, 2018.

PORTO, I. M. et al. New techniques for the recovery of small amounts of mature enamel proteins. Journal of Archaeological Science, v. 38, n. 12, p. 3596-3604, dez. 2011a.

PORTO, I. M. et al. Recovery and identification of mature enamel proteins in ancient teeth. European Journal of Oral Sciences, v. 119, p. 83-87, dez. 2011b.

RAMSTHALER, F. et al. Digital forensic osteology: Morphological sexing of skeletal remains using volume-rendered cranial CT scans. Forensic Science International, v. 195, n. 1-3, p. 148-152, 2010.

RISSECH, C.; MALGOSA, A. Pubis growth study: Applicability in sexual and age diagnostic. Forensic Science International, 2007.

ROGERS, T. L. Sex determination of adolescent skeletons using the distal humerus. American Journal of Physical Anthropology, 2009.

SALIDO, E. C. et al. The human enamel protein gene amelogenin is expressed from both the $X$ and the $Y$ chromosomes. American journal of human genetics, v. 50, n. 2, p. 303-16, 1992.

SCHEUER, L. Brief communication: A blind test of mandibular morphology for sexing mandibles in the first few years of life. American Journal of Physical Anthropology, 2002.

SCHUTKOWSKI, H. Sex determination of infant and juvenile skeletons: I. 
Morphognostic features. American Journal of Physical Anthropology, 1993.

SHANKAR, S. et al. Sexual dimorphism using odontometrics among the pediatric population of Erode district: A population study. International Journal of Forensic Odontology, 2018.

SIVAGAMI, A. V.; RAO, A. R.; VARSHNEY, U. A simple and cost-effective method for preparing DNA from the hard tooth tissue, and its use in polymerase chain reaction amplification of amelogenin gene segment for sex determination in an Indian population. Forensic Science International, 2000.

SMITH, C. E. Cellular and chemical events during enamel maturationCritical Reviews in Oral Biology and Medicine, 1998.

STEWART, N. A. et al. The identification of peptides by nanoLC-MS/MS from human surface tooth enamel following a simple acid etch extraction. RSC Advances, v. 6, n. 66, p. 61673-61679, 2016.

STEWART, N. A. et al. Sex determination of human remains from peptides in tooth enamel. Proceedings of the National Academy of Sciences, p. 201714926, 2017.

STULL, K. E.; GODDE, K. Sex Estimation of Infants Between Birth and One Year Through Discriminant Analysis of the Humerus and Femur. Journal of Forensic Sciences, v. 58, n. 1, p. 13-20, 2013.

SUTTER, R. C. Nonmetric Subadult Skeletal Sexing Traits: I. A Blind Test of the Accuracy of Eight Previously Proposed Methods Using Prehistoric Known-Sex Mummies from Northern Chile. Journal of Forensic Sciences, 2003.

TABB, D. L.; ENG, J. K.; YATES, J. R. Protein Identification by SEQUEST. In: Proteome Research: Mass Spectrometry. [s.l: s.n.]. p. 125-142.

TEAM, R. C. R: A Language and Environment for Statistical ComputingR Foundation for Statistical Computing, 2016.

TUTKUVIENE, J. et al. Age- and sex-related growth patterns of the craniofacial complex in European children aged 3-6 years. Annals of Human Biology, v. 43, n. 6, p. 510-519, 2016.

UBELAKER, D. H.; DEGAGLIA, C. M. Population variation in skeletal sexual dimorphism. Forensic Science International, v. 278, p. 407.e1-407.e7, 2017.

VICIANO, J.; LÕPEZ-LÁZARO, S.; ALEMÁN, I. Sex estimation based on deciduous and permanent dentition in a contemporary spanish population. American Journal of Physical Anthropology, 2013.

VLAK, D.; ROKSANDIC, M.; SCHILLACI, M. A. Greater sciatic notch as a sex indicator in juveniles. American Journal of Physical Anthropology, 2008.

WADSWORTH, C. et al. Comparing ancient DNA survival and proteome content in 
69 archaeological cattle tooth and bone samples from multiple European sites. Journal of Proteomics, v. 158, p. 1-8, 2017.

WANG, C. et al. One-shot method for purification of multiple natural amelogenin isoforms. Journal of Materials Science and Technology, 2018.

WATSON, J. T.; SPARKMAN, O. D. Introduction to Mass Spectrometry: Instrumentation, Applications and Strategies for Data Interpretation: Fourth Edition, 2008.

WEAVER, D. S. Sex differences in the llia of a known sex and age sample of fetal and infant Skeletons. American Journal of Physical Anthropology, 1980.

WELKER, F. et al. Ancient proteins resolve the evolutionary history of Darwin's South American ungulates. Nature, 2015.

WELKER, F. Palaeoproteomics for human evolution studies. Quaternary Science Reviews, v. 190, p. 137-147, 2018.

WILLIAMS, D. et al. Sex determination by PCR analysis of DNA extracted from incinerated, deciduous teeth. Science and Justice - Journal of the Forensic Science Society, 2004.

XIA, Y.; REN, A.; PUGACH, M. K. Truncated amelogenin and LRAP transgenes improve Amelx null mouse enamel. Matrix Biology, 2016.

XU, C.; MA, B. Software for computational peptide identification from MS - MS data. Drug Discovery Today, v. 11, n. 13/14, p. 595-599, 2006. 


\section{Anexo}

- ANEXO A - Aprovação da emenda do Comitê de Ética em Pesquisa 
ANEXO A

\section{USP - FACULDADE DE ODONTOLOGIA DE RIBEIRÃO PRETO DA USP - FORP/USP}

\section{PARECER CONSUBSTANCIADO DO CEP}

\section{DADOS DA EMENDA}

Título da Pesquisa: "Análise da presença de metais no esmalte em dentes decíduos de crianças residentes em regióes distintas da cidade de Ribeirão Preto - SP: relações neurotóxicas e abertura de dados junto às comunidades escolares".

Pesquisador: Raquel Fernanda Gerlach

Área Temática:

Versão: 3

CAAE: 82840018.8 .0000 .5419

Instituição Proponente:Universidade de Sao Paulo

Patrocinador Principal: Financiamento Próprio

\section{DADOS DO PARECER}

Número do Parecer: 2.819.635

Apresentação do Projeto:

Emenda. Os pesquisadores solicitam incluir a análise de peptídeos de esmalte em 200 dentes, já aprovados no parecer inicial.

Objetivo da Pesquisa:

Os mesmos descritos inicialmente.

Avaliação dos Riscos e Benefícios:

Os mesmos descritos inicialmente.

Comentários e Consideraçōes sobre a Pesquisa:

Emenda adequada e justificada.

Considerações sobre os Termos de apresentação obrigatória:

Adequados.

Recomendações:

Aprovado.

Conclusões ou Pendências e Lista de Inadequações:

Emenda aprovada.

Considerações Finais a critério do CEP:

Emenda aprovada conforme deliberado na $218^{\mathrm{a}}$ Reunião Ordinária do CEP/FORP de 09/08/2018.

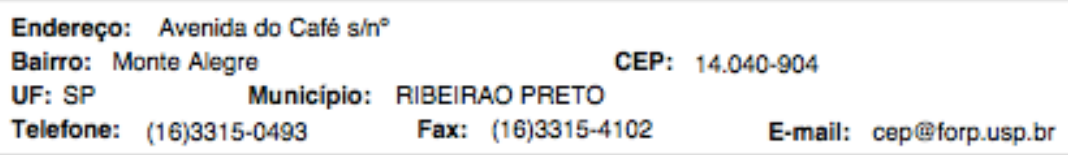




\section{USP - FACULDADE DE ODONTOLOGIA DE RIBEIRÃO PRETO DA USP - FORP/USP}

Continuagăo do Parecer: 2.819 .635

Este parecer foi elaborado baseado nos documentos abaixo relacionados:

\begin{tabular}{|c|c|c|c|c|}
\hline Tipo Documento & Arquivo & Postagem & Autor & Situação \\
\hline $\begin{array}{l}\text { Informaçōes Básicas } \\
\text { do Projeto }\end{array}$ & $\begin{array}{l}\text { PB_INFORMAÇOES_BÁSICAS_118297 } \\
\text { 2_E1.pdf }\end{array}$ & $\begin{array}{c}01 / 08 / 2018 \\
10: 42-28\end{array}$ & & Aceito \\
\hline Outros & emenda.pdf & $\begin{array}{c}01 / 08 / 2018 \\
10: 33: 17\end{array}$ & $\begin{array}{l}\text { Raquel Fernanda } \\
\text { Gerlach }\end{array}$ & Aceito \\
\hline Outros & Doacao.pdf & $\begin{array}{c}23 / 03 / 2018 \\
10: 08: 17\end{array}$ & $\begin{array}{l}\text { Raquel Fernanda } \\
\text { Gerlach }\end{array}$ & Aceito \\
\hline $\begin{array}{l}\text { Projeto Detalhado / } \\
\text { Brochura } \\
\text { Investigador }\end{array}$ & Projeto.pdf & $\begin{array}{c}02 / 03 / 2018 \\
13: 47: 29\end{array}$ & $\begin{array}{l}\text { Raquel Fernanda } \\
\text { Gerlach }\end{array}$ & Aceito \\
\hline Outros & Citacao.pdf & $\begin{array}{c}01 / 02 / 2018 \\
13: 34: 02 \\
\end{array}$ & $\begin{array}{l}\text { Raquel Fernanda } \\
\text { Gerlach }\end{array}$ & Aceito \\
\hline Folha de Rosto & Folha.pdf & $\begin{array}{c}01 / 02 / 2018 \\
13: 31: 27\end{array}$ & $\begin{array}{l}\text { Raquel Fernanda } \\
\text { Gerlach }\end{array}$ & Aceito \\
\hline $\begin{array}{l}\text { TCLE / Termos de } \\
\text { Assentimento / } \\
\text { Justificativa de } \\
\text { Ausência }\end{array}$ & TCLE.pdf & $\begin{array}{c}01 / 02 / 2018 \\
13: 30: 29\end{array}$ & $\begin{array}{l}\text { Raquel Fernanda } \\
\text { Gerlach }\end{array}$ & Aceito \\
\hline $\begin{array}{l}\text { Declaração de } \\
\text { Pesquisadores }\end{array}$ & Anuencia.pdf & $\begin{array}{c}\text { 01/02/2018 } \\
13: 30: 08\end{array}$ & $\begin{array}{l}\text { Raquel Fernanda } \\
\text { Gerlach }\end{array}$ & Aceito \\
\hline $\begin{array}{l}\text { Declaração de } \\
\text { Manuseio Material } \\
\text { Biológico / } \\
\text { Biorepositório / } \\
\text { Biobanco } \\
\end{array}$ & Biobanco.pdf & $\begin{array}{c}01 / 02 / 2018 \\
13: 28: 54\end{array}$ & $\begin{array}{l}\text { Raquel Fernanda } \\
\text { Gerlach }\end{array}$ & Aceito \\
\hline $\begin{array}{l}\text { Declaração de } \\
\text { Instituição e } \\
\text { Infraestrutura }\end{array}$ & Infraestrutura.pdf & $\begin{array}{c}01 / 02 / 2018 \\
13: 28: 29\end{array}$ & $\begin{array}{l}\text { Raquel Fernanda } \\
\text { Gerlach }\end{array}$ & Aceito \\
\hline Cronograma & Cronograma.pdf & $\begin{array}{c}01 / 02 / 2018 \\
13: 27: 44\end{array}$ & $\begin{array}{l}\text { Raquel Fernanda } \\
\text { Gerlach }\end{array}$ & Aceito \\
\hline
\end{tabular}

\section{Situação do Parecer:}

Aprovado

\section{Necessita Apreciação da CONEP:}

Não

RIBEIRAO PRETO, 14 de Agosto de 2018

Assinado por:

Simone Cecilio Hallak Regalo

(Coordenador)

Endereço: Avenida do Café sin ${ }^{\circ}$

Bairro: Monte Alegre

UF: SP $\begin{array}{llll}\text { UF: SP } & \text { Municipio: } & \text { RIBEIRAO PRETO } & \\ \text { Telefone: } & (16) 3315-0493 & \text { Fax: (16)3315-4102 } & \text { E-mail: cep@forp.usp.br }\end{array}$

CEP: $14.040-904$ 


\section{USP - FACULDADE DE ODONTOLOGIA DE RIBEIRÃO \\ PRETO DA USP - FORP/USP

Continuaçẫo do Parecer: 2.819.635 
